This dissertation has been

65-2339

microfilmed exactly as received

HORVĀTH, Bert, 1932-

SELENIUM DIOXIDE OXIDATION OF OLEFINS.

University of Arizona, Ph.D., 1964

Chemistry, organic

University Microfilms, Inc., Ann Arbor, Michigan 


\title{
SELENIUM DIOXIDE OXIDATION OF OLEFINS
}

\author{
by
}

Bert Horvāth

A Dissertation Submitted to the Faculty of the

$$
\text { DEPARTMENT OF CHEMISTRY }
$$

In Partial Fulfillment of the Requirements

For the Degree of

DOCTOR OF PHILOSOPHY

In the Graduate College

THE UNIVERSITY OF ARIZONA

\author{
1964
}


THE UNIVERSITY OF ARIZONA

GRADUATE COLLEGE

I hereby recommend that this dissertation prepared under my direction by $S_{\text {Sert }} \mathrm{f}$ toruath entitled Selenium Dioxide Oxidation 0 Colefins

be accepted as fulfilling the dissertation requirement of the degree of $=$ Doctor of Philosophy

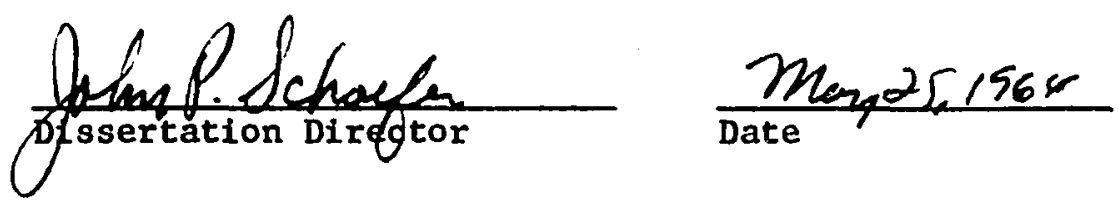

After inspection of the dissertation, the following members of the Final Examination Committee concur in its approval and récomend its acceptance :*
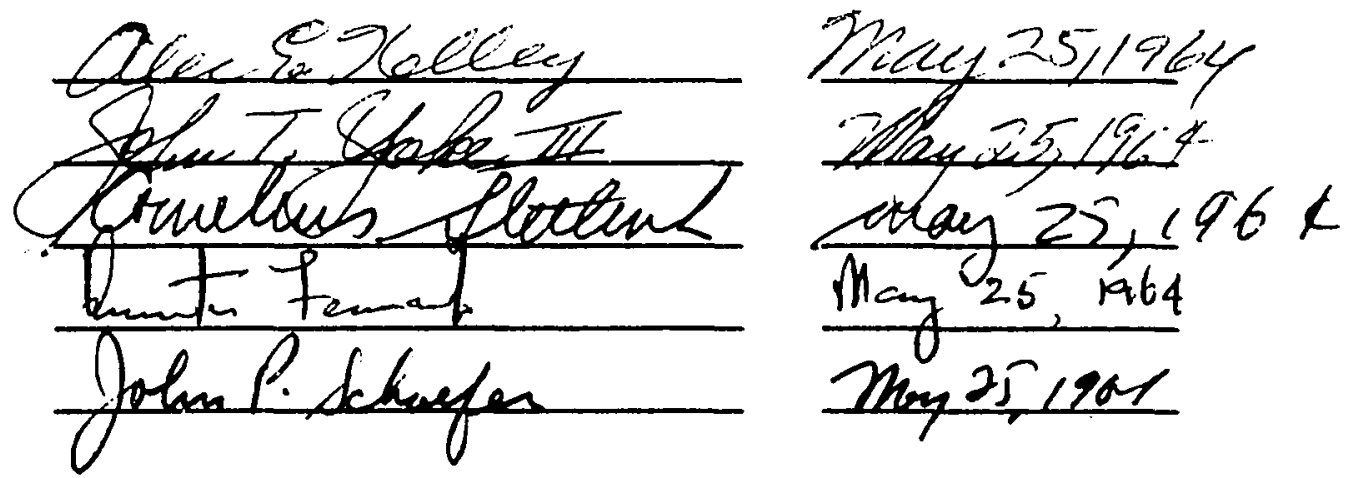

*This approval and acceptance is contingent on the candidate's adequate performance and defense of this dissertation at the final oral examination. The inclusion of this sheet bound into the library copy of the dissertation is evidence of satisfactory performance at the final examination. 


\section{STATEMENT BY AUTHOR}

This dissertation has been submitted in partial fulfillment of requirements for an advanced degree at The University of Arizona and is deposited in the University Library to be made avallable to borrowers under rules of the Library.

Brief quotations from this dissertation are allowable without special permission, provided that accurate acknowledgment of source 18 made. Requests for permission for extended quotation from or reproduction of this manuscript in whole or in part may be granted by the head of the major department or the Dean of the Graduate College when in his judgment the proposed use of the material is in the interests of scholarship. In all other instances, however, permission must be obtained from the author.

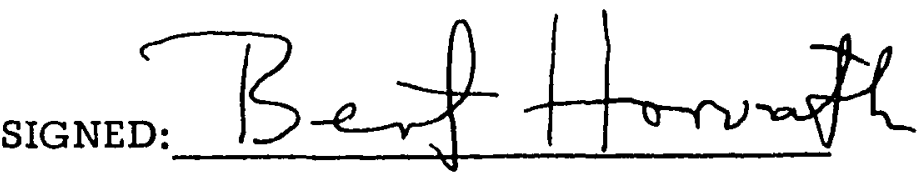


To my father

whose ultimate vision

made this dissertation possible 


\section{ACKNOWLEDGMENTS}

The author wishes to express his thanks to Dr. John P. Schaefer, research director, for his contributions and advice during the course of this research. Thanks are also due to Dr. Henry Kircher of the Agricultural Biochemistry Department for his sage advice at a particularly critical stage of this work; to Dr. Alec Kelly who offered many valuable suggestions as well as for his critical reading of this manuscript.

Special thanks are due to Mrs. E. G. Horvath for her numerous invaluable contribution's during the entire course of this endeavor.

Support of this research from the United States Army for the year 1962-63 and a Phillips Petroleum Fellowship for 1963-64 is gratefully acknowledged. 
TABLE OF CONTENTS

Page

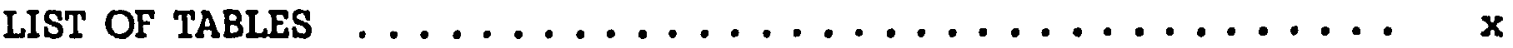

LIST OF ILLUSTRATIONS .................... xil

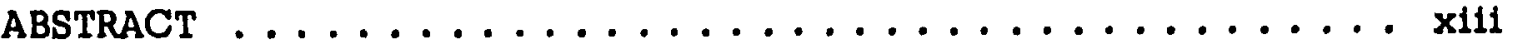

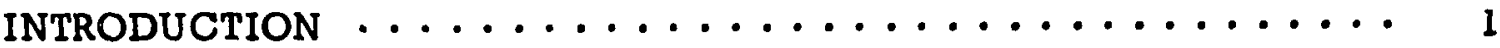

EXPERIMENTAL $\ldots \ldots \ldots \ldots \ldots \ldots$

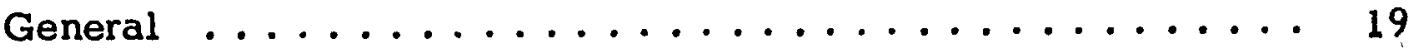

Selenium Dioxide Oxidation of a-Methyl Styrene ........ 20

Preparation of Standards and Reactants and Purification

of Stock Reagents . . . . . . . . . . . . 20

Acetic Acid, Glacial ................... 20

Selenium Dioxide ..................... 20

Purification of a-Methyl Styrene........... 21

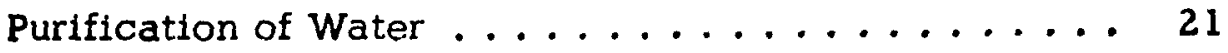

3-Acetoxy-2-phenyl-1-propene ........... 21

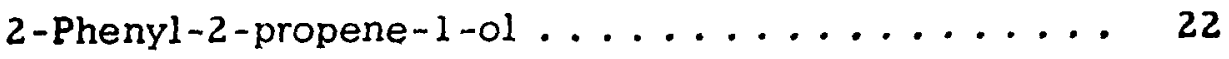

2-Pheny1-2-propene-1-al (Atropaldehyde) ...... 22

p-Nitro-a-methyl Styrene.............. 23

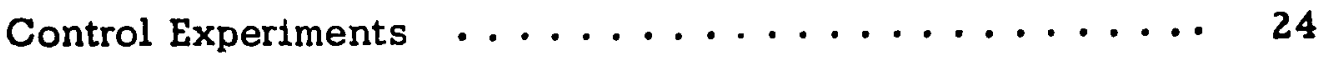


Page

Selenium Dioxide Oxidation of a-Methyl Styrene $\ldots \ldots 24$

General Procedure.................. 24

Catalysis Experiments .............. 25

Hydrolysis of 3-Acetoxy-2-phenyl-1-propene ...... 26

Oxidation of a Mixture of AMS, 3-Acetoxy-2-phenyl-1propene, 2-Phenyl-2-propene-1-ol and 2-Phenyl-2propene-1-al .................... 26

Miscellaneous $\sigma_{x i d a t i o n s ~} \ldots \ldots \ldots \ldots \ldots \ldots$

Kinetics ................... 27

Stock Solution A ............... 28

Stock Solution B ............... 28

The Oxidation Reaction ............. 28

Isolation of Intermediate $(s) \ldots \ldots \ldots \ldots \ldots$

Purification $\ldots \ldots \ldots \ldots \ldots \ldots \ldots \ldots$

Chemistry of Intermediates . . . . . . . . . 34

Summary of Results $\ldots \ldots \ldots \ldots \ldots \ldots \ldots$

Discussion .................. 35

Selenium Dioxide Oxidation of 1,3-Diphenylpropene $\ldots \ldots 51$

Preparation of Standards and Substrates ........ 51

1,3-Diphenyl-1-propanol $\ldots \ldots \ldots \ldots \ldots \ldots$

1,3-Diphenyl-1-propanone $\ldots \ldots \ldots \ldots \ldots$

1,3-Diphenylpropane $\ldots \ldots \ldots \ldots \ldots \ldots \ldots$

Benzoin .................... 54 
Page

2, 4,6-Trimethylbenzaldehyde (Mesitaldehyde) .... 54

Acetomesitylene ................... 54

$1,3,5$-Trilsopropylbenzene ............. 54

$2,4,6$-Trilsopropylbenzaldehyde $\ldots \ldots \ldots 55$

Aceto-2, 4,6-trlisopropylbenzene ........ 56

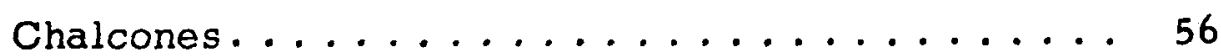

Chalcone (Benzalacetophenone) .......... 56

4-Methoxychalcone .................... 57

4 '-Methoxychalcone ................ 57

4-Chlorochalcone ................. 57

4 '-Chlorcchalcone .................... 57

2, 4, 6-Trimethylchalcone (Mesitalacetophenone) ... 57

.2', 4', 6'-Trimethylchalcone ............. 57

$2,4,6$-Triisopropylchalcone ................ 58

$2^{\prime}, 4^{\prime}, 6^{\prime}$-Triisopropylchalcone ............. 58

Hydrochalcols ......................... 58

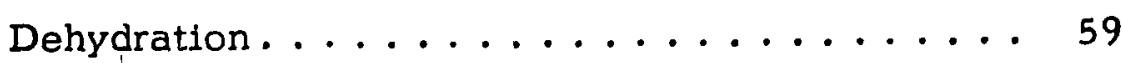

Deuteriobenzoin....................61

Deuterio Benzoin Acetate .............. 61

Deuteriobenzaldehyde ..................63

3-Deuterio-1,3-diphenyl-1-propene .........663

1,2-Dibromo-1,3-diphenylpropane ......... 64 
Page

1,2 -Dibromobenzalacetophenone ......... 64

1,2 -Dibromo-3-acetoxy-1,3-diphenylpropane..... 64

3-Deuterio-1,3-diphenyl-2-propene-1-ol ......665

3-Deuterio-1-acetoxy-1,3-diphenyl-2-propene ... 65

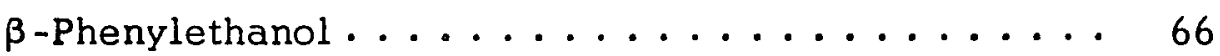

Phenylacetaldehyde ................. 67

a, $\mathbf{a}^{\prime}$-Dideuteriophenylacetaldehyde ........ 68

Selenium Dioxide Oxidation of 1,3-Diphenylpropene ... 68

General Procedure ...................... 68

Isolation of the Reaction Products .......... 71

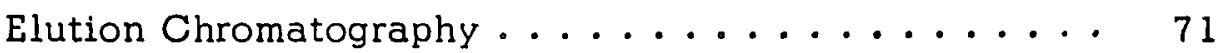

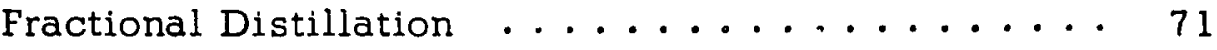

Molecular Distillation ............. 72

Fractional Crystallization of Dibromide Derivatives . • 72

Debromination of 1,3-Diphenyl-1,2-propane

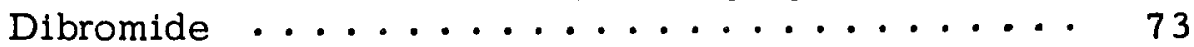

Debromination of 3 -Acetoxy-1,3-diphenylpropane-

1,2 -dibromide $\ldots \ldots \ldots \ldots \ldots \ldots \ldots$

Selenium Dioxide Oxidation of Dervatives of 1,3-

Diphenylpropene and $\underline{m}$-Dinitrobenzene $\ldots \ldots 74$

Attempted Oxidation of $\mathrm{m}$-Dinitrobenzene...... 74

Oxidation of 1,3-Diphenylpropene in the Presence of $\underline{\mathrm{m}}$-Dinitrobenzene ................ 74

Oxidation of 3-Acetoxy-1,3-diphenylpropene

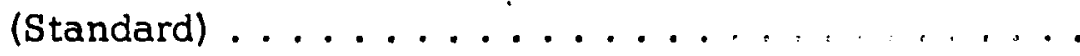


Page

Oxidation of 1,3-Diphenyl-1-propanone $\ldots 75$

Catalysis Experiments................... 75

Isolation of the Intermediate ........... 75

General Procedure ................ 75

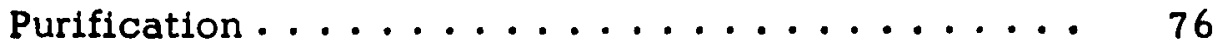

Chemistry of the Intermediate ............ 78

Degradation Experiments ............... 80

Selenium Dioxide Oxidation of 3-Deuterio-1, 3diphenyl-1-propene .............. 80

Reduction of the Crude Oxidate .......... 80

Oxidation of the Saturated Alcohol ......... 81

Isomerization Experiments ............... 82

Attempted Isomerization of 3-Deuterio-1, 3diphenyl-1-propene ............... 82

Isomerization of 3-Deuterio-1-acetoxy-1, 3diphenyl-2-propene .............. 82

Competition Experiments ............... 82

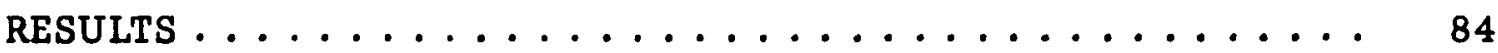

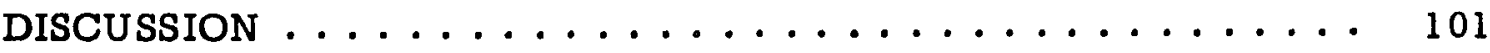

BIBLIOGRAPHY OF OLEFIN OXIDATIONS BY $\mathrm{SeO}_{2} \ldots \ldots \ldots$

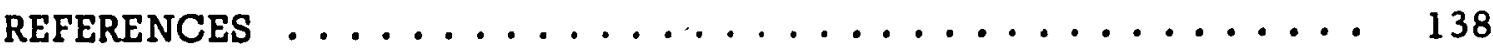




\section{LIST OF TABLES}

Table

Page

1 Solvent Composition. $3 \mathrm{hr}, \frac{\mathrm{AMS}}{\mathrm{SeO}_{2}}=2$, Temp. $=100^{\circ}$,

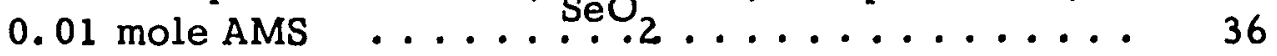

2 Solvent Composition. $24 \mathrm{hr} ., \frac{\mathrm{AMS}}{\mathrm{SeO}}={ }^{\prime} 2, \mathrm{Temp} .=100^{\circ}$,

0.01 mole AMS .................... 37

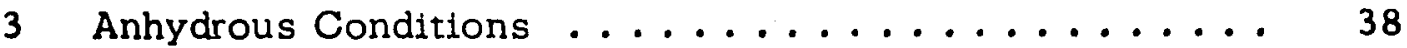

4 A 1:1 Mole Ratio of Reactants ............... 39

5 Miscellaneous Solvents and Conditions ......... 40

6 Catalysis Experiments .................. 41

7 "Mixture Oxidation" .................... 43

8 Miscellaneous Oxidations with $\mathrm{SeO}_{2} \cdot \mathrm{MnO}_{2}$ and Manganese Dioxide...................... 43

9 Kinetic Data of a Typical Run . . . . . . . . . . . 44

10 Hydrolysis of 3 -Acetoxy-2-phenyl-1-propene ....... 44

11 List of Hydrochalcols. 1,3-Diaryl-1-propanols, $\mathrm{ArCHOHCH}_{2} \mathrm{CH}_{2} \mathrm{Ar}^{\prime} \ldots \ldots \ldots 60 . \ldots \ldots$

12 List of Olefins. 1,3-Diarylpropenes, $\mathrm{ArCH}=\mathrm{CHCH}_{2} \mathrm{Ar} \cdot \cdots \quad 62$

13 Solvent Medium Experiments ............... 93

14 Optimum Reaction Time Experiments ............ 94

15 Optimum Reaction Time Experiments ........... 95

16 Effect of Anhydrous Conditions ................ 97 
17 The Effect of Water on Reaction Rate ... . . . . . 97

18 The Effect of Olefin Concentration ............ 98

19 Salt Effects .............................. 98

20 Selenium Dioxide Oxidation of Substituted 1,3Diphenylpropene .................. 99

21 Competition of 1,3-Diarylpropenes and 1,3-Diphenylpropene for Selentum Dioxide........... 100 


\section{LIST OF ILLUSTRATIONS}

Figure

Page

1 Infrared Spectrum of the Crude Product .......... 30

$2 \quad$ Infrared Spectrum of Fraction II Crystals (KBr pellets) 32

3 Ultraviolet Spectrum of Fraction II Crytals in $95 \%$

Ethanol ..................... 32

4 Infrared Spectrum of Fraction I Oil $\ldots \ldots \ldots 33$

5 Ultraviolet Spectrum of Fraction I Oil .......... 33

$6 \mathrm{SeO}_{2}$ Oxidation of AMS; Plot of the Kinetic Data $\ldots . . .45$

7 Percent of HOAc vs. Aldehyde in the $\mathrm{SeO}_{2}$ Oxidation of a-Methyl Styrene ............... 46

8 Percent of HOAc vs. Acetate in the $\mathrm{SeO}_{2}$ Oxidation of a-Methyl Styrene .................448

9 Selentum Dioxide Oxidation of a-Methyl Styrene .... 52

10 Infrared Spectrum of the Crystals ........... 77

11 Ultraviolet. Spectrum of the Crystals .......... 77

12 Preparation of 3-Deuterio-1,3-diphenylpropene $\ldots \ldots 6$

13 Oxidation of 3-Deuterio-1,3-diphenylpropene ..... 89

14 Isomerization of Deuteriated 1,3-Diphenylpropen-1-ol

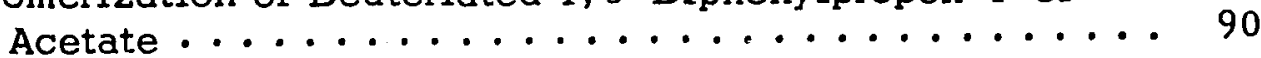




\section{ABSTRACT}

The oxidation of a-methyl styrene and 1,3-diphenylpropene with selenium dioxide in acetic acid was investigated. Work with the former substrate was abandoned because of experimental uncertainty in the results, but the latter compound produced 1,3dipheny 1-2-propen-1-ol acetate in high yleld. Oxidation of 1,3diphenylpropene labeled with deuterium on the methylene groups indicated a preference for $C-H$ versus $C-D$ bond breaking $\left(k_{H} / k_{D}\right)$ of 3.1 at $115^{\circ} \mathrm{C}$; the deuterium distribution in the product indicated that a symmetrical allylic carbonium ion transition state is formed. A study of substituent effects revealed that electron-rich olefins are more reactive than electron-deficient olefins and that the relative rate of oxidation is a sensitive function of the steric environment of the double bond. Furthermore, experiments concerning the reaction time, reaction medium, catalysis, salt effects and isolation of the intermediates were carried out. A possible mechanism consistent with these results is suggested. 


\section{INTRODUCTION}

Although the oxidizing action of selenium dioxide has been known for a long time (Gmelin 1907), its ability to oxidize organic compounds was not appreciated until a systematic study was completed in 1932 by Riley, Morley, and Friend. General reactions of selenium dioxide are summarized accordingly:

\begin{tabular}{|c|c|c|}
\hline Reactant & Product & Note \\
\hline $\mathrm{RCH}_{2} \|_{\mathrm{R}^{\prime}}$ & RCCR. & $\begin{array}{l}\mathrm{R}, \mathrm{R}^{\prime}=\mathrm{H}, \mathrm{Ar} \\
\text { acyl or }-\mathrm{C}^{-}-\mathrm{CH}_{3}\end{array}$ \\
\hline $\mathrm{RCH}_{2} \mathrm{CH}_{2} \mathrm{R}^{\prime}$ & $\mathrm{RCH}^{\prime}=\mathrm{CHR}^{\prime}$ & $\begin{aligned} \mathrm{R}, \mathrm{R}^{\prime}= & -\mathrm{CH}=\mathrm{CH}_{2} \\
& \mathrm{H}, \mathrm{R}, \mathrm{Ar}^{2}\end{aligned}$ \\
\hline$\left\|_{\mathrm{RCCH}_{2} \mathrm{CH}_{2}}^{\mathrm{O}}\right\|_{\mathrm{R}^{\prime}}$ & $\mathrm{RCCH}_{\mathrm{R}=\mathrm{CHCR}}$ & $\mathrm{R}, \mathrm{R}^{\prime}=\mathrm{R}, \mathrm{Ar}$ \\
\hline & & $\mathrm{X}=\mathrm{OR}, \mathrm{OH}$, or \\
\hline $\mathrm{RCH}_{2} \mathrm{CH}=\mathrm{CHR}$ & $\mathrm{RCHCH}=\mathrm{CHR}^{\prime}$ & $-\mathrm{C}-\mathrm{CH}_{3}$ \\
\hline
\end{tabular}

$\mathrm{RCH}_{2} \mathrm{CH}=\mathrm{CHR}^{\prime}$<smiles>[R]C=C[R]</smiles>

$\mathrm{R}, \mathrm{R}^{\prime}=\mathrm{R}, \mathrm{Ar}$

$\mathrm{RCH}_{2} \mathrm{C} \equiv \mathrm{CR}^{\prime}$<smiles></smiles>

$R, R^{\prime}=R, A r$ 


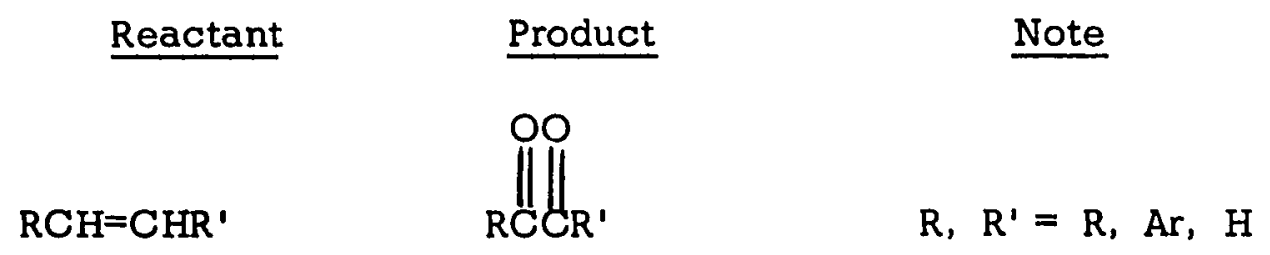

Solvents which are most frequently employed are acetic acid, acetic anhydride, alcohols, and cyclic ethers. Anisole, water, aliphatic and aromatic hydrocarbons, chlorinated products, acetonitrile, pyridine, nitrobenzene, and diglyme have also been used successfully. With olefins the oxidation products and relative yields are solvent dependent (Urion 1934; Alder and Stern 1933).

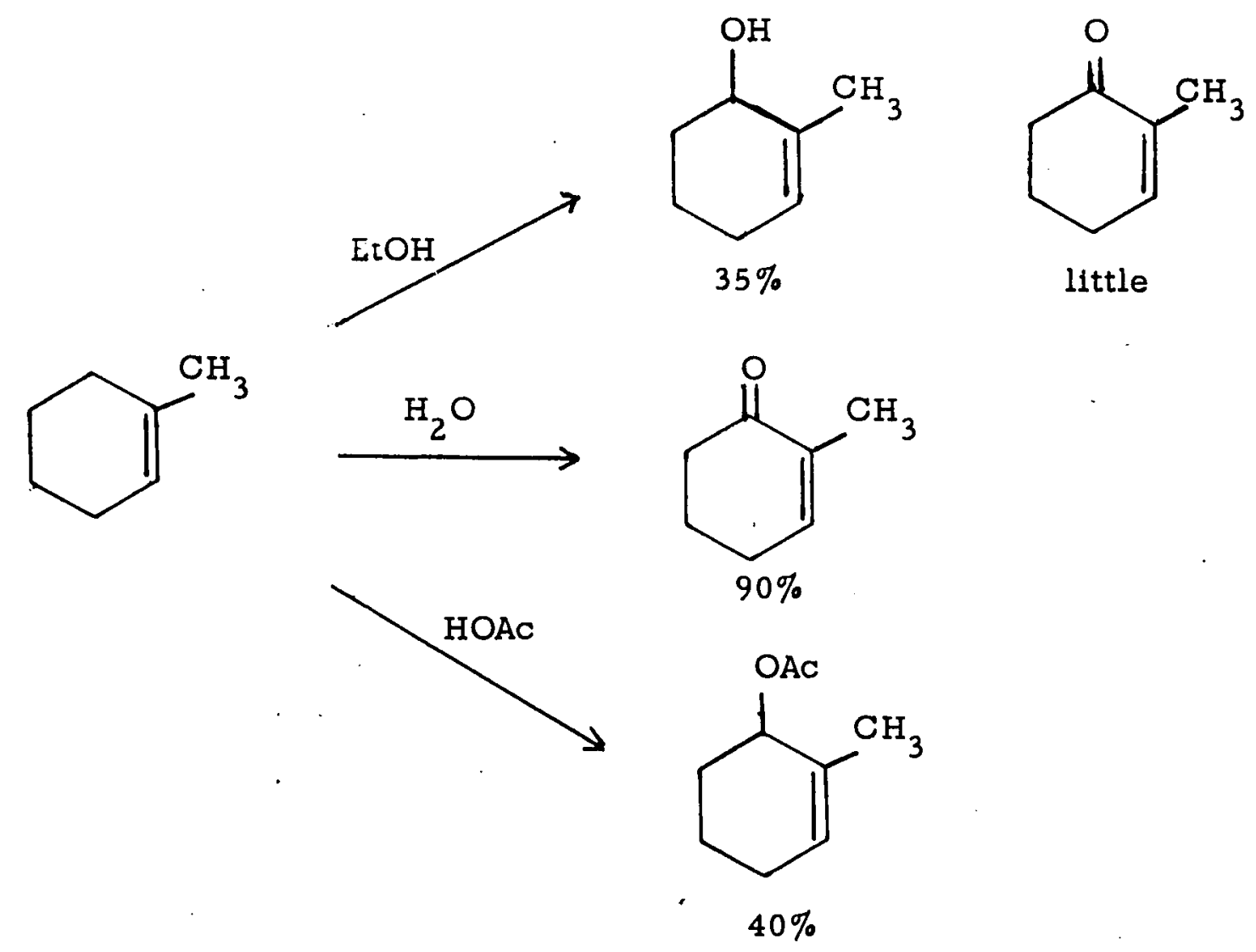



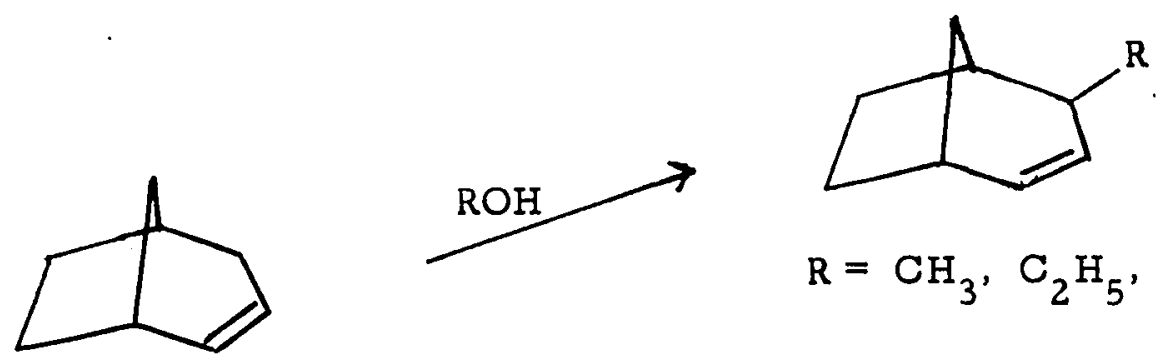

$$
\mathrm{R}=\mathrm{CH}_{3}, \mathrm{C}_{2} \mathrm{H}_{5}, \mathrm{C}_{5} \mathrm{H}_{11}
$$
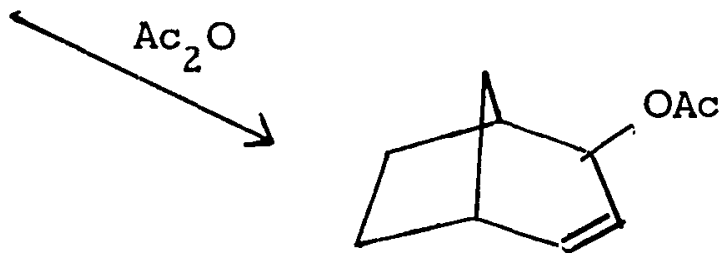

The effect of reaction temperature is illustrated by the oxidation of $\Delta-9,10$-octahydronaphthalene (Campbell and Harris 1941).

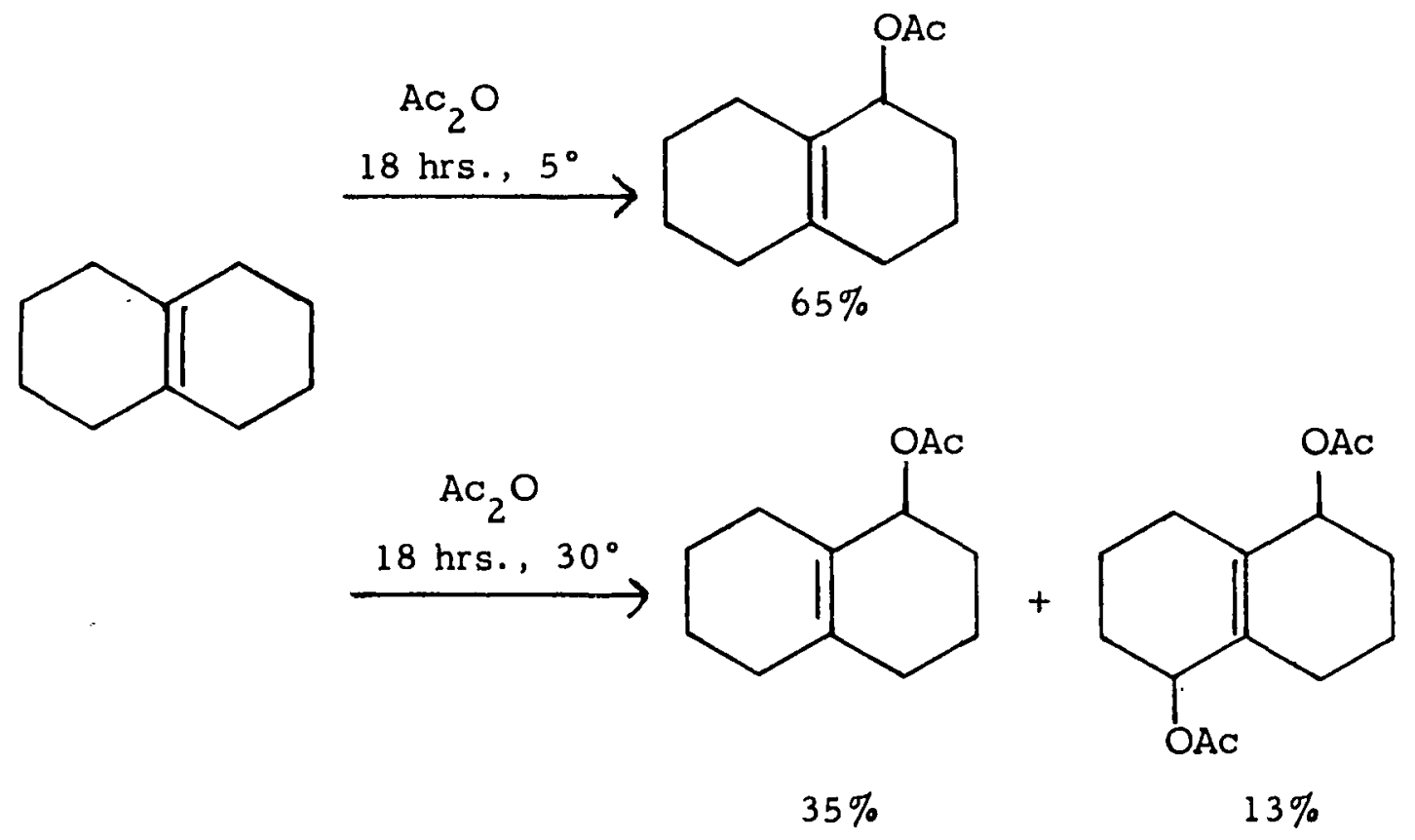




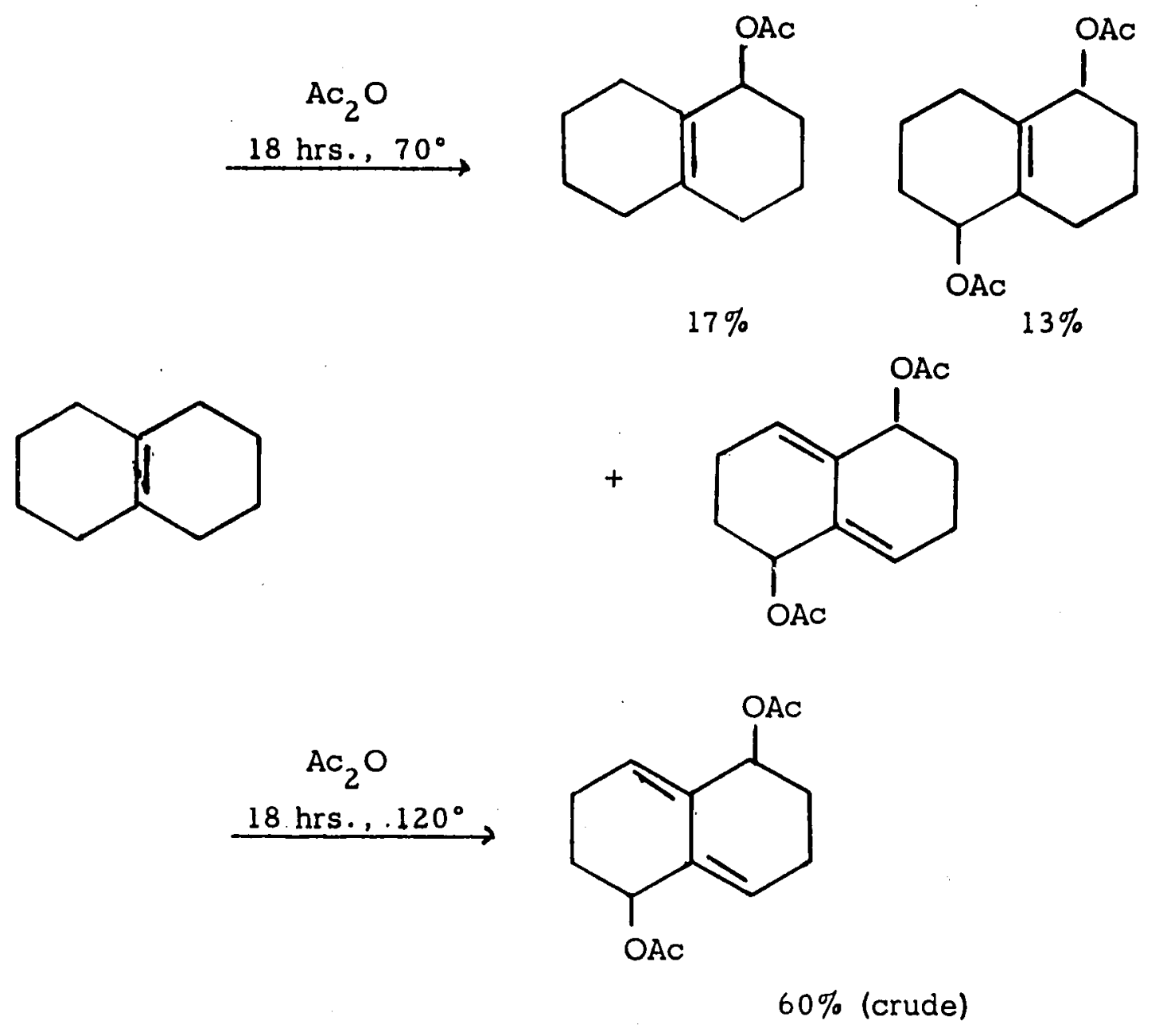

Simple olefins do not undergo oxidation at the a-methylene position (Riley, Morley and Friend 1932).

$$
\mathrm{CH}_{3} \mathrm{CH}=\mathrm{CH}_{2} \frac{\mathrm{SeO}_{2}}{\text { (vapor) }} \mathrm{CH}_{3} \|_{\mathrm{CCH}}
$$

$19 \%$

However, olefins with at least five carbon atoms behave normally (Riley, Morley and Friend 1932). 


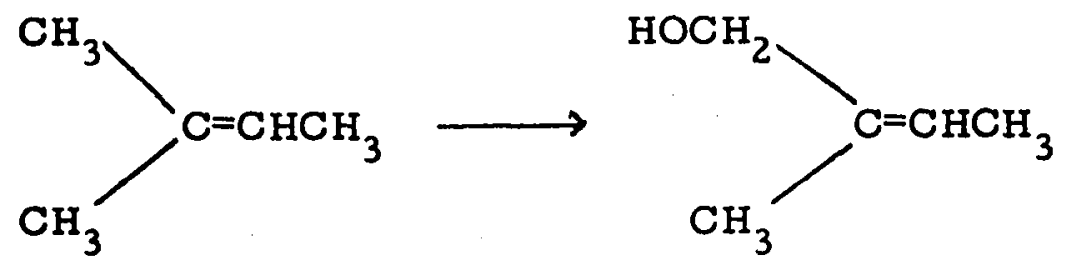

With large molecular weight olefins the reaction products are not always predictable, but occasionally a good yield of a single product is reallzed (Treibs 1937).

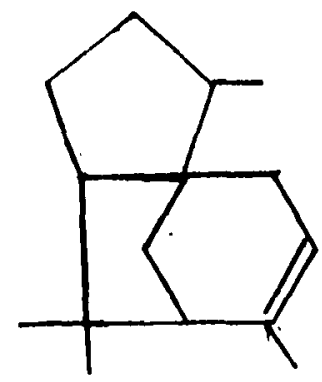

cedrene

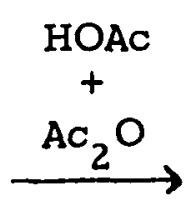

When two or more double bonds are present in the substrate aromatization and/or extension of conjugation may occur (Astin, Moulds, and Riley 1935; Borgwardt and Schwenk 1934).<smiles>CC1=CCC(C(C)C)C=C1</smiles>
$\stackrel{\mathrm{HOAC}}{\longrightarrow}$<smiles>Cc1ccc(C(C)C)cc1</smiles><smiles>CC(C)c1ccc(C=O)cc1</smiles> 
and

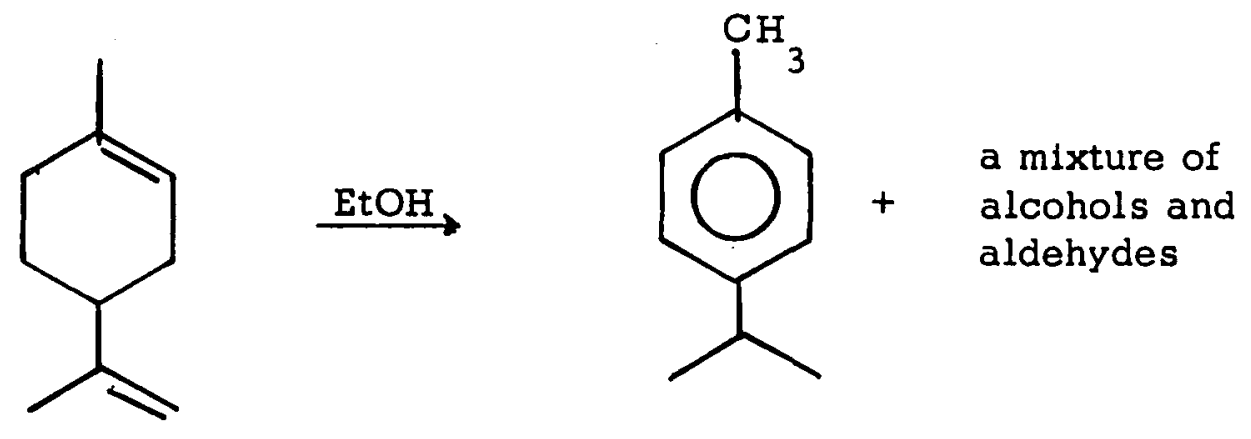

In general, the carbonyl group seems to be a more powerful activator than the double bond (Dane, et al., 1937).<smiles>CC1=CCCC1=O</smiles><smiles>CC1=CCCCC1=O</smiles>

Exceptions are known to occur to this rule (Dane, et al.,

1938).<smiles>CC1=CC(=O)CC(C)C1</smiles>
$\stackrel{\text { HOAC, }}{\longrightarrow}$

Here oxidation has occurred at the methylene group alpha to the double bond as well as at the vinylic hydrogen.

Even in comparatively simple olefins a multitude of products may be formed due to double bond migration before or after the oxidation (Guillemonat 1938, 1939). 
<smiles>CC1CC=CCC1</smiles>
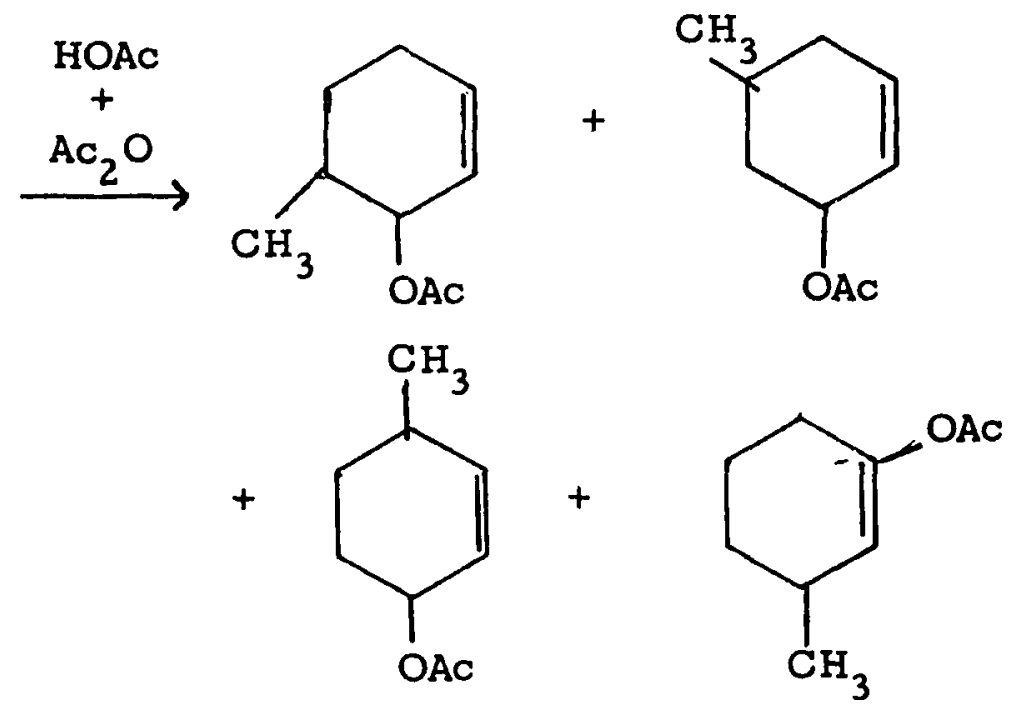

The behavior of certain strained bicyclic olefins revealed an unexpected resistance to oxidation (Hirsjärvi 1956, 1957).

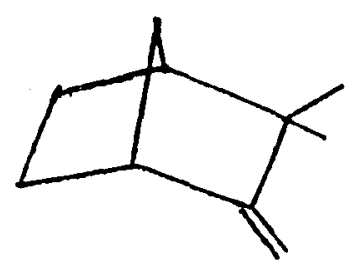

camphene
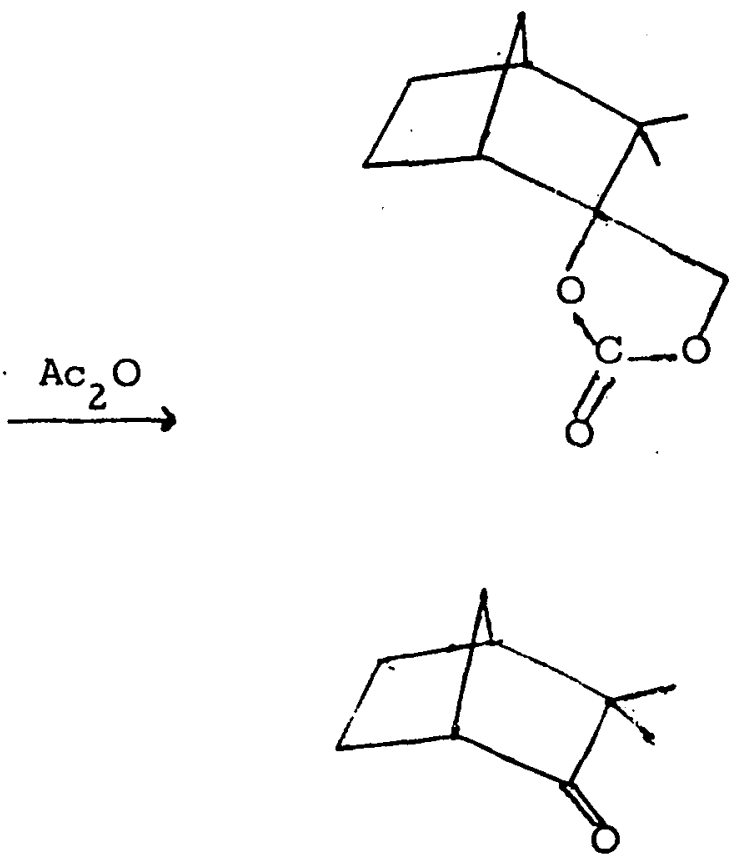


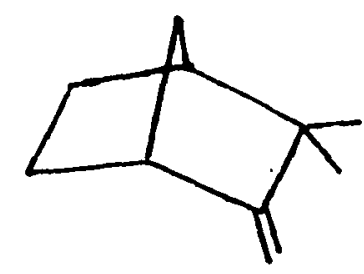

camphene
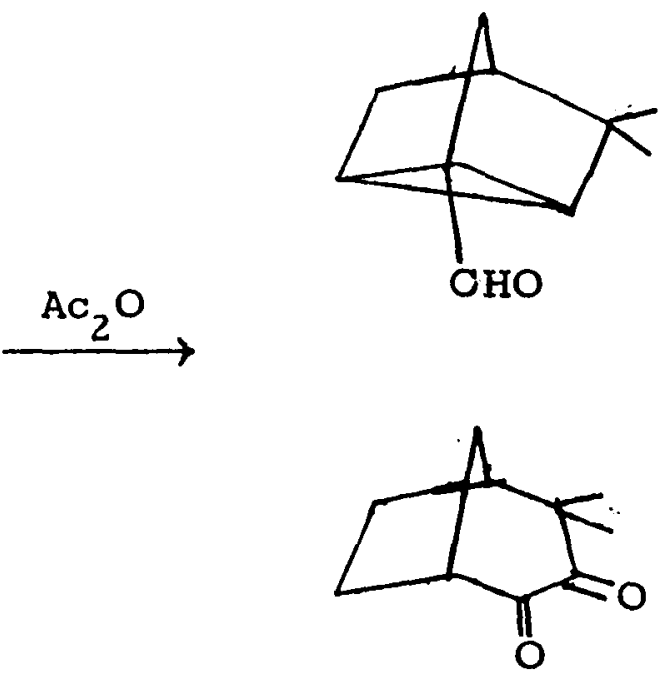

The presence of the [3.2.1] bicyclo product indicates that ring expansion has occurred, a novel phenomenon in selenium dioxide oxidation of terpenes or alicyclics.

For a comprehensive review of selenium dioxide oxidations up to 1947 see Rabjohn (1949).

Several aspects of selenium dioxide oxidations not found in Rabjohn's review are elaborated in a compendium by Waitkins and Clark (1945).

The oxidation of olefins included up to March 1964 in Chem1cal Abstracts is summarized in the Bibliography.

Gullemonat (1935-1939) experimented with 2-methyl-2butene in an endeavor to elucidate the mechanism of olefin oxidation by selenium dioxide. He postulated the existence of intermediate 
selenium complexes and suggested the following sequence of steps in the oxidation reaction:

(1) $4 \mathrm{RCH}=\mathrm{CHCH}_{3}+\mathrm{SeO}_{2} \longrightarrow\left(\mathrm{RCH}=\mathrm{CHCH}_{2}\right)_{4} \mathrm{Se}+2 \mathrm{H}_{2} \mathrm{O}$

(2) $\left(\mathrm{RCH}=\mathrm{CHCH}_{2}\right)_{4}+\mathrm{H}_{2} \mathrm{O} \longrightarrow\left(\mathrm{RCH}=\mathrm{CHCH}_{2}\right)_{2} \mathrm{Se}+\mathrm{RCH}=\mathrm{CHCH}_{3}$

$+\mathrm{RCH}=\mathrm{CHCH}_{2} \mathrm{OH}$

(3) $\left(\mathrm{RCH}=\mathrm{CHCH}_{2}\right)_{2} \mathrm{Se}+\mathrm{H}_{2} \mathrm{O} \longrightarrow \mathrm{RCH}=\mathrm{CHCH}_{2} \mathrm{OH}+\mathrm{RCH}=\mathrm{CHCH}_{3}$

$+\mathrm{Se}$

Guillemonat, moreover, formulated the following set of rules for predicting the course of olefin oxidations from empirical correlation of experimental evidence:

(1) Oxidation occurs preferentially in the order: $\mathrm{CH}_{2}>\mathrm{CH}_{3}$ $>\mathrm{CH}$.

(2) The a-position to the most substituted end of the double bond is oxidized.

(3) In case of endocyclic double bonds, oxidation occurs within the ring whenever possible.

(4) Terminal double bonds will migrate and primary alcohol (or acetate) will be formed instead of the expected secondary products. 
Close examination of the postulated intermediates of Guillemonat's mechanism raises several objections. First of all, he did not suggest in what manner these intermediates could be formed. Secondly, tetraalkyl selenium species are unknown to date and their possible existence is questionable. Moreover, the known chemical behavior of dialkyl and diaryl selenides in general refutes the proposition that alcohols are formed by their hydrolysis, especially under relatively mild conditions (HoubenWeyl 1955). It should be pointed out, however, that data on unsaturated organoseleniums is scarce and they may behave somewhat differently from their saturated analogs; further experimental data is needed to clarify this point. Hydrocarbons, aldehydes (or ketones) are known to be formed by pyrolysis, or by other more drastic experimental procedures from dialkyl and diaryl organoselentums.

As for Guillemonat's rules, examination of the since accumulated experimental data seems to substantiate that (1) tertiary hydrogens have the least tendency to be oxidized, (2) in simple aliphatic systems oxidation always occurs at the most substituted end of the double bond, and (3) oxidation occurs within the ring--wherever possible--in case of endocyclic double bonds. With terpenes, sterolds and complex substrates these rules sometimes fall. The question of double bond migration is more complex than was recognized by Guillemonat and it will be examined in detail elsewhere. 
Mousseron and Jacquier in 1952 performed a series of selenium dioxide oxidations in the alicyclic series. Although their attempts were neither theoretically directed nor so interpreted, one of their experimental results is nevertheless of significance from the point of view of the reaction mechanism.

They oxidized optically active 4 -methylcyclohexene $[a]_{579}=$ $+106.0^{\circ}$ in acetic anhydride. The corresponding mixture of acetates (60\% yield) of 5-methyl-2-cyclohexene-1-ol was not identified as such, but after saponification, oxidation, and hydrogenation, the resulting saturated ketone was identified as 3-cyclohexanone, as the major product. This ketone retained an optical activity of $85 \%$ of theoretical after the above sequence of operations, $[a]_{579}=-10.5^{\circ}$.

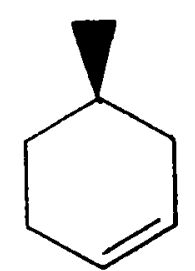

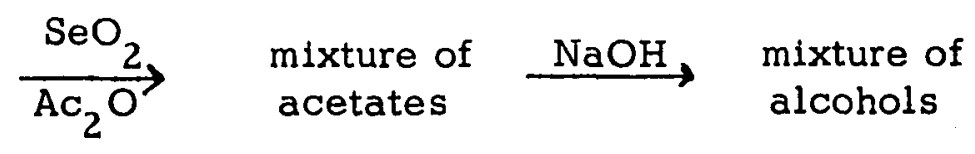

$$
[a]_{579}=+106^{\circ}
$$
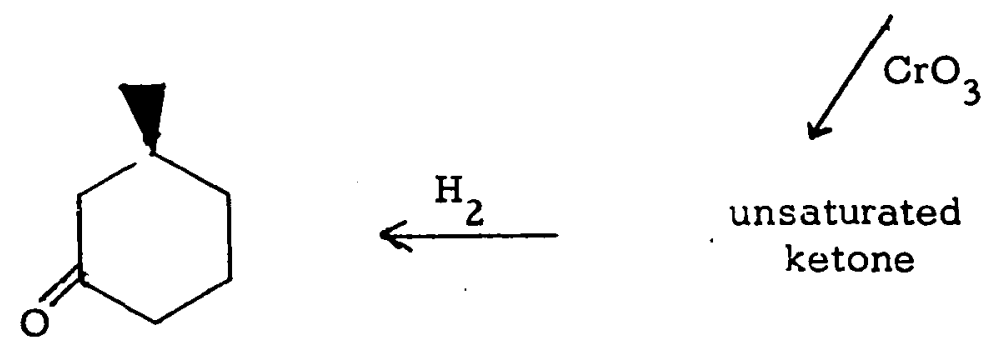

$$
[a]_{579}=-10.5^{\circ}
$$

lit. $[\mathrm{a}]_{\mathrm{D}}=-12.6^{\circ}$ and $11.5^{\circ}$

(Adams, et al., 1942; Macbeth and Mills 1947). 
The significance of this experiment is that the configuration of Mousseron and Jacquier's hydrocarbon can be ascertained and the stereochemical course of the oxidation reaction can be followed.

Mousseron originally prepared optically active 4-methyl cyclohexene from pulegone by a reverse aldol condensation (Mous seron, et al., 1946; Adams, et al., , 1942) to give 3-methylcyclohexanone $\left([a]_{D}=+12.6^{\circ}\right)$ followed by reduction of the ketone and subsequent dehydration of the alcohol.

Since oxidation of the olefin eventually led to 3 -methylcyclohexanone with opposite sign of rotation as the 3-methylcyclohexanone used to prepare the olefin, it follows that it must have been the allylic position at which oxygen was introduced and not the vinylic one. Introduction of oxygen at the vinylic position would have produced the ketone with a positive rotation in predominance corresponding to an over-all inversion of configuration of the methyl group.

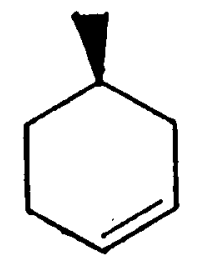

$[a]_{578}=+106^{\circ}$
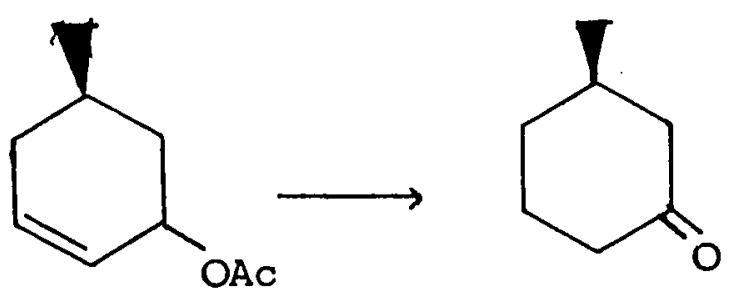

$[\mathrm{a}]_{\mathrm{D}}=+12.2^{\circ}$

(not observed) 
However, Mousseron used sodium hydroxide in the hydrolysis of the acetate mixture and this could have resulted in double bond shift by an $\mathrm{S}_{\mathrm{N}}{ }^{2}$ mechanism. Until this aspect is clarified, Mousseron's work must be regarded with caution.

More recently Nelson and Trachtenberg (1962) has reported on mechanism of olefin oxidation by selenium dioxide. His work appears - to be an extension and refinement of Mousseron and Jacquier's experiment with optically active 4-methylcyclohexene.

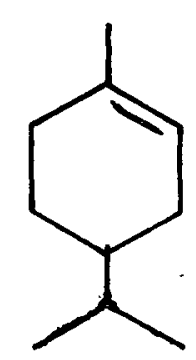

D-carvomenthene
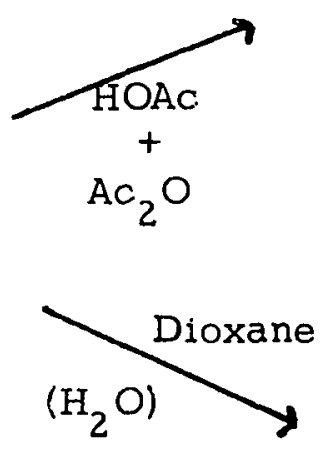

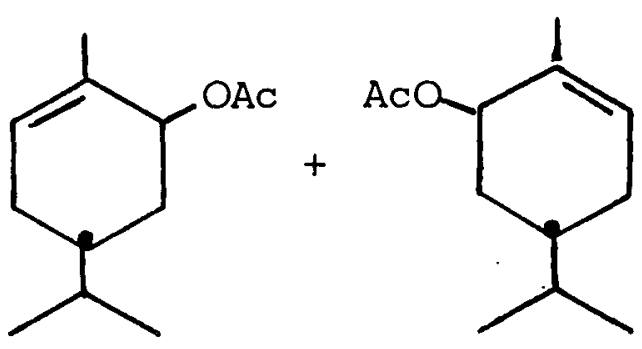

racemic

carvomenthol acetate

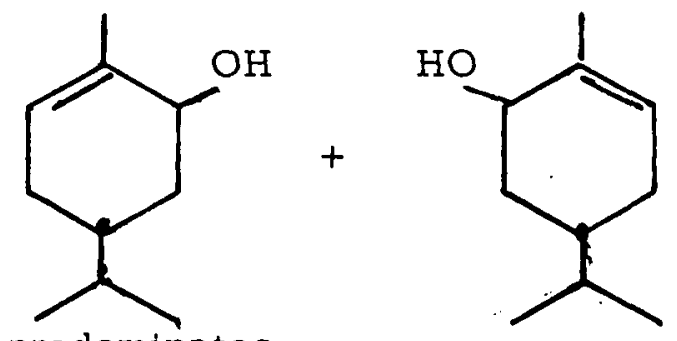

predominates L-carvomenthol (highly racemic)

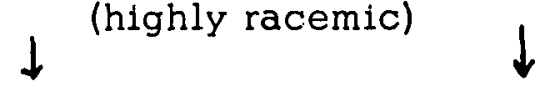<smiles>CC1=CCC(C(C)C)CC1=O</smiles> 
The net result of their experiments was that (1) in acetic anhydride-acetic acid solvent only racemic acetate was formed, but (2) in moist dioxane L-carvomenthane and L-carvomenthol acetate were produced, but these were highly racemic. In the latter solvent this corresponded to racemization with a slight excess inversion of the double bond as the over-all course of the oxidation.

The stereochemistry of the ketone was established by converting it back to $\mathrm{L}$-carvomenthene having an opposite (but smaller) rotation. Then the alcohol was related to the ketone.

Based on the optical behavior and stereochemical findings ("as well as on other facts in the literature") the following mechanism was proposed:
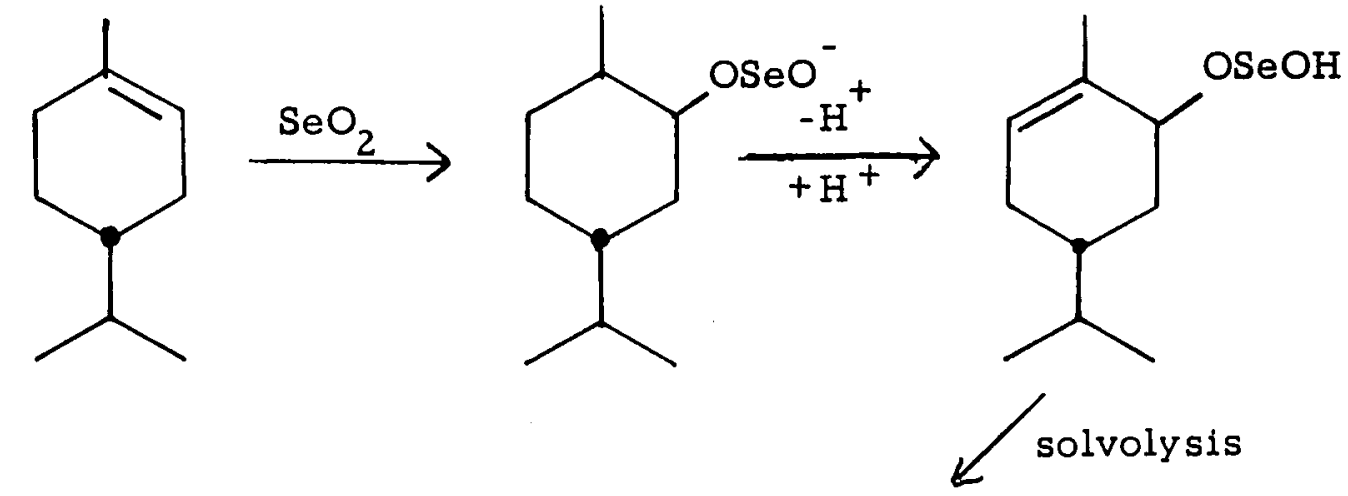

ketones

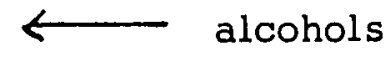

Electrophilic attack of selenium dioxide on $\underline{\text { D-carvomenthene }}$ forms a selenium species from which a $\beta$ elimination of a proton occurs; by subsequent solvolysis the alcohol is then derived. 
At the time of writing of this dissertation no publication of this work has appeared in the literature. Evidence for the proposed selenium intermediates is not known. Neither is it shown that the ketone arises from the alcohol and not directly from some seleniumcontaining species (oxidation of the proposed intermediate alcohol, of course, would resolve the point). Furthermore, the first postulated selenium intermediate is a monoester derivative of the unknown "hyposelenous acid" species (e.g., a carbon-oxygen linkage). The stability of the resulting alcohols and acetates under the reaction conditions is also unknown; allylic acetates do rearrange with relative ease (Ingold and Shoppe 1929; Burton and Ingold 1928) and the corresponding alcohols may behave similarly to a lesser extent.

Consequently, an interpretation of these experimental results is harzardous and could be misleading until more experiments are performed.

Wiberg and Nielsen (private communication) disagree with Nelson and Trachtenberg's experimental results accordingly:

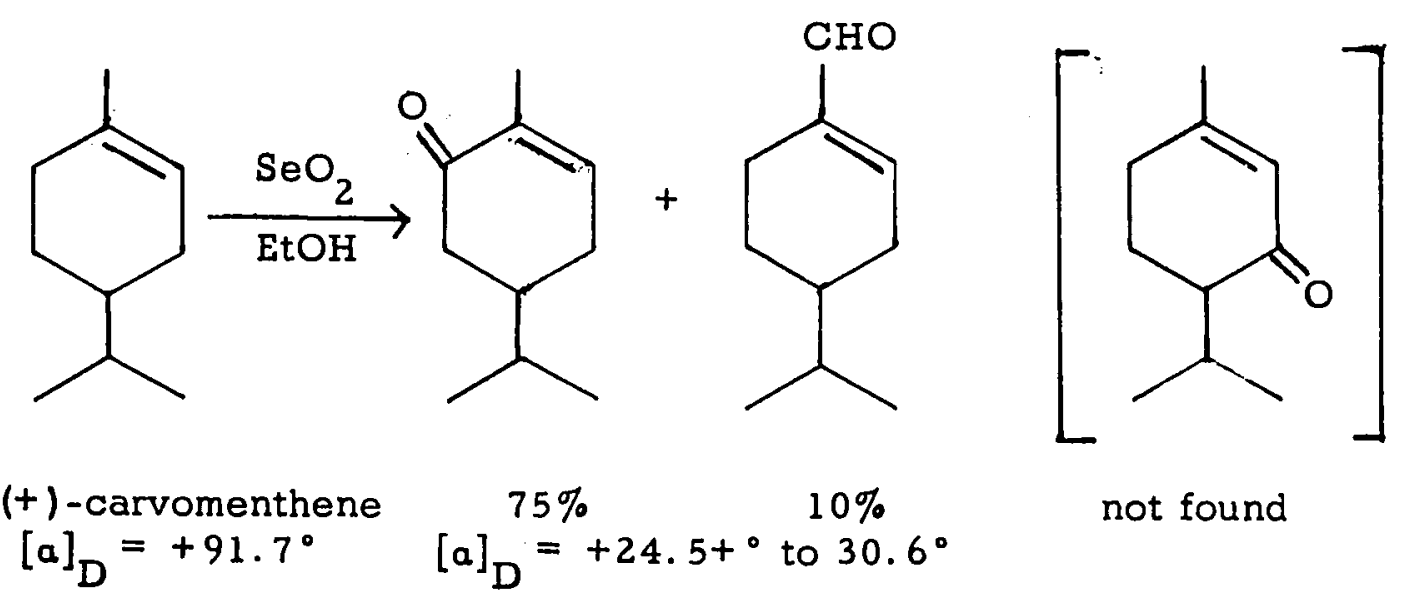


The net result is a $44-55 \%$ retention of rotation. Nevertheless the discrepancy may be a result of the different solvent used by these investigators.

They further note that Trachtenberg used the Wolff-Kishner reduction to make $(-)$-carvomenthene from $(+)$-carvotanacetone and double bond migration is more likely to result in this procedure.

Wiberg and Nielsen, in contrast to Nelson and Trachtenberg, suggest a selenic acid derivative (e.g., a carbon-selenium linkage) as the intermediate species accordingly.
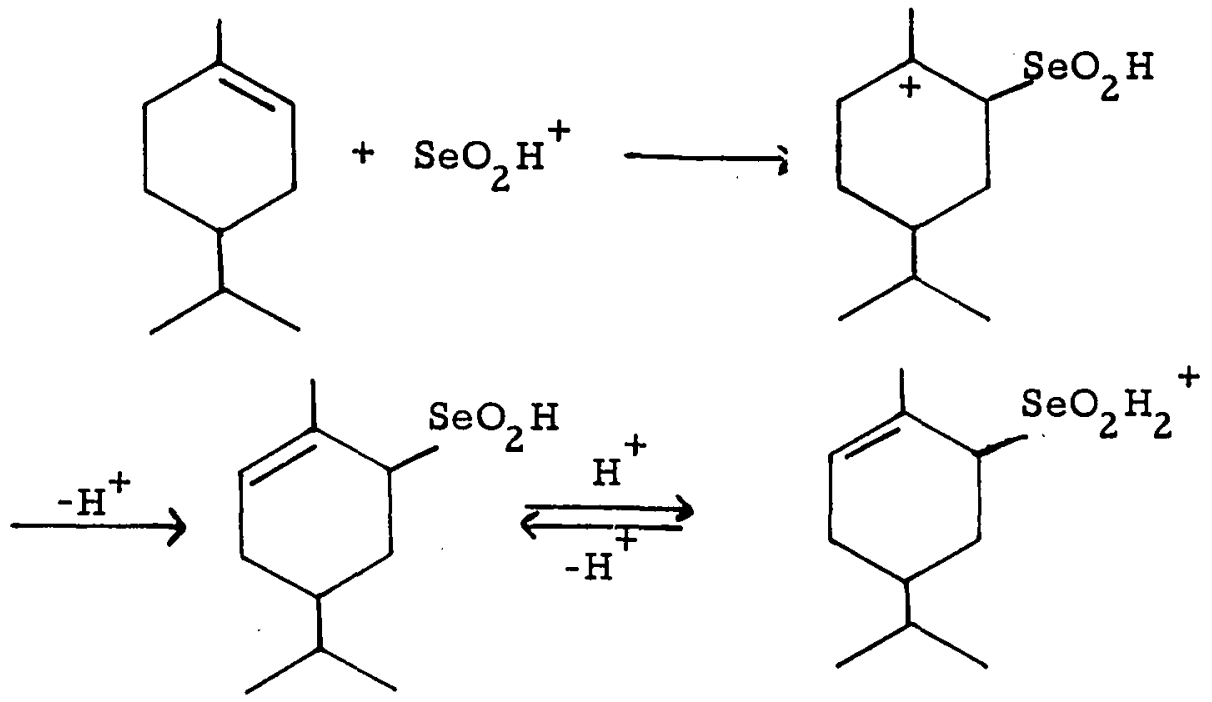

The difference then between Nelson and Trachtenberg vs. Wiberg and Nielsen is in the chemical structure of the proposed intermediates. Since the details of these proposed intermediates are strictly speculative at the present time it is profitable to regard these two 
mechanisms as being identical in all main features and the interpretation of both is as follows.

Acetic acid being a good lonizing solvent promotes the formation of a transition state similar to that in an $\mathrm{S}_{\mathrm{N}}{ }^{1}$ type reaction, e.g., $+$ - Then attack by the solvent at,either side is equally probable and a completely racemic product is obtained without inversion.

Water (in dioxane or in ethanol), being more nucleophilic than acetic acid, could perform an $\mathrm{S}_{\mathrm{N}}{ }^{2}$ or $\mathrm{S}_{\mathrm{N}}{ }^{2}$ type of attack accordingly:<smiles>C[C+]CC1(CC)CC(C(C)C)CC=C1C</smiles><smiles>CC1=CCC(C(C)C)CC1O</smiles><smiles>CC1=CCC(C(C)C)CC1(O[OH+])OS(=O)[OH2+]</smiles><smiles>CC1=CCC(C(C)C)CC1O</smiles> 
Since water may have had a slight steric preference in Trachtenberg's system--a high degree-but not complete racemization resulted.

This mechanistic hypothesis would explain the formation of selenium containing products arising from two moles of hydrocarbon and one of selenium dioxide. The allyl seleninic acid intermediate could react with another mole of alkene in the same fashion as in the intial reaction.

Wiberg and Nielsen have demonstrated configurational stability of their optically active hydrocarbon under the chosen reaction conditions. Although the nature of the intermediate seleniumcontaining species is only speculative, the proposed allyl selenium intermediates is not unreasonable. Otherwise the same experimental deficiencies apply as in Nelson and Trachtenberg's work concerning the stability of the primary oxidation products under the reaction conditions. 


\section{EXPERIMENTAL}

\section{General}

Melting points were determined in capillary tubes with calibrated thermometers in a Mel-Temp commercial apparatus.

Boiling points were not corrected. Refractive Indices were measured with an Abbe refractometer.

Infrared spectra were recorded on a Perkin-Elmer Infracord and ultraviolet spectra were recorded on a Perkin-Elmer Model 202 Spectrophotometer; since the machines were not calibrated, positions of maxima may be in error by a few millimicrons.

Nuclear magnetic resonance (NMR) spectra were measured on a Varian Model A-60 High Resolution nuclear magnetic resonance spectrometer. Carbon tetrachloride was the solvent unless otherwise specified.

Vapor phase chromatography (v.p.c.) was performed on a Model $609 \mathrm{~F}$ and M Flame Ionization chromatograph and on an Aerograph research instrument with a Varian Recorder. Identification of compounds was accomplished by direct comparison with the standards. Peak areas were calculated by cutting out the respective areas on graph paper and welghing them on a Mettler balance. When components were 
poorly resolved, the shape of the peak was approximated as closely as possible.

Some compounds were purified on a special preparative chromatography setup with 1-1/4 inch x 6 feet Carbowax on firebrick column, designed and built by Dr. Robert Bates.

Thin-layer chromatography was performed on a Model A-200 assembly made by the Research Specialities Co.

Microanalyses were done by Elek Micro Analytical Laboratories, Los Angeles, Calif., and by Mr. Joseph Nemeth, Urbana, Illinois.

Selenium Dioxide Oxidation of a-Methyl Styrene

Preparation of Standards and Reactants and Purification of Stock Reagents

Acetic Acid, Glacial. --Du Pont Reagent grade acetic acid was purified by the method of Fieser (1957), b.p. 117.5-118 . Vapor phase chromatography indicated no contaminants in the fraction collected over this boiling point range.

Selenium Dioxide. - To $50 \mathrm{~g}$. of commercial selenium dioxide in a 1-1. Erlenmeyer flask was added $10 \mathrm{ml}$. of fuming nitric acid. The flask was heated until all traces of nitrogen oxides and water vapor disappeared, when a cold-finger condenser was inserted about 3-4 
inches into the flask to prevent the escape of selenium dioxide vapors. The bottom of the flask was vigorously heated; in a short time the flask was filled with colorless selenium dioxide crystals in the form of long thin tufts. The sublimate was stored in a desiccator. This method of sublimation is an extremely efficient one and suitable for large-scale work.

Purification of a-Methyl Styrene. --To 2 1. commercial a-methyl styrene (AMS) in a round-bottom flask $3.0 \mathrm{~g}$. hydroquinone was added and AMS was fractionally distilled, b. p. $164-66^{\circ}$, lit. b. p. $165^{\circ}$ (Lange 1956). Vapor phase chromatography indicated no contaminants. The olefin was stored in a. refrigerator without inhibitor and was stable for months.

Purification of Water. --Water was purified by distillation from potassium permanganate (Fieser 19.57).

3-Acetoxy-2-phenyl-1 propene. - -(Hatch and Patton 1954.) Eighty grams ( 0.70 mole) of selenium dioxide was added in small portions to a vigorously stirred mixture of $236 \mathrm{~g} .(2.00$ moles $)$ of AMS, $158 \mathrm{~g}$. (1.55 moles) of acetic anhydride, and $108 \mathrm{~g} \cdot(1.80$ moles) of acetic acid. An exothermic reaction took place and the temperature increased to $70-80^{\circ}$. The reaction was maintalned at 
this temperature for $1 \mathrm{hr}$. and then at $125^{\circ}$ for $2.5 \mathrm{hrs}$. The precipitated selenium was removed by filtration and the residue was distilled under reduced pressure to give $150 \mathrm{~g}$. of crude product, b. p. $1.084-6^{\circ}$, $\mathrm{n}_{\mathrm{D}}^{26.5} 1.5249 ;$ lit. b. p. ${ }_{5} 112-13^{\circ}, \mathrm{n}_{\mathrm{D}}^{25} 1.5261$ (Hatch and Patton 1954).

2-Phenyl-2-propene-1-ol. --(Hatch and Patton 1954.) A solution of $42 \mathrm{~g} .(1.05$ moles $)$ of sodium hydroxide in $368 \mathrm{ml}$. of water was added to $176 \mathrm{~g}$. (1.00 mole) of 3-acetoxy-2-phenyl-1propene and $0.1 \mathrm{~g}$. of hydroquinone, and the mixture was refluxed with vigorous stirring for 7 hrs. The reaction mixture was hydrolyzed with excess $10 \%$ sulfuric acid, and subsequently extracted with ether. The ether solution of the product was dried over anhydrous potassium carbonate. Distillation at reduced pressure gave $105 \mathrm{~g}$. 10.79 mole, $79 \%$ yield) of 2-phenyl-2-propene-1-ol, b. p. $1.093-5^{\circ}$; lit. b.p. 11.0 116-18 (Hatch and Patton 1954). About 97-8\% purity was established by v.p.c.

2-Phenyl-2-propene-1-al (Atropaldehyde). --To $100 \mathrm{ml}$. of carbon tetrachloride $17.4 \mathrm{~g}$. (0.13 mole) 2-phenyl-2-propene-1-ol was added. To this solution $100 \mathrm{~g}$. (1.2 moles) of freshly prepared manganese dioxide (Wilson and Harris 1951; Heyl 1948) was introduced 
at once and stirred vigorously for $24 \mathrm{hrs}$. The unreacted manganese dioxide was filtered off and the reaction mixture was fractionally distilled to give 11.2 g. $(63 \%)$ aldehyde, b. p. ${ }_{10} 90^{\circ} ;$ lit. b. p. $1296^{\circ}$ (Normart 1955).

p-Nitro-a-methyl Styrene. --The procedure of Sterling and Bogert (1939) was employed with some modifications. A mixture of $83 \mathrm{~g}$. nitric acid (sp. gr. 1.42) and $125 \mathrm{~g}$. sulfuric acid (sp. gr. 1.84) was slowly stirred into $100 \mathrm{~g}$. freshly purified and distilled cumene. The temperature was maintained at $30-40^{\circ}$ and the stirring was continued for $2 \mathrm{hrs}$. under a nitrogen atmosphere. The product was steam distilled and the mono nitro compound was purified by fractional distillation. It

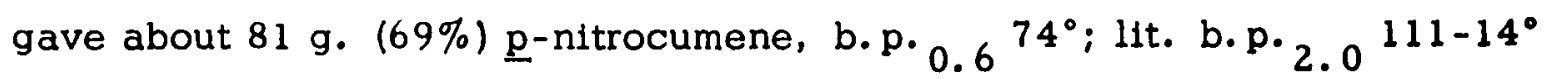
(Okamoto and Brown 1957); v.p.c. Indicated about $96 \%$ purity.

$$
\text { To } 40 \mathrm{~g} \cdot(0.150 \mathrm{~mole}) \mathrm{p} \text {-nitrocumene, } 80 \mathrm{~g} \cdot(0.450 \mathrm{~mole})
$$
$\mathrm{N}$-bromosuccinimide and $1.0 \mathrm{~g}$. benzoyl peroxide were added in $300 \mathrm{ml}$. carbon tetrachloride and refluxed for $6 \mathrm{hrs.} \mathrm{(Okamoto} \mathrm{and} \mathrm{Brown} \mathrm{1957).}$ The succinimide was removed by flltration, $100 \mathrm{~g} \cdot(0.770$ mole $)$ quinoline was added to the solution, and the reaction mixture was refluxed for another 2 hours. The solvent was removed under reduced pressure and the product was fractionally distilled, b. p. 30 127-30\%. The p-nitro-amethyl styrene solidified in the receiver; it was recrystallized from 
absolute ethanol. About $22 \mathrm{~g} \cdot(55 \%)$ product was obtained, m.p. 50-52 ; 1it. $51-52.5^{\circ}$ (Okamoto and Brown 1957). The crystals were stored in a desiccator or under nitrogen atmosphere.

\section{Control Experiments}

To $400 \mathrm{ml}$. of $90 \%$ acetic acid $60 \mathrm{ml}$. AMS was added and heated at $100^{\circ}$ for 24 hours. Again, to $50 \mathrm{ml}$. of $90 \%$ acetic acid $2.9 \mathrm{~g}$. of 3-acetoxy-2-phenyl-1-propene and $10 \mathrm{~g}$. of AMS were added and the solution was heated at $100^{\circ} \mathrm{C}$. for $12 \mathrm{hrs}$. Distillation of the reaction mixture in both cases indicated that no polymers were formed.

Selenium Dioxide Oxidation of a-Methyl Styrene

General Procedure. - - In $1.0 \mathrm{ml}$. of water $1.11 \mathrm{~g} .(0.010$ mole) of selenium dioxide was dissolved (unless otherwise stated) and to this solution $2.36 \mathrm{~g} .(0.020 \mathrm{~mole})$ or $1.18 \mathrm{~g} \cdot(0.010 \mathrm{~mole})$ of AMS was added in $100 \mathrm{ml}$. of the indicated solvent. The reaction mixture was heated for a period of time. The precipitated metallic selenium was filtered on a tared filter paper, washed with benzene and ether, dried and weighed. The "extent of oxidation" was determined from the quantity of selentum obtained. After cooling to room temperature, the reaction mixture was poured into $500 \mathrm{ml}$. of ice water. From the milky, colloidal suspension the organic products were extracted with three . 100-ml. portions of benzene. The comblned benzene extracts were 
neutralized with sodium bicarbonate solution, washed with water, and dried over anhydrous magnesium sulfate. The solvent was removed under reduced pressure and the crude oxidate residue was analyzed by v.p.c. using a 10-ft. silicone grease column.

Since this is a known reaction (Hatch and Patton 1954), the relative distribution of the products was ascertained by direct comparison with standards. However, it was subsequently found that when the crude oxidate was distilled (in larger scale experiments) about 30 to $50 \%$ of the crude oxidate was undistillable residue. This observation consequently casts some doubt on the numerical correctness of the v.p.c. distribution results.

Spot checks with distilled reaction mixtures revealed no drastically different product distribution except that the unsaturated alcohol is more susceptible to polymerization than the aldehyde or the acetate. Therefore the trends indicated in the tables are thought to be meaningful, although some real doubt exists concerning their quantitative validity.

\section{Cata lysis Experiments}

Experiments were carried out at $100^{\circ} \mathrm{C}$. in $100 \mathrm{ml}$. of solvent unless otherwise noted; anhydrous sodium acetate was employed as catalyst. Results are summarized in Table 6. 
When $0.1 \underline{M}$ toluenesulfonic acid was used as catalyst, a white substance was formed (thought to be poly AMS); due to this complication acid catalysis was not further explored.

Hydrolysis of 3-Acetoxy-2-phenyl-1-propene

Selenous acid, $\mathrm{H}_{3} \mathrm{SeO}_{3}$, is formed when selenium dioxide is dissolved in water; its ionization constants are $k_{1}=3 \times 10^{-3}$ and $\mathrm{k}_{2}=5 \times 10^{-8}$.

To $1.94 \mathrm{~g} \cdot(0.010 \mathrm{~mole})$ of unsaturated acetate was added $1.0 \mathrm{~g} \cdot(0.010 \mathrm{~mole})$ of malonic acid $\left(\mathrm{k}_{1}=1.4 \times 10^{-3}\right.$ and $\mathrm{k}_{2}=$ $8 \times 10^{-7}$ ) in $100 \mathrm{ml}$. of $95 \%$ acetic acid; the mixture was heated at $100^{\circ} \mathrm{C}$. for $6 \mathrm{hrs}$. The same experiment was repeated with $85 \%$ phos phoric acid $\left(k_{1}=7.5 \times 10^{-3}\right.$ and $\left.k_{2}=6.2 \times 10^{-8}\right)$. The usual workup (see oxidation of AMS Experimental) was employed to recover the products. Results are summarized in Table 10.

Oxidation of a Mixture of AMS, 3-Acetoxy-2 -phenyl-1 -propene, 2-Phenyl-2-propene-1-ol and 2-Phenyl-2-propene-1-al

A mixture of products was collected from a number of oxidations. Since the composition of this mixture was known it was suitable for use to determine whether the alcohol or the acetate would oxidize further to the aldehyde. 
To $52 \mathrm{~g}$. of mixture (see composition in Table 7) $12.5 \mathrm{~g}$. of selenium dioxide was added in $500 \mathrm{ml}$. of $50 \%$ dioxane. The solution was refluxed for 24 hours.

To $32 \mathrm{~g}$. of mixture $5 \mathrm{~g}$. of selenium dioxide plus $20 \mathrm{~g}$. of manganese dioxide were added and refluxed for 24 hours in pure benzene (heterogeneous).

The results are summarized in Table 7 .

\section{Miscellaneous Oxidations}

When an equi-molar ratio of selenium dioxide and manganese dioxide were intimately mixed and heated together a reaction occurred. The color changed from dark brown to belge-yellow and a new, distinct complex of unknown structure with the empirical formula of $\mathrm{SeO}_{2} \cdot \mathrm{MnO}_{2}$ resulted (Gmelin 1907).

This reagent $(2 \mathrm{g.})$ in a $1: 1$ oxidant to olefin mole ratio was evaluated under our usual reaction conditions as shown in Table 8 . It proved to be ineffective as an oxidant. When $5 \mathrm{~g}$. of manganese dioxide was added to the usual oxidation system, reaction occurred as before. Results are tabulated in Table 8.

Kinetics

Standard sodium thiosulfate was prepared according to Kolthoff and Sandell (1946). $\quad N=0.0583$. 
Stock Solution A.--In $750 \mathrm{ml}$. of acetic acid $47.20 \mathrm{~g}$. of AMS was dissolved.

Stock Solution B. - - In $250 \mathrm{ml}$. of water $11.10 \mathrm{~g}$. of selenium dioxide was dissolved.

The Oxidation Reaction. --In a 250-ml. Erlenmeyer flask $75 \mathrm{ml}$. of stock solution A was introduced and the Erlenmeyer flask was placed in the constant temperature bath. Stock solution B $(10 \mathrm{ml}$.) and $15 \mathrm{ml}$. of pure acetic acid were similarly introduced into a 50-ml. Erlenmeyer flask and placed in the constant temperature bath. After thermal equilibrium was attained (in about flve minutes) solution B was added to solution $A$. This gave a reaction mixture which was $0.400 \underline{M}$ in AMS, $0.004 \mathrm{M}$ in selenium dioxide with a total volume of $100 \mathrm{ml}$. of $90 \%$ acetlc acid. Altquots of $10 \mathrm{ml}$. were withdrawn every 10 minutes and quenched in $50 \mathrm{ml}$. of cold chloroform. The inorganic compounds were extracted with two $50-\mathrm{ml}$. portions of ice-cold water. To the combined extracts $10 \mathrm{ml}$. of $10 \%$ potassium lodide, and $20 \mathrm{ml}$. of concentrated hydrochloric acid were added in that order, and the precipitated selenium was filtered using a cotton plug. The solution was titrated with standard thiosulfate solution and the end point was recorded amperometrically. Results of a typical experiment are summarized in Table 9 and Figure 6. 
Isolation of Intermediate(s)

After extensive experimentation the following procedure was found to be suitable for the isolation of selenium-containing intermediates. Selenium dioxide $11 \mathrm{~g} .(0.1 \mathrm{~mole})$, was dissolved in $3 \mathrm{ml}$. of water with warming and $60 \mathrm{ml}$. $(0.5 \mathrm{~mole})$ of AMS was dissolved in $400 \mathrm{ml}$. of $90 \%$ acetic acid. The solutions were combined to react for 48 hours at room temperature. The reaction mixture became a golden yellow color but no selenium precipitated. The solvent was removed under reduced pressure and the unreacted AMS was distilled off at high vacuum between $30-40^{\circ}$. The crude product $(30 \mathrm{g.})$ is an odoriferous thick syrup which was distilled at $10^{-3}$ to $10^{-4} \mathrm{~mm}$. with considerable decomposition. The pot temperature was about $200^{\circ}$.

The infrared spectrum of the crude reaction mixture (undistilled) indicates strong absorptions at $3400 \mathrm{~cm}^{-1}$ and at $1720 \mathrm{~cm}^{-1}$.

Purification. - -A chromatography column of $200 \mathrm{~g}$. neutral alumina was prepared. It was washed with acetone and dried at $170^{\circ}$ for 3 hours. The crude product ( $10 \mathrm{~g}$.) was dissolved in a few milliliters of toluene and was absorbed onto the column; it was eluted with petroleum ether, b. p. $60-75^{\circ}$, to give fraction I, and subsequently washed with $100 \mathrm{ml}$. of ether and $200 \mathrm{ml}$. of $95 \%$ ethanol, fraction II. 


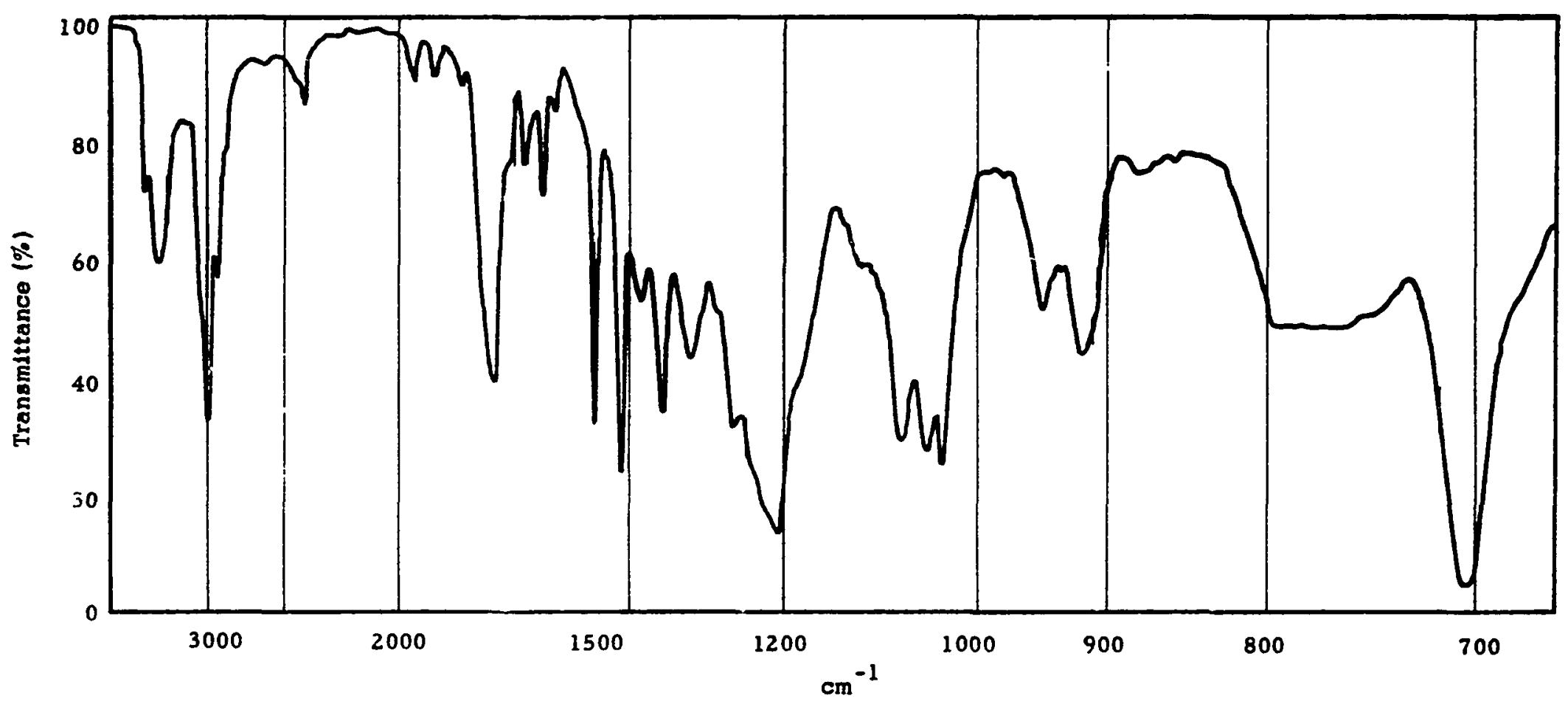

Figure 1. --Infrared Spectrum of the Crude Product. 
Fraction II was evaporated under reduced pressure and crude crystals or a thick, light yellow liquid was obtained. In $500 \mathrm{ml}$. of hot petroleum ether, b. p. $60-75^{\circ}, 5 \mathrm{~g}$. of crude crystals were dissolved and then the volume was concentrated to about $250-300 \mathrm{ml}$. The solution was permitted to cool slowly to room temperature where crystallization began. This crystallization process was repeated several times, and eventually pure, colorless crystals were obtained, m.p. $96-97.5^{\circ}$ dec. This product was soluble in all common organic solvents except heptane, petroleum ether and cyclohexane.

Anal. C, 62.67; H, 6.37.

The same work-up procedure was repeated with fraction I but no crystals could be obtained; the light yellow, moderately viscous oil was not analyzed with v.p.c. for purity.

When essentially anhydrous conditions were employed (pure acetic acid and $20 \mathrm{ml}$. of acetic anhydride) with 24-36 hours reaction time almost.pure I could be obtained.

The presence of water favored the formation of II under homogeneous conditions with 96 hours reaction time. Nevertheless this compound was formed in low yield $(30-40 \%)$ even under the most favorable conditions. 


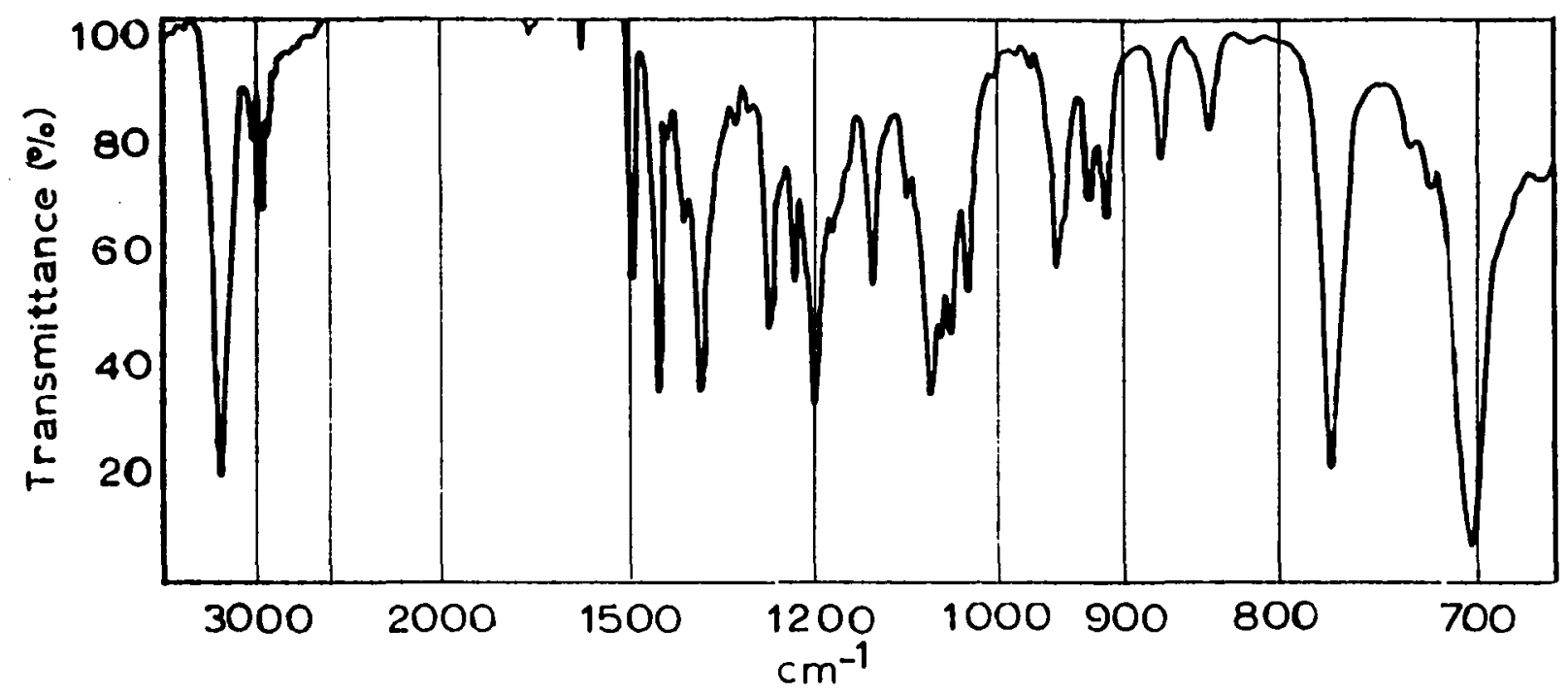

Figure 2. --Infrared Spectrum of Fraction II Crystals (KBr pellets).

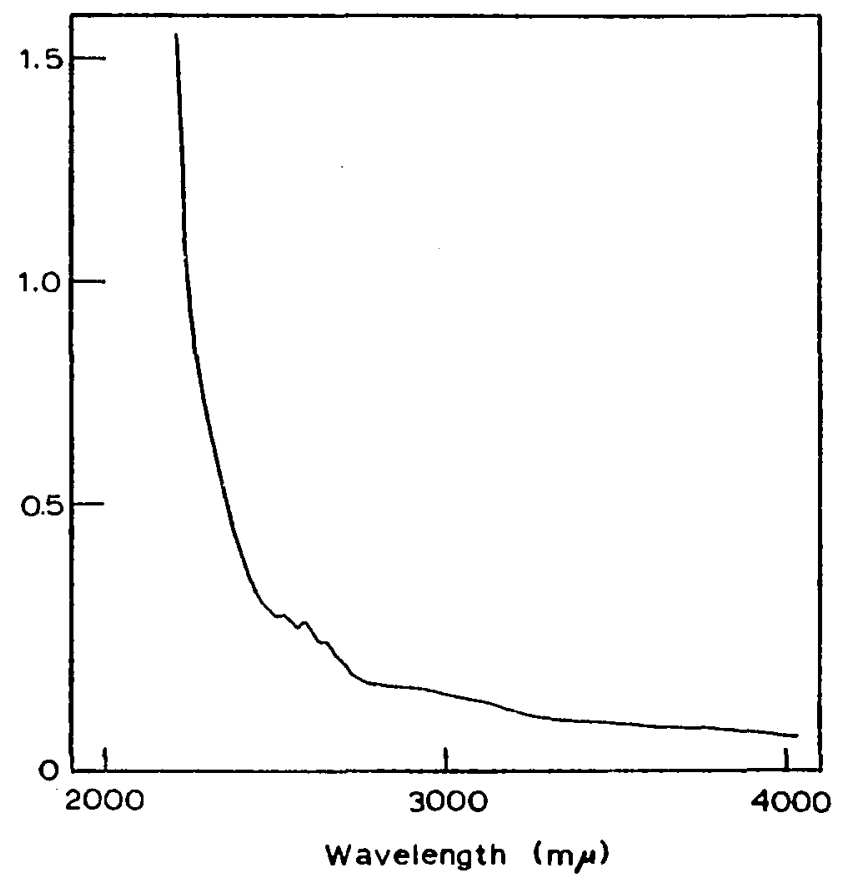

Figure 3. --Ultraviolet Spectrum of Fraction II Crystals in $95 \%$ Ethanol. 


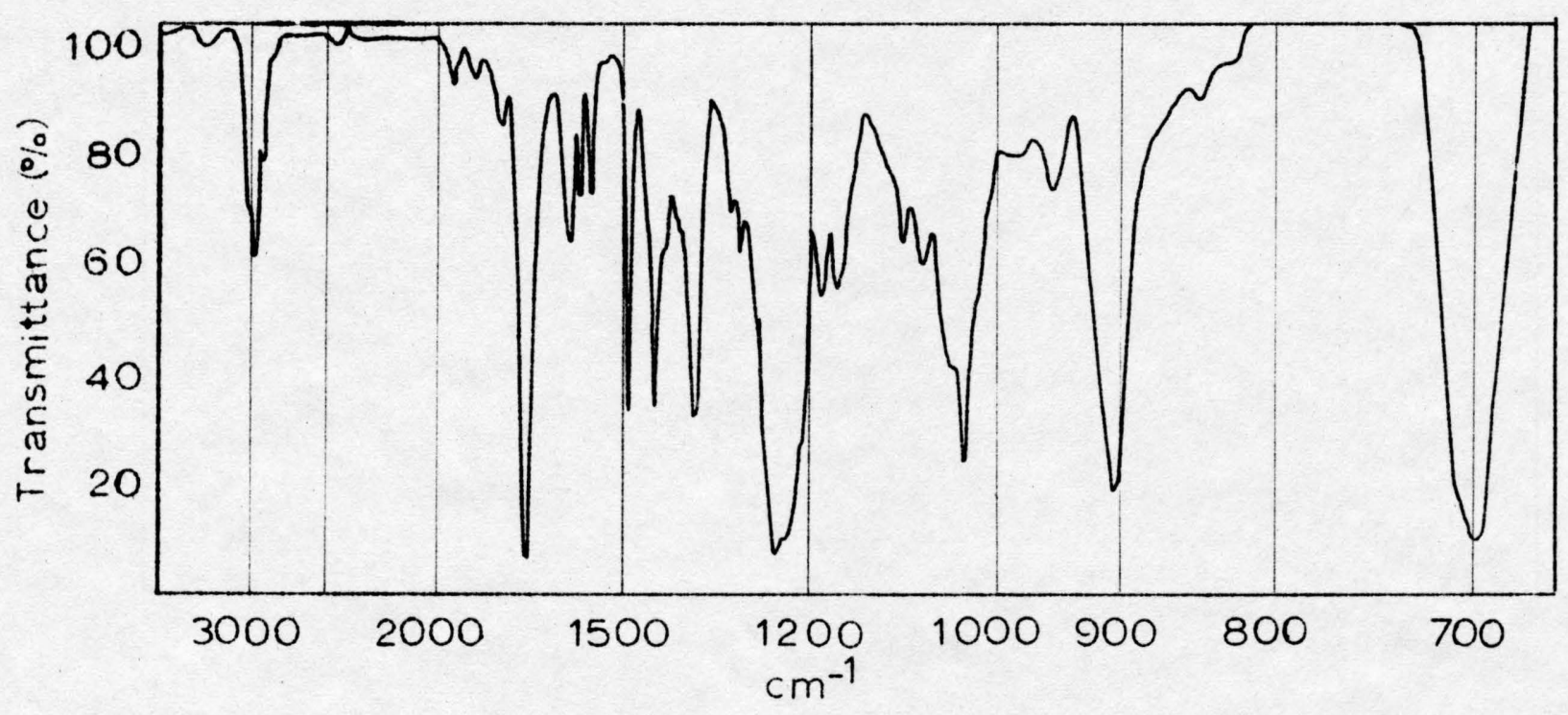

Figure 4. --Infrared Spectrum of Fraction I Oil.

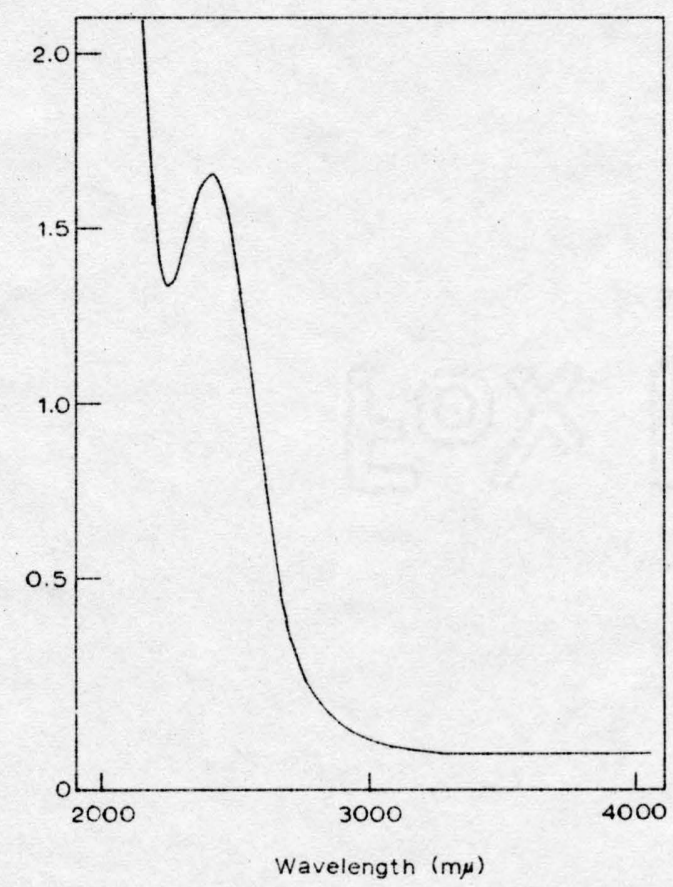

Figure 5. --Ultraviolet Spectrum of Fraction I Oil. 


\section{Chemistry of Intermediates}

On long standing (4-6 months) a mixture of $I$ and II in acetic acid decomposed at room temperature into selentum and the normal oxidation products (vide ante).

The purified crystalline substance, II, was air- and moisturesensitive and decomposed in a desiccator in 2-3 months. The decomposition products were not identified except for the black selenium.

Fraction II was dissolved in $90 \%$ acetic acid containing $5 \mathrm{ml}$. of formic acid; it decomposed after 5 hrs. refluxing into unsaturated acetate and AMS.

Fraction II was refluxed in $50 \mathrm{ml}$. of water and $6 \mathrm{~g}$. of phosphoric acid (heterogeneous) for $5 \mathrm{hrs}$. No selenium precipitated. A yellow color resulted; however, no reaction products were isolated and identified.

Fraction II was refluxed in $10 \%$ potassium hydroxide (heterogeneous) for 5 hrs. A rapid reaction occurred but no selenium precipitated.

Fraction I was treated as fraction II immediately preceding. No selenium precipitated but all absorption at $1720 \mathrm{~cm}^{-1}$ disappeared. When the reaction mixture was poured into $500 \mathrm{ml}$. of water a copious quantity of some white crystalline material precipitated. The substance was not identified. 
A freshly prepared mixture of I and II (or the fractions separately) readily gave a test for selenium dioxide (or selenoxide) with potassium lodide, starch solution, and hydrochloric acid. However, after several weeks the blue color development became increasingly sluggish.

Summary of Results

See Tables 1-10 and Figure 6 on the following pages.

$\underline{\text { Discussion }}$

The presence of 2-phenyl-2-propen-1-al (atropaldehyde) could be rationalized by several theoretically feaslble pathways. The experimental results (Tables 3, 4 and 7 ) eliminate the following possibilities:

(a) Further oxidation of the unsaturated alcohols

(b) Oxidation of the unsaturated acetate, e.g., from diacetates<smiles>C=C(c1ccccc1)C(OC(C)=O)C(C)C</smiles>

(c) Directly from AMS.

Water (especially in the acetic acid solvent system) promotes the formation of atropaldehyde in direction proportion (Table 2) as illustrated in Figure 7.

Some unsaturated alcohol is formed by hydrolysis of the unsaturated acetate (Table 10) but, surprisingly, its presence is not 
TABLE 1. --Solvent Composition.

$3 \mathrm{hr} ., \frac{\mathrm{AMS}}{\mathrm{SeO}_{2}}=2$, Temp. $=100^{\circ}, 0.01$ mole AMS

\begin{tabular}{ccccccc}
\hline \multirow{2}{*}{ \% HOAC } & $\begin{array}{c}\text { Total } \\
\text { Oxidation }\end{array}$ & \multicolumn{5}{c}{ \% Distribution of Products } \\
\cline { 3 - 7 } & AMS & Ald. & Alc. & Ac. & U \\
\hline $100^{\mathrm{b}}$ & 45 & 39 & 12 & 15 & 29 & 5 \\
99 & 57 & 33 & 16 & 16 & 32 & 4 \\
95 & 61 & 37 & 12 & 16 & 34 & 2 \\
90 & 57 & 35 & 13 & 19 & 30 & 3 \\
70 & 56 & 42 & 18 & 18 & 18 & 4 \\
$65^{\mathrm{C}}$ & 54 & 47 & 20 & 20 & 11 & 3 \\
$60^{\mathrm{d}}$ & 50 & 50 & 17 & 20 & 13 & - \\
50 & 54 & 56 & 15 & 17 & 12 & 2 \\
25 & 18 & 82 & 5 & 9 & 5 & - \\
$25^{\mathrm{e}}$ & 15 & 86 & - & 14 & - & - \\
$0^{\mathrm{f}}$ & & & No Reaction & & & \\
\hline
\end{tabular}

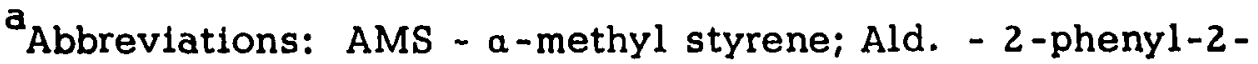
propene-1-al; Alc. - 2-pheny1-2-propene-1-ol; Ac. - 3-acetoxy-2-phenyll-propene; U - Unknown.

$\mathrm{b}_{\mathrm{The}} \mathrm{SeO}_{2}$ is insoluble (no $\mathrm{H}_{2} \mathrm{O}$ was added).

Apparently homogeneous.

$d_{\text {Heterogeneous from here on down. }}$

esomewhat emulsified with soap.

$f_{\text {Pure water. }}$ 
TABLE 2. --Solvent Composition.

$24 \mathrm{hr} ., \frac{\mathrm{AMS}}{\mathrm{SeO}_{2}}=2$, Temp. $=100^{\circ}, 0.01$ mole AMS

\begin{tabular}{ccccccc}
\hline \multirow{2}{*}{$\begin{array}{c}\text { Total } \\
\text { Oxidation }\end{array}$} & \multicolumn{5}{c}{ \% Distribution of Products } \\
\cline { 3 - 7 } & AMS & Ald. & Alc. & Ac. & U \\
\hline 99 & 77 & 23 & 6 & 14 & 54 & 5 \\
97 & 72 & 28 & 6 & 13 & 50 & 4 \\
93 & 75 & 25 & 11 & 11 & 48 & 4 \\
90 & 77 & 23 & 12 & 13 & 48 & 4 \\
85 & 74 & 24 & 11 & 9 & 52 & 4 \\
80 & 75 & 25 & 21 & 13 & 38 & 3 \\
70 & 71 & 30 & 21 & 14 & 32 & 4 \\
\hline
\end{tabular}


TABLE 3. - Anhydrous Conditions.

24 hrs. $\frac{\text { AMS }}{\mathrm{SeO}_{2}}=2$, Temp. $=100^{\circ} \mathrm{C} ., 0.1$ mole AMS

\begin{tabular}{|c|c|c|c|c|c|c|}
\hline \multirow{2}{*}{ Solvent } & \multirow{2}{*}{$\begin{array}{c}\text { Total } \\
\text { Oxidation }\end{array}$} & \multicolumn{5}{|c|}{$\%$ Distribution of Products ${ }^{a}$} \\
\hline & & AMS & Ald. & Alc. & Ac. & $\mathrm{U}$ \\
\hline \multicolumn{7}{|l|}{$900 \mathrm{ml}$. HOAC } \\
\hline $\begin{array}{r}50 \mathrm{ml} \cdot \mathrm{Ac}_{2} \mathrm{O} \\
5 \mathrm{ml} \cdot \mathrm{H}_{2} \mathrm{O}\end{array}$ & 64 & 18 & 2 & 5 & 72 & 4 \\
\hline \\
\hline $\begin{array}{c}50 \mathrm{ml} \cdot \mathrm{Ac}_{2} \mathrm{O}^{\mathrm{O}} \\
5 \mathrm{ml} \cdot \mathrm{H}_{2} \mathrm{O}\end{array}$ & 67 & 14 & - & 4 & 82 & - \\
\hline \multicolumn{7}{|l|}{$480 \mathrm{ml}$. HOAC } \\
\hline $\begin{array}{c}480 \mathrm{ml} \cdot \mathrm{Ac}_{2} \mathrm{O} \\
10 \mathrm{ml} \cdot \mathrm{H}_{2} \mathrm{O}\end{array}$ & 60 & 18 & - & 10 & 71 & - \\
\hline \multicolumn{7}{|l|}{$900 \mathrm{ml}$. HOAC } \\
\hline $\begin{array}{r}50 \mathrm{ml} \cdot \mathrm{Ac}_{2} \mathrm{O}^{\mathrm{C}} \\
5 \mathrm{ml} \cdot \mathrm{H}_{2} \mathrm{O}\end{array}$ & 74 & 12 & trace & trace & 82 & 5 \\
\hline \multicolumn{7}{|l|}{$900 \mathrm{ml} . \mathrm{HOAC}_{\mathrm{d}}$} \\
\hline $\begin{array}{c}50 \mathrm{ml} \cdot \mathrm{Ac}_{2} \mathrm{O}^{\mathrm{d}} \\
5 \mathrm{ml} \cdot \mathrm{H}_{2} \mathrm{O}\end{array}$ & 63 & 13 & - & 4 & 82 & - \\
\hline
\end{tabular}

All runs were distilled.

$\mathrm{b}_{\text {Heat }} \mathrm{SeO}_{2}$ and solvent to $100^{\circ}$ before adding AMS.

$\mathrm{C}_{48} \mathrm{hrs}$.

$\mathrm{d}_{24 \mathrm{hrs}}$. at room temperature plus $24 \mathrm{hrs}$. at $100^{\circ} \mathrm{C}$. 
TABLE 4. --A 1:1 Mole Ratio of Reactants.

$24 \mathrm{hr} ., \frac{\mathrm{AMS}}{\mathrm{SeO}_{2}}=1$. Temp. $=100^{\circ} \mathrm{C} ., 0.01$ mole AMS

\begin{tabular}{|c|c|c|c|c|c|c|}
\hline \multirow{2}{*}{$\begin{array}{c}\% \text { HOAC } \\
+ \\
10 \mathrm{ml} . \mathrm{Ac}_{2} \mathrm{O}\end{array}$} & \multirow{2}{*}{$\begin{array}{c}\% \\
\text { Total } \\
\text { Oxidation }\end{array}$} & \multicolumn{5}{|c|}{$\%$ Distribution of Products } \\
\hline & & AMS & Ald. & Alc. & Ac. & $\mathrm{U}$ \\
\hline 100 & 87 & 4 & 5 & 34 & 54 & 4 \\
\hline $\begin{array}{l}840 \mathrm{ml} \cdot \mathrm{HOAc} \\
100 \mathrm{ml} \cdot \mathrm{Ac}_{2} \mathrm{O}^{\mathrm{a}} \\
10 \mathrm{ml} \cdot \mathrm{H}_{2} \mathrm{O}\end{array}$ & 87 & 5 & - & 14 & 75 & 6 \\
\hline $100^{b}$ & 87 & 10 & 8 & 26 & 53 & 4 \\
\hline 98 & 86 & 5 & 3 & 26 & 63 & 3 \\
\hline 90 & 88 & 8 & 11 & 33 & 48 & - \\
\hline 80 & 89 & 26 & 19 & 26 & 28 & 2 \\
\hline 70 & 88 & 18 & 19 & 31 & 30 & 3 \\
\hline $70^{C}$ & 87 & 20 & 11 & 11 & 57 & - \\
\hline $70^{\mathrm{d}}$ & 92 & 34 & 17 & 16 & 32 & - \\
\hline $70^{\mathrm{e}}$ & 88 & 25 & 11 & 30 & 30 & 4 \\
\hline
\end{tabular}

$a_{0.1}$ mole AMS was used.

$\mathrm{b}_{48 \mathrm{hrs}}$.

$c_{0.1}$ molar scale: distilled.

$\mathrm{d}_{\text {Repeat above. }}$

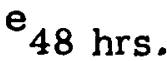


TABLE 5.--Miscellaneous Solvents and Conditions.

\begin{tabular}{|c|c|c|c|c|c|c|c|c|}
\hline \multirow{2}{*}{$\begin{array}{c}\text { Solvent } \\
\%\end{array}$} & \multirow{2}{*}{$\frac{\mathrm{AMS}}{\mathrm{SeO}_{2}}$} & \multirow{2}{*}{$\begin{array}{l}\text { Time } \\
\text { hrs. }\end{array}$} & \multirow{2}{*}{$\begin{array}{l}\text { Temp. } \\
{ }^{\circ} \mathrm{C} \text {. }\end{array}$} & \multirow{2}{*}{$\begin{array}{l}\text { Total } \\
\text { Oxida- } \\
\text { tion } \%\end{array}$} & \multicolumn{4}{|c|}{$\begin{array}{l}\% \text { Product } \\
\text { Distribution }\end{array}$} \\
\hline & & & & & AMS & Ald. & Alc. & U \\
\hline Benzene, 99 & 1 & 3 & 80 & 82 & 18 & 21 & 55 & 7 \\
\hline Benzene, 99 & 2 & 15 & 80 & 44 & 56 & 25 & 15 & 4 \\
\hline Dioxane, 99 & 1 & 24 & 100 & 66 & 34 & 5 & 38 & 24 \\
\hline Dioxane, 70 & 2 & 3 & refl. & 51 & 49 & 22 & 27 & 3 \\
\hline Dioxane, 60 & 1 & 3 & refl. & 58 & 43 & 15 & 42 & 2 \\
\hline Dioxane, 60 & 2 & 3 & refl. & 52 & 48 & 23 & 24 & 5 \\
\hline Pyridine, 80 & 2 & 3 & refl. & 41 & 59 & 7 & 26 & 8 \\
\hline n-Bu Ether, 99 & 1 & 24 & 140 & 90 & 10 & 9 & 66 & 15 \\
\hline Ethyl acetate, $90^{\mathrm{a}}$ & 2 & 3 & refl. & 37 & 63 & 7 & 17 & 13 \\
\hline Formic acid, 90 & 2 & 3 & refl. & tar res & ults & & & \\
\hline Formic acid, $70^{\mathrm{a}}$ & 2 & 4 & refl. & 60 & 40 & 27 & 15 & $\mathrm{~b}$ \\
\hline THF, 97 & 1 & 24 & 60 & 86 & 14 & 8 & 81 & - \\
\hline THF, 80 & 1 & 24 & 65 & 55 & 49 & 10 & 43 & - \\
\hline THF, 80 & 2 & 3 & refl. & 36 & 64 & 19 & 14 & 3 \\
\hline
\end{tabular}


TABLE 6. --Catalysis Experiments.

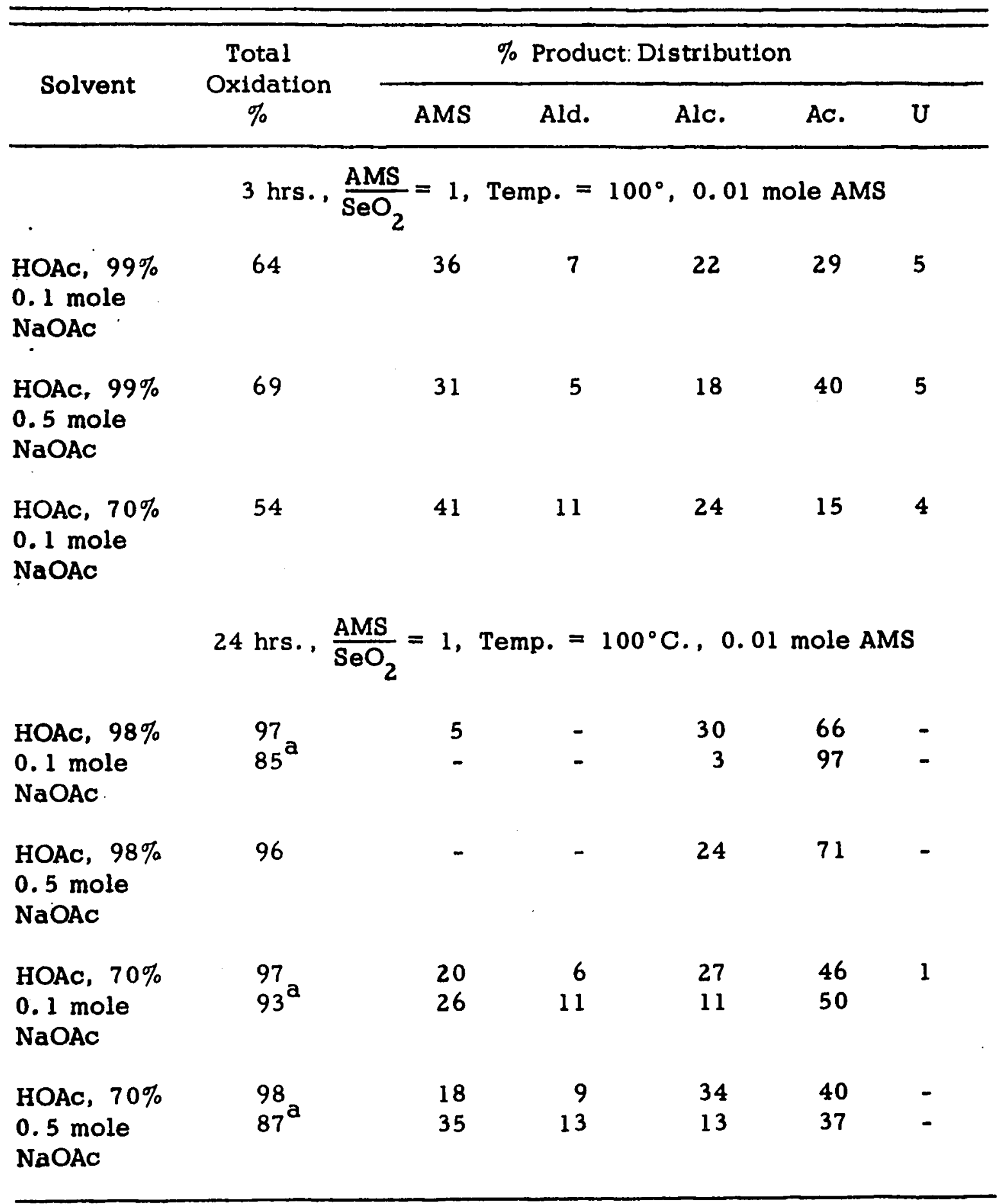


TABLE 6--Continued

\begin{tabular}{|c|c|c|c|c|c|c|}
\hline \multirow{2}{*}{ Solvent } & \multirow{2}{*}{$\begin{array}{c}\text { Total } \\
\text { Oxidation } \\
\%\end{array}$} & \multicolumn{5}{|c|}{$\%$ Product Distribution } \\
\hline & & AMS & Ald. & Alc. & Ac. & $\mathrm{U}$ \\
\hline & $24 \mathrm{hrs}$. & $\frac{\mathrm{AMS}}{\mathrm{SeO}_{2}}=2$ & Temp. = & $10^{\circ} \mathrm{C}$. & $\mathrm{mol}$ & MS \\
\hline $\begin{array}{l}\text { HOAc, } 99 \% \\
0.1 \text { mole } \\
\text { NaOAC }\end{array}$ & 89 & 34 & trace & trace & 67 & \\
\hline $\begin{array}{l}\text { HOAC, } 70 \% \\
0.1 \text { mole } \\
\text { NaOAC }\end{array}$ & 77 & 18 & 4 & trace & 24 & \\
\hline $\begin{array}{l}\text { HOAC, } 70 \% \\
0.5 \text { mole } \\
\text { NaOAC }\end{array}$ & 70 & 60 & trace & trace & 17 & \\
\hline
\end{tabular}

$a_{0.1}$ mole AMS was used; products were determined after distillation of the reaction mixture. 
TABLE 7. - "Mixture Oxidation."

\begin{tabular}{lccccccc}
\hline \multirow{2}{*}{ Solvent } & $\begin{array}{c}\text { Total } \\
\text { Oxidation } \\
\%\end{array}$ & \multicolumn{5}{c}{$\%$ Distribution of Products } \\
\cline { 3 - 7 } & $\mathrm{a}$ & 41 & 15 & 19 & 24 & 2 \\
\hline-- & 75 & 25 & 16 & 45 & 8 & 6 \\
Dioxane, $50 \%$ & 75 & Ald. & Alc. & Ac. & U \\
Benzene & 82 & 18 & 9 & 57 & 6 & 9 \\
\hline
\end{tabular}

a Original composition.

TABLE 8. - Miscellaneous Oxidations with $\mathrm{SeO}_{2} \cdot \mathrm{MnO}_{2}$ and Manganese Dioxide.

\begin{tabular}{|c|c|c|c|c|c|c|c|c|}
\hline \multirow{2}{*}{$\begin{array}{l}\text { Solvent } \\
+ \\
5 \mathrm{~g} \cdot \mathrm{MnO}_{2}\end{array}$} & \multirow{2}{*}{$\frac{\mathrm{AMS}}{\mathrm{SeO}_{2}}$} & \multirow{2}{*}{$\begin{array}{l}\text { React. } \\
\text { Time } \\
\text { hrs. }\end{array}$} & \multirow{2}{*}{$\begin{array}{l}\text { Temp. } \\
{ }^{\circ} \mathrm{C} .\end{array}$} & \multirow{2}{*}{$\begin{array}{c}\text { Total } \\
\text { Oxid. } \\
\%\end{array}$} & \multicolumn{4}{|c|}{$\begin{array}{l}\% \text { Distribution } \\
\text { of Products }\end{array}$} \\
\hline & & & & & AMS & Ald. & Alc. & U \\
\hline Benzene & 1 & 15 & 80 & 34 & 66 & 20 & 11 & 2 \\
\hline Dioxane, $60 \%$ & 1 & 3 & reflux & 41 & 59 & 29 & 10 & 2 \\
\hline
\end{tabular}


TABLE 9. --Kinetic Data of a Typical Run.

\begin{tabular}{ccc}
\hline $\begin{array}{c}\text { Time } \\
(\text { min. })\end{array}$ & $\begin{array}{c}\mathrm{S}_{2} \mathrm{O}_{3}= \\
0.0580 \mathrm{~N})\end{array}$ & Log $\mathrm{C}$ \\
\hline $11: 11$ & 23.20 & 1.365 \\
$30: 26$ & 19.70 & 1.294 \\
$50: 10$ & 19.10 & 1.281 \\
$81: 62$ & 16.00 & 1.204 \\
$112: 47$ & 14.80 & 1.170 \\
$147: 52$ & 11.30 & 1.053 \\
$191: 59$ & 10.80 & 1.033 \\
$222: 40$ & 7.80 & 0.889 \\
\hline
\end{tabular}

TABLE 10.--Hydrolysis of 3-Acetoxy -2-phenyl-1-propene.

\begin{tabular}{llcc}
\hline Acid & \multicolumn{3}{c}{$\%$ Product Distribution } \\
\cline { 2 - 4 } & Alc. & Ac. & Unknown \\
\hline Phosphoric acid & 7 & 87 & 6 \\
Malonic acid & 5 & 91 & 4 \\
\hline
\end{tabular}




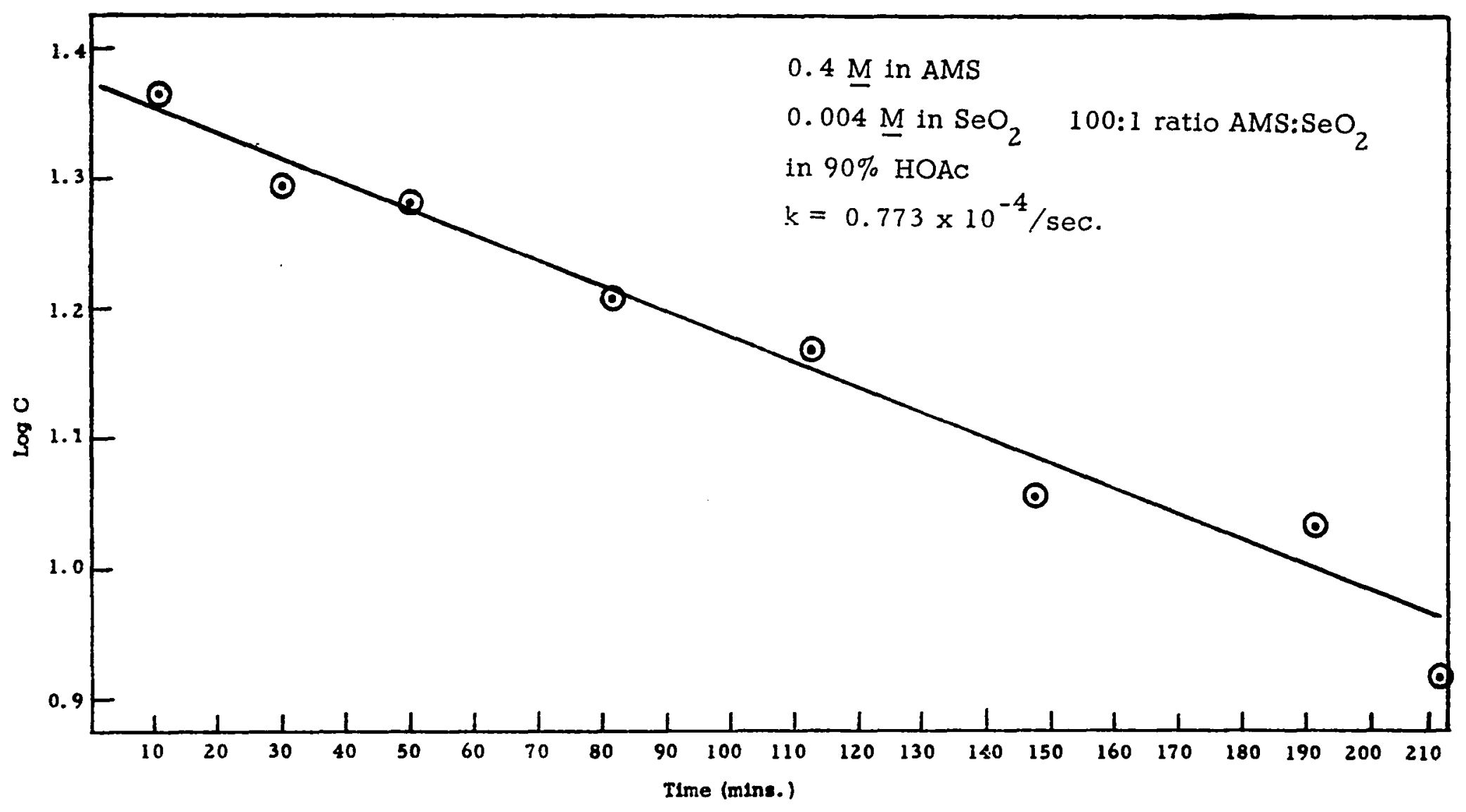

Figure 6. $--\mathrm{SeO}_{2}$ Oxidation of AMS; Plot of the Kinetic Data. $30.00^{\circ} \mathrm{C} ., 10-\mathrm{ml}$. aliquots. 


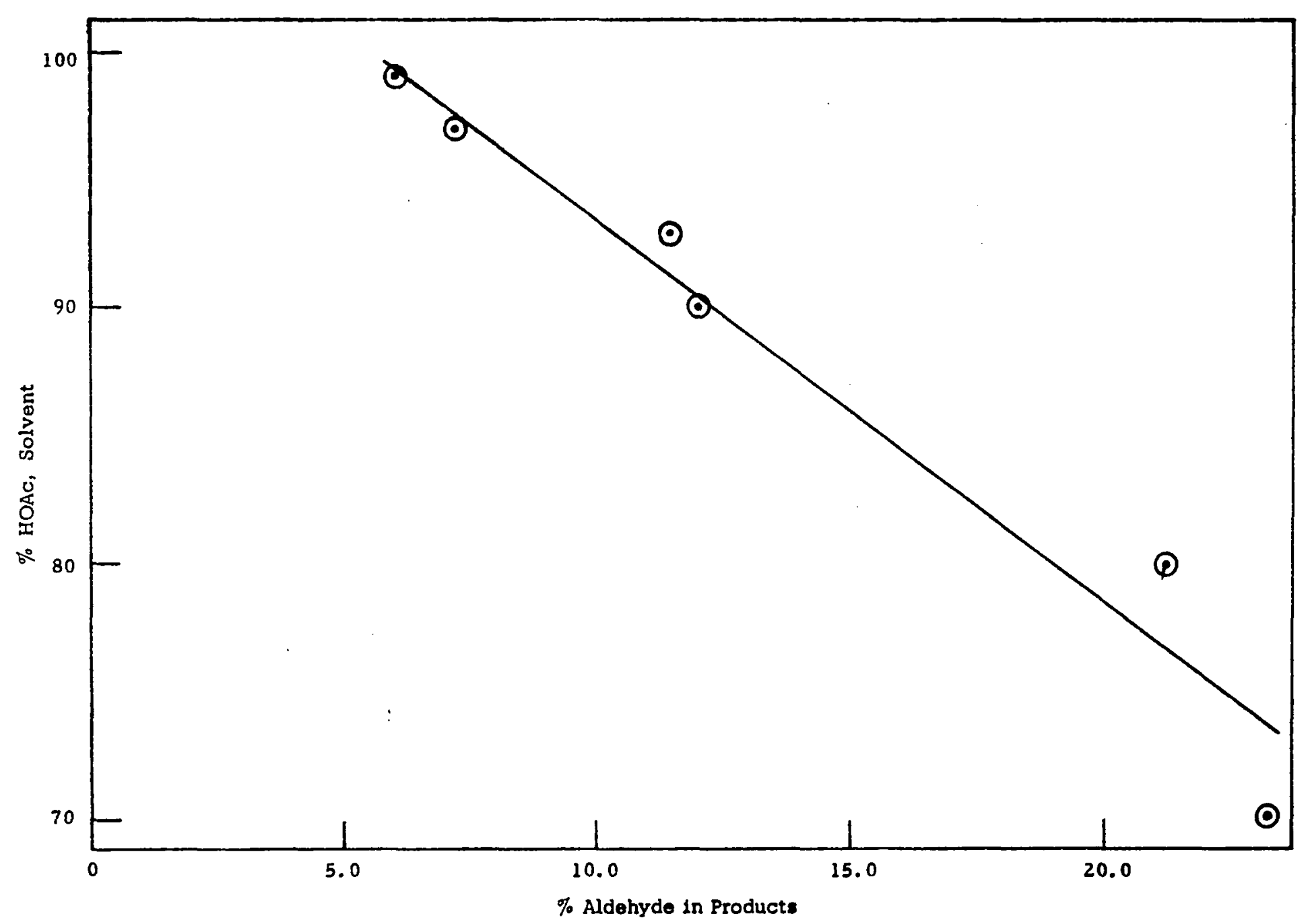

Figure 7. --Percent of HOAC vs. Aldehyde in the $\mathrm{SeO}_{2}$ Oxidation of a-Methyl Styrene. 24 hrs. reaction time, 2:1 AMS to $\mathrm{SeO}_{2}$ mole ratio.

出 
proportional to the amount of water present, but rather to the (increased) quantity of selenium dioxide (Table 2, Figure 8). This trend is at variance with the possibility of a solvolysis reaction at any stage of the reaction as the source of the alcohol, particularly in view of the known chemistry of allylic carbonium ion. Consequently, water and/or selenium dioxide may have a more complex role in the oxidation reaction.

The unsaturated acetate most 11kely arises by the action of the solvent medium on some selenium-containing intermediate or on other species formed thereof (Tables 5 and 6). Acetate ion catalysis further supports this view. The presence of water decreases the amount of acetate formed in a direct ratio as illustrated in Figure 8 due to hydrolysis. Solvent medium effects are anomalous (Table 5). The reaction proceeds in basic, neutral, and acidic solvents, but the rate of oxidation is fastest in acidic medium, which suggests acid catalysis. As for polar vs. non-polar solvents, visual indications are that the rate is faster in polar solvents. Product distribution studies are inconclusive, mainly because not enough solvent systems were evaluated. The relative nucleophilicity of the solvent may yet be correlated with product distribution.

Kinetic experiments at $90^{\circ} \mathrm{C}$. and $70^{\circ} \mathrm{C}$. revealed that selenium dioxide disappeared too rapidly for convenient measurements; fair amounts of selenium precipitated at these temperatures. At $50^{\circ} \mathrm{C}$. much less 


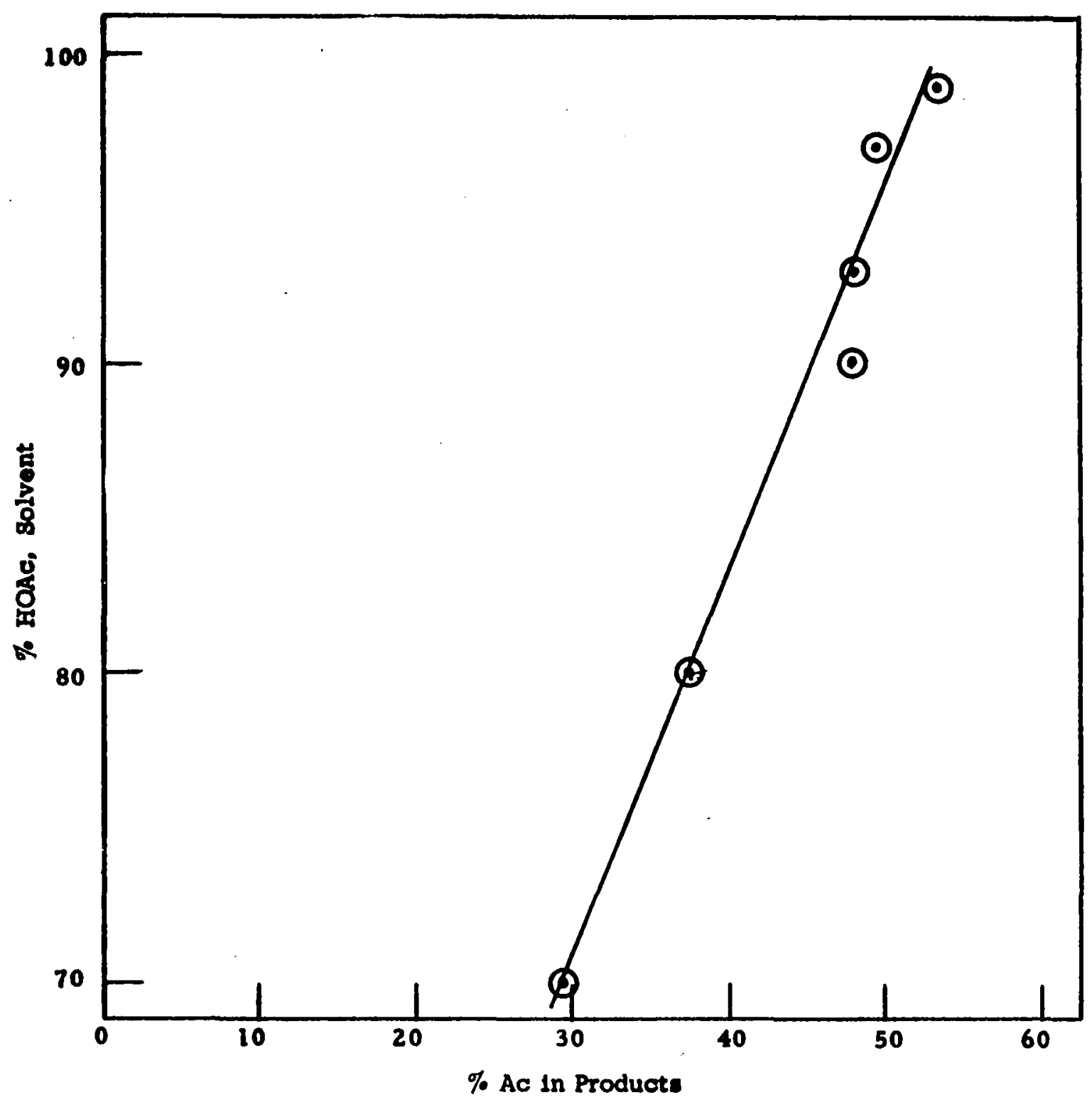

Figure 8. - Percent of HOAc vs. Acetate in the $\mathrm{SeO}_{2}$ Oxidation of a-Methyl Styrene. 24 hrs. reaction time, 2:1 AMS to $\mathrm{SeO}_{2}$ mole ratio. 
selenlum precipitated and at $30^{\circ}$ none at all was observed, yet the selenium dioxide concentration decreased rapidly (Table 9, Figure 6). This result suggests that a selenium-containing intermediate was formed. Rate constants did not show a high degree of reproducibility. Following the disappearance of selenium dioxide, even when considerable amount of selenium is precipitated, is therefore unreliable as an indicator of the oxidation rate. Soluble selenium complexes may be formed at any temperature, and the obtained rate constants will be in error as well as the mechanistic implications of the rate expression misleading. Due to this unexpected complication further study of the AMS system was eventually abandoned.

The isolated intermediates are only incompletely characterized. Infrared, ultraviolet, chemical analysis, general chemical behavior, and other physical characteristics nevertheless suggest that fraction II is either a hydrated selenoxide (A) or some hydroxy selenide (B) of the following structure:<smiles>CC(C[Sb](O)(O)CC(C)c1ccccc1)c1ccccc1</smiles> 


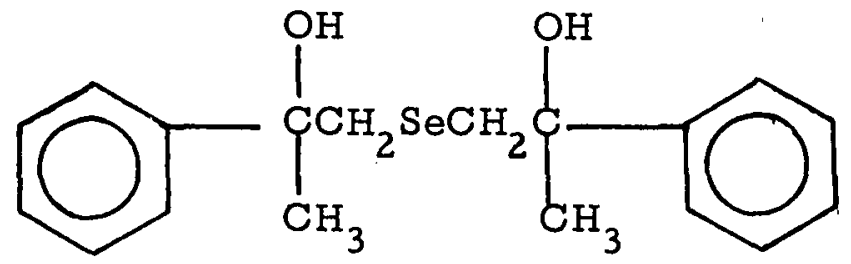

$B^{\prime}$

(may cyclize or dehydrate, $\mathrm{B}^{\prime}$ )

These proposed structures can be rationalized as originating from $\mathrm{C}$, depending on where the bond-breaking occurs. The actual structure

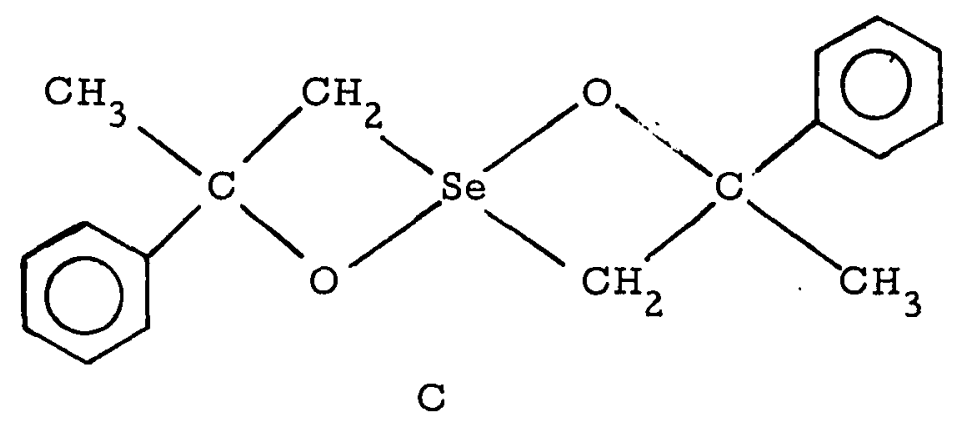

for II is therefore likely to be very solvent dependent.

The formation of $\mathrm{C}$ is postulated by the addition of selenium dioxide successively to the double bonds. If this postulate is proved correct, it will represent the first general method of introducing the Se-O (selenoxide) functional grouping directly into the molecule. Selenious and selenic acids reputedly do not add to unsaturated linkages (HoubenWeyl 1955; Gilman and Cason 1951).

Private communication from Marathon Oil Company lends further support to our postulate because of the following selenoxide derivative formation from ethylene: 


$$
\mathrm{SeO}_{2}+2 \mathrm{CH}_{2}=\mathrm{CH}_{2} \stackrel{\mathrm{HOAC}}{\longrightarrow} \mathrm{ACOCH}_{2} \mathrm{CH}_{2} \|_{\mathrm{SeCH}_{2} \mathrm{CH}_{2} \mathrm{OAC}}^{\mathrm{O}}
$$

A schematic sequence of events consistent with the trends indicated in our experiments and compatible with the chemistry of a selenoxide is detalled in Figure 9 for the over-all oxidation reaction in the a-methyl styrene system.

Because of the questionable quantitative aspects of the product distribution results, we believe that any elaboration of the scheme in Figure 9 is unwarranted until further experiments are performed and the indicated trends verified.

\section{Selenium Dioxide Oxidation of 1,3-Diphenylpropene}

\section{Preparation of Standards and Substrates}

1,3-Diphenyl-1-propanol. --In $200 \mathrm{ml}$. of acetic acid, $21 \mathrm{~g}$. of chalcone was dissolved and $2.0 \mathrm{~g}$. of Pd/C catalyst was slowly added in acetic acid. The chalcone was then hydrogenated until two moles of hydrogen were taken up. The catalyst was removed by filtration and the reaction mixture was poured into $1000 \mathrm{ml}$. of water. After the organics were extracted with ether, neutralized with sodium carbonate, and subsequently washed and dried, the ether layer was then evaporated and the crude alcohol fractionally distilled

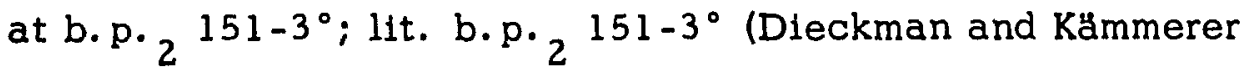




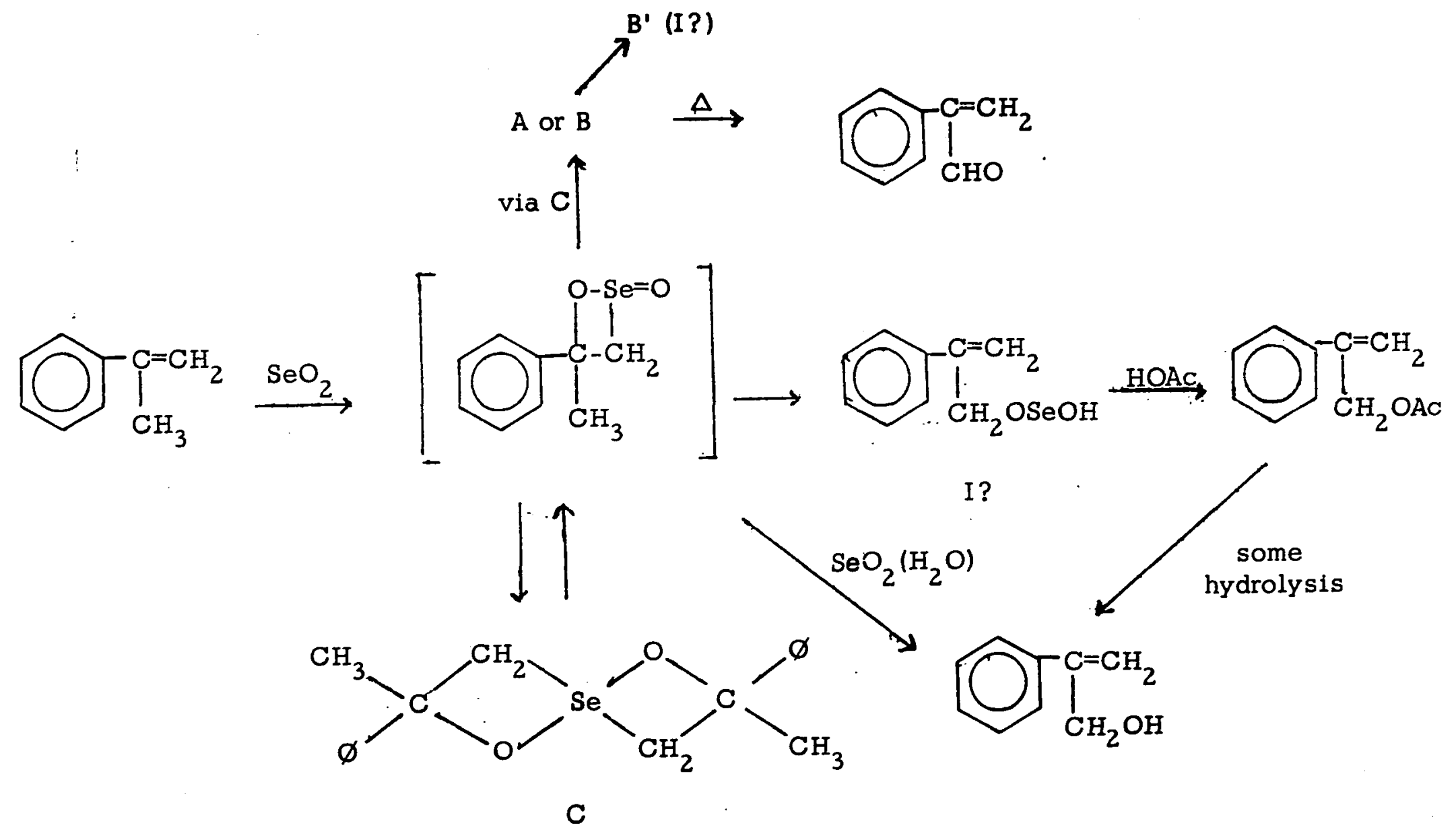

Figure 9. - -Selenium Dioxide Oxidation of a-Methyl Styrene. 
1906). Only $13 \mathrm{~g} .(62 \%)$ yield was realized by this procedure, and several fractional distillations were necessary on a Todd column to secure pure material.

$$
\text { 1,3-Diphenyl-1-propanone. --(Adams, et al., 1961.) This }
$$

compound was prepared by the hydrogenation of chalcone in ethyl acetate with platinum oxide catalyst. A $90 \%$ yield was realized, m.p. $71-2^{\circ} \mathrm{C} . ;$ 11t. $72-3^{\circ} \mathrm{C}$. (Adams, et al., 1961).

1,3-Diphenylpropane. - The title compound was prepared from chalcone by the "in situ" hydrogenolysis of the intermediate 1,3-diphenylpropanol. In $200 \mathrm{ml}$. of glacial acetic acid, $21 \mathrm{~g} .(0.10$ mole $)$ of chalcone was dissolved. Then $1 \mathrm{~g}$. of palladium on chracoal plus $0.5 \mathrm{~g}$. of platinum oxide were introduced into the solution and the reaction mixture was hydrogenated at room temperature until 1,3-diphenylpropane was formed according to the stoichiometry of the absorbed hydrogen. At this point $3 \mathrm{ml}$. of $60 \%$ perchloric acid was added to the mixture and hydrogenation was resumed until no more hydrogen was taken up (about $2 \mathrm{hrs}$.). The reaction mixture was gravity filtered and the solvent was removed under reduced pressure. The product $11.6 \mathrm{~g} .(55 \%)$ was obtained by repeated fractional distillation, b.p. $1.0111-13^{\circ}$, lit. (Sabatier and Murat 1915). Vapor phase chromatography indicated about $97 \%$ purity. 
Benzoin. - - Benzoin was prepared by the condensation of benzaldehyde with sodium cyanide without modification of the given procedure (Adams and Marvel 1961), but on a one-molar scale; $172 \mathrm{~g}$. $(85 \%)$ of benzoin, m.p. $129^{\circ}$; lit. $129^{\circ}$ (Adams and Marvel 1961) was isolated.

$$
\text { 2, 4, 6-Trimethylbenzaldehyde (Mesitaldehyde). --The title }
$$

compound was prepared from mesitylene by the Gattermann reaction using the procedure of Fuson, et al., (1960) Method A. The zinc cyanide was made according to the method of Adams and Levine (1923). The yield was $69 \%$, b. p. ${ }_{15} 117-9^{\circ} ;$ lit. b.p. ${ }_{16} 118-121^{\circ}$ (Adams and Levine 1923).

Acetomesitylene. - The procedure of Hufferd and Noyes (1921) was employed starting with mesitylene and acetyl chloride under normal Friedel-Crafts conditions. Quantitative yield was obtained, b. p. 20 $120-1^{\circ}$; lit. b.p. ${ }_{19} 122^{\circ}$ (Hufferd and Noyes 1921).

1,3,5-Trilsopropylbenzene. - -In a three-neck, round-bottom flask $120 \mathrm{~g}$. (1 mole) of cumene and $266 \mathrm{~g}$. (2 moles) of anhydrous aluminum chloride were mixed. To this, $250 \mathrm{~g}$. (2 moles) of isopropyl bromide was slowly added with vigorous stirring. The $\mathrm{HBr}$ was quickly removed by moderate aspirator vacuum as it was formed. The reaction 
mixture was heated for $40-60$ mins. at $60-70^{\circ}$ with continuous stirring. After the evolution of hydrogen bromide ceased, the viscous mass was poured gradually into $300 \mathrm{ml}$. of $10 \%$ hydrochloric actd and much ice, and the organics were extracted with three $200-\mathrm{ml}$. portions of water and dried. The product was distilled at atmospheric pressure. The fraction boiling between $220-260^{\circ}$ was collected in $70 \%$ yield. This fraction consists of $1,3,5$ - and 1,2,4-triisopropyl benzenes.

Isomerization. --To $285 \mathrm{~g}$. of $1,3,5$ - and 1,2,4-trisopropyl benzene (about $1: 1$ ratio) $60 \mathrm{~g}$. of anhydrous alumfnum chloride was added with vigorous stirring. The reaction mass turned a green color. Heat was applied at $60-70^{\circ}$ for $10 \mathrm{hrs}$. while stirring was continued. Work-up was accomplished as before, but the benzene was also washed with $10 \% \mathrm{NaOH}$ and hot water to remove traces of aluminum salts. A preliminary fraction boiling between $220-240^{\circ}$ at atmospheric pressure was collected. Then careful fractional distillation on a Todd column yielded $130 \mathrm{~g}$. of chromatographically almost pure 1, 3,5-tri-

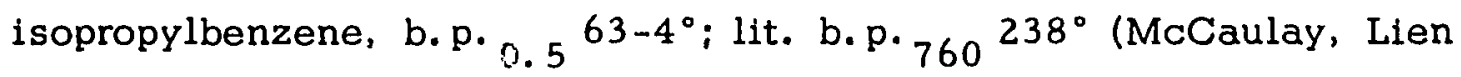
and Launer 1954).

2, 4,6-Trilsopropylbenzaldehyde. - This compound was prepared by the Gattermann reaction from 1, 3,5-trilsopropylbenzene as per 
the procedure of Fuson, et al., (1960), Method A (without modification). The yleld was $65 \%$, b. p. ${ }_{3} 120-123^{\circ}$; lit. b. p. ${ }_{4} 123-6^{\circ}$ (Fuson, et al., 1960).

Aceto-2, 4, 6-trilsopropylbenzene. --To a stirred mixture of $400 \mathrm{~g}$. of carbon tetrachloride, $47 \mathrm{~g} .(0.6 \mathrm{~mole})$ of acetyl chloride, and $72 \mathrm{~g}$. of anhydrous aluminum chloride, $102 \mathrm{~g}$. $(0.5$ mole $)$ of $1,3,5-$ triisopropylbenzene was added in 45 mins. at $10^{\circ}$. Stirring was continued for $2 \mathrm{hrs}$. The reaction mixture was worked up in the usual manner. The product was recrystallized twice from ethanol, which enabled complete separation of the isomers, m.p. $85-6^{\circ}$; lit. $96-7^{\circ}$ (Beets, Meerburg and Van Essen 1959).

Chalcones. --Commercially available aldehydes were purified by washing with sodium carbonate solution, drying and distilling. Commercial ketones were purified by distillation. The base condensations were carried out by the general procedure of Kohler and Chadwell (1944). In the condensation of chlorobenzaldehyde with acetophenone, the time of contact was reduced to one-half hour.

Chalcone (Benzalacetophenone) m. p. $58^{\circ}$; lit. $62^{\circ}$ and $58^{\circ}$ (Lange 1956; Hellbron and Bunbury 1953). The yield was 95\%. 
4-Methoxychalcone. - M. p. 73-5 ; lit. $75-6^{\circ}$ (Kohler and Conant 1917), $70 \%$ yield.

4'-Methoxychalcone.--M.p. $104-106^{\circ} \mathrm{C}$.; lit. $105-6^{\circ} \mathrm{C}$. (Staudinger and Kon 1907), 75\% yield.

4-Chlorochalcone --M.p. $113-15^{\circ} \mathrm{C}$.; lit. $114-115^{\circ} \mathrm{C}$.

Szmant and Basso 1952), 84\% yield.

4'-Chlorochalcone. - -M.p. $97-8^{\circ} \mathrm{C} . ;$ lit. $97-8^{\circ} \mathrm{C}$. (Lyle and Paradis 1955), $88 \%$ yield.

2, 4,6-Trimethylchalcone (Mesitalacetophenone). --The solution was cooled to $0^{\circ} \mathrm{C}$. before the aldehyde was added. The reaction mixture was then kept at $0^{\circ} \mathrm{C}$. for three hours; after that period the temperature was permitted to rise to $25^{\circ} \mathrm{C}$. where it reacted for 36 more hours, m.p. 96-97. $5^{\circ} ;$ lit. $97.5-98.5^{\circ}$ (Fuson and Jackson $1950) ; 84 \%$ yield. This same procedure was followed in the preparation of all hindered chalcones.

$$
2^{\prime}, 4^{\prime}, 6^{\prime}-\text { Trimethylchalcone. --M.p. } 61-2^{\circ} \mathrm{C} \text {; 1 1it. } 63^{\circ}
$$

(Nesmeyanov and Sazanova 1949). This chalcone was also prepared in very good yield from mesitylene and cinnamoyl chloride under Friedel-Crafts reaction conditions (Nesmeyanov and Sazanova 1949). The acyl halide and anhydrous aluminum chloride were mixed first 
and to this the mesitylene added. Reaction time was 3-4 hours. Normal Friedel-Crafts workup yielded the chalcone.

2,4,6-Triisopropylchalcone. - - M.p. $98-9^{\circ} \mathrm{C} ., 89 \%$ yield. Anal. Calcd. for $\mathrm{C}_{24} \mathrm{H}_{30}$ : C, 86.30; H, 8.98.

Found: C, $85.82 ; \mathrm{H}, 8.95$.

The infrared spectrum of this compound shows the expected

peaks.

2', 4',6'-Triisopropylchalcone. --M.p. 99-100 C. ; lit. 100-101 $\mathrm{C}$. (Fuson and Rachlin 1945), 88\% yield.

Hydrochalcols. - The chalcone, in an extraction thimble, was placed in an apparatus similar to a Soxhlet extractor but designed to provide continuous return of the extracting liquid. Lithium aluminum hydride (0.6 mole per mole of chalcone) was dissolved in absolute ether (one liter per mole) by heating with a heat lamp; the refluxing ether extracted the chalcone from the thimble. This device was necessary since many of the substituted chalcones were only sparingly soluble in ether. An intermediate purple color was sometimes observed. Refluxing was continued until the solution in the flask was colorless, * then for an additional half hour. The excess

* In the hindered series usually red, green and other persistent intermediate colors were produced. Furthermore, THF was substituted as solvent in another series of runs to insure a better yield in shorter reaction time. 
reagent was decomposed with water and then $5 \%$ sulfuric acid was added with swirling until all solid was dissolved. The ether layer was washed with water, and dried with anhydrous potassium carbonate. The ether was evaporated finally by heating to $100^{\circ}$ at $10 \mathrm{~mm}$. pressure. Some of the non-hindered hydrochalcols could be distilled without much decomposition at $0.5 \mathrm{~mm}$. Others were recrystallized from ether-petroleum ether, or from aqueous methanol. The hindered hydrochalcols are sensitive to dehydration even at room temperature over a period of time. Elution chromatography (heptane) on neutral alumina accelerated dehydration, but at the same time it permitted the separation of the two compounds. The yellow-colored olefin was eluted first whereas the hydrochalcol was collected by washing the column with methanol.

Dehydration. --The hydrochalcol $(50 \mathrm{~g}$. or less) was heated to $125-150^{\circ}$ by a Glas-Col mantle. Then freshly fused and powdered potassium bisulfate ( $10 \%$ by weight) was added all at once, and the apparatus was immediately arranged for vacuum distillation. The olefin was distilled at a few millimeter pressure, as rapidly as possible, consistent with keeping the head temperature not more than $10^{\circ}$ above the indicated boiling point. The distillate, usually yellow, was fractionated on a Todd column. The chromatographically pure fractions 
Received without page(s) 60 .

Fllmed as recelved.

University Microfilms, Inc. 
were actually cis-trans isomeric mixtures that could be separated to some extent by refrigeration. None of the presumably trans solids were 1solated, however.

Deuteriobenzoin. A. - -To $106 \mathrm{~g} \cdot(0.50 \mathrm{~mole})$ of benzoin was added $200 \mathrm{ml}$. of dry tetrahydrofuran, $10 \mathrm{~g} .(0.50 \mathrm{~mole})$ of deuterium oxide, and $25 \mathrm{~g}$. of anhydrous potassium carbonate; the solution was refluxed for 24 hours and the solvent was then removed using an aspirator. This cycle was repeated six times and then oxidative cleavage gave benzaldehyde containing 0.88 deuterium atoms per mole.

B. To $106 \mathrm{~g} .(0.50 \mathrm{~mole})$ of benzoin in $200 \mathrm{ml}$. of refluxing dry tetrahydrofuran was added $24 \mathrm{~g} \cdot(0.50 \mathrm{~mole})$ of sodium hydride in a $50 \%$ mineral oil suspension under a nitrogen atmosphere with vigorous stirring. A thick paste formed which was diluted with another $800 \mathrm{ml}$. of solvent and the suspension was refluxed for 24 hours. To this mixture was added $30 \mathrm{~g}$. ( 1.5 moles) of deuterium oxide and the solution was refluxed for 48 hours. The reaction mixture was poured into ice water and was filtered. The benzoin obtained gave benzaldehyde containing 0.60 deuterium atoms per mole.

Deuterio Benzoin Acetate. --In 100 ml. of a 1:1 mixture of pyridine and acetic anhydride $10.6 \mathrm{~g} \cdot(0.05 \mathrm{~mole})$ of benzoin $(0.877$ $\mathrm{D}$ atoms/mole) was dissolved and refluxed for 10 minutes. The reaction mixture was then cooled to room temperature where it reacted for another 
TABLE 12.--List of Olefins. 1,3-Diarylpropenes, $\mathrm{ArCH}=\mathrm{CHCH}_{2} \mathrm{Ar}^{\prime}$

\begin{tabular}{llccc}
\hline \multicolumn{1}{c}{$\mathrm{Ar}$} & $\mathrm{Ar}^{3}$ & $\begin{array}{c}\text { Yield } \\
(\%)\end{array}$ & $\begin{array}{c}\text { b.p. } \\
\left({ }^{\circ} \mathrm{C} .\right)\end{array}$ & $\begin{array}{c}\text { pressure } \\
(\mathrm{mm} .)\end{array}$ \\
\hline $\mathrm{C}_{6} \mathrm{H}_{5}$ & $\mathrm{C}_{6} \mathrm{H}_{5}$ & 50 & $161-2$ & 7.5 \\
$\mathrm{C}_{6} \mathrm{H}_{5}$ & $\mathrm{p}^{-\mathrm{C}_{6} \mathrm{H}_{5} \mathrm{OCH}_{3}}$ & 65 & 173 & 3.0 \\
$\underline{\mathrm{p}-\mathrm{C}_{6} \mathrm{H}_{5} \mathrm{OCH}_{3}}$ & $\mathrm{C}_{6} \mathrm{H}_{5}$ & 63 & $174-5$ & 3.0 \\
$\mathrm{C}_{6} \mathrm{H}_{5}$ & $\mathrm{p}_{-\mathrm{C}_{6} \mathrm{H}_{4} \mathrm{Cl}}$ & 58 & $168-9$ & 3.0 \\
$\mathrm{p}_{-} \mathrm{C}_{6} \mathrm{H}_{5} \mathrm{Cl}$ & $\mathrm{C}_{6} \mathrm{H}_{5}$ & 62 & 168 & 3.0 \\
$\mathrm{C}_{6} \mathrm{H}_{5}$ & mesityl & 65 & $169-70$ & 3.0 \\
\hline
\end{tabular}

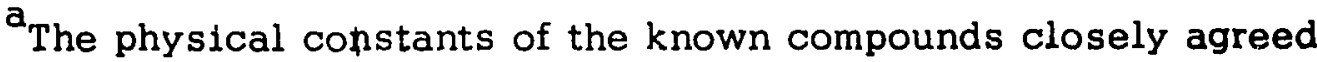
with those given in the literature (Rondesvedt, Jr., 1951).

b Analysis for $\mathrm{C}_{18} \mathrm{H}_{16}: \mathrm{C}, 91.48 ; \mathrm{H}, 8.46$.
Found: C, $91.65 ; \mathrm{H}, 8.26$. 
6 hours. On pouring it into cold water a yellow oil separated which eventually solidified. Several recrystallizations from ethanol gave 8.7 g. (70\%) fluffy deuterio benzoin acetate, m.p. $87-8^{\circ} \mathrm{C} . ;$ it. 85- $6^{\circ} \mathrm{C}$. (Heilbron 1953) for benzoin acetate.

Deuteriobenzaldehyde. --To 1 liter of dry benzene and $300 \mathrm{ml}$. of absolute ethanol $106 \mathrm{~g}$. ( 0.50 mole $)$ of deuterio benzoin was added. The solution was brought to reflux and $300 \mathrm{~g}$. (about 0.7 mole) of slightly moist freshly prepared lead tetraacetate was added in one portion. The solution was heated at reflux for one hour and allowed to cool to room temperature after which the insoluble lead (II) acetate was removed by filtration through a sintered glass funnel. The filtrate was washed with $50 \mathrm{ml}$. of dilute hydrochloric acld and refiltered, after which it was washed twice with $300-\mathrm{ml}$. portions of water, neutralized with sodium bicarbonate, washed again with water, and dried over anhydrous magnesium sulfate. Fractional distillation (after removal of the benzene) gave 50 grams $(60 \%)$ of benzaldehyde, b. p. ${ }_{14} 66-66.5^{\circ}$, which was chromatographically pure and contained 0.88 deuterium atoms per mole.

\section{3-Deuterio-1,3-diphenyl-1-propene. --The procedure of} Rondestvedt was used. Deuteriobenzaldehyde and acetophenone were condensed to give deuteriochalcone containing 0.87 deuterium 
atoms per mole. Reduction to saturated alcohol with lithium aluminum hydride and dehydration with potassium acid sulfate gave the desired olefin containing 0.87 deuterium atoms per mole. The over-all yield varied from 40 to $60 \%$.

1,2-Dibromo-1,3-diphenylpropane. --To $3.0 \mathrm{~g}$. of diphenylpropene in $20 \mathrm{ml}$. of carbon tetrachloride, bromine (in carbon tetrachloride) was added dropwise until the bromine color persisted. The solvent was removed under reduced pressure and the thick, yellowish paste was twice recrystallized from hot ethanol. It gave $3.6 \mathrm{~g}$. of pure product, m.p. $110^{\circ}$, lit. $110^{\circ}$ (Burton and Ingold 1928).

\section{1,2-Dibromobenzalacetophenone. --Four grams of chalcone} was dissolved in $25 \mathrm{ml}$. of carbon tetrachloride. Bromine was added dropwise to the cooled solution until the bromine color persisted. The precipitated dibromide was filtered off and washed with two $20-\mathrm{ml}$. portions of hot ethanol. The yield was quantitative, m.p. $156^{\circ}$; 1 it. $156-157^{\circ}$ (Bülow and von Sicherer 1901).

1,2-Dibromo-3-acetoxy-1,3-diphenylpropane.--To $1.5 \mathrm{~g}$. of the above distilled reaction mixture was added $10 \mathrm{ml}$. of carbon tetrachloride and to this solution was added a solution of bromine in carbon tetrachloride unt1l the bromine color persisted. After evaporation of 
the carbon tetrachloride the pasty yellow residue was recrystallized several times from ethanol to give a pure sample of the title compound, m.p. $177-179^{\circ}$; 11t. $176-177^{\circ}$ (Burton and Ingold 1928).

3-Deuterio-1,3-dipheny1-2-propene-1-ol. --To $20.0 \mathrm{~g}$. of 1 -deuterio-1,3-diphenyl-3-propen-1-one, containing 0.60 atoms of deuterium per mole, was added $200 \mathrm{ml}$. of absolute ether and $1.0 \mathrm{ml}$. of absolute ethanol. Then $2.0 \mathrm{~g}$. sodium borohydride was introduced and the reaction mixture was stirred for 48 hours at room temperature after which it was poured into an iced solution of $4 \%$ sulfuric acid and stirred for 45 minutes. The ether layer was separated, neutralized, and dried with magnesium sulfate. Evaporation of the ether gave 18.2 g. of a white crystalline mass. After two recrystallizations from ligroin (b. p. $66-75^{\circ}$ ) it melted at $55-56^{\circ}$; lit. $57-58^{\circ}$ (Wasserman and Aubrey 1955). Deuterium analysis indicated 0.59 deuterium atoms per mole.

\section{3-Deuterio-1-acetoxy-1,3-diphenyl-2-propene. --To $5 \mathrm{~g}$. of} the above alcohol was added $15 \mathrm{ml}$. of acetic anhydride and $15 \mathrm{ml}$. of anhydrous pyridine and the solution was allowed to stand at $35-40^{\circ}$ for 4 hours. The solution was poured into $100 \mathrm{ml}$. of water and extracted with three 50-ml. portions of ether. The ether layer was then washed with cold dilute hydrochloric acid, water, cold dilute sodium hydroxide, 
water, and then dried over magneslum sulfate. Distillation gave 3.6 g. of pure acetate, b. p. $11211^{\circ}$; lit. b.p. $11211^{\circ}$ (Burton and Ingold 1928). The acetate was reduced with lithium aluminum hydride and oxidized with chromic acid according to the procedure described elsewhere and the resulting 1,3-diphenylpropan-1-one contained 0.58 dueterium atoms per mole indicating that a negligible percentage of rearrangement occurred during acetylation and the degradation procedure.

B-Phenylethanol. --(Nystrom and Brown 1947) In $300 \mathrm{ml}$. of anhydrous ether $18 \mathrm{~g} .(0.5 \mathrm{~mole})$ of lithium aluminum hydride was dissolved with stirring. To the stirred solution $68 \mathrm{~g} \cdot(0.5$ mole) of phenylacetic acid (dissolved in $150 \mathrm{ml}$. of anhydrous ether) was added dropwise in $2 \mathrm{hrs}$. The reaction mixture was refluxed for 4 hours. Hydrolysis was accomplished with $300 \mathrm{ml}$. of $10 \%$ hydrochloric acid over ice. With two $150-\mathrm{ml}$. portions of ether the organic products were extracted; washing the ether with two $150-\mathrm{ml}$. portions of water removed all inorganic contaminants. The ether was removed under heat lamp in hood and the product was fractionally distilled; $42 \mathrm{~g}$. was obtained, b. p. $760223-25^{\circ}$; lit. b.p. ${ }_{750} 219-221^{\circ}$ (Skita and Ritter 1911). Infrared analysis indicated complete reduction of the carboxylic acid. 
Phenylacetaldehyde. --(a) In $500 \mathrm{ml}$. of AR grade acetone $42 \mathrm{~g}$. of $\beta$-phenylethanol was dissolved and the solution was cooled to $0^{\circ}$. To this solution the cooled oxidant consisting of a mixture of $28 \mathrm{~g}$. chromium trioxide, $28 \mathrm{~g}$. of concentrated sulfuric acid and $140 \mathrm{ml}$. of water was added in small portions over a period of 20 minutes. Oxidation was continued in ice water for another $20 \mathrm{~min}$ utes. The reaction mixture was processed by pouring it into 1 liter of water. The organics were extracted with three $300-\mathrm{ml}$. portions of carbon tetrachloride. Evaporation of the solvent and fractional distillation of the crude product gave only $6 \mathrm{~g}$. (15\% yield) of phenylacetaldehyde, b. p. $760194-5^{\circ}$; lit. b. p. $760^{195^{\circ}}$ (Erlenmeyer and Lipp 1883).

This procedure was repeated several times with numerous modffications, but no substantially better yleld was realized, and this method for making phenylacetaldehyde was eventually abandoned.

(b) Grignard reagent of $126 \mathrm{~g}$. (1 mole) benzyl chloride and $24 \mathrm{~g}$. (1 mole) of magnesium was prepared by conventional technique. To this dark green product $74 \mathrm{~g}$. ( 1 mole) of dry dimethylformamide was added in $74 \mathrm{~g}$. of anhydrous ether. A mildly exothermic reaction ensued. After all amide was added over a period of $1-1 / 2$ hours the reaction mixture was refluxed for an additional hour. Hydrolysis was accomplished with $600 \mathrm{ml}$. of 
$10 \%$ hydrochloric acid. The ether solution was extracted with three $200-\mathrm{ml}$. portions of ether. The ether was then neutralized, washed, dried and evaporated. Fractional distillation gave $41 \mathrm{~g}$. of pure product, b. p. $252^{\circ}$; lit. b. p. $760^{195^{\circ}}$ (Erlenmeyer and Lipp 1883).

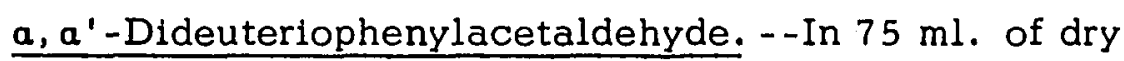
tetrahydrofuran $13 \mathrm{~g}$. of phenylacetaldehyde was dissolved. To this solution $12 \mathrm{~g}$. $\left(0.6\right.$ mole) of $\mathrm{D}_{2} \mathrm{O}$ and 3 drops of concentrated hydrochloric acid were introduced. The solution was homogeneous. The exchange reaction was heated with a heat lamp to $30-50^{\circ}$ for 48 hours under a nitrogen atmosphere: Recovery of the deuterated product was accomplished when the reaction mixture was poured into $500 \mathrm{ml}$. of water, was extracted with three $100-\mathrm{ml}$. portions of ether and the solvent was removed under a spirator vacuum.

The above procedure was repeated twice with $16 \mathrm{~g}$. of $\mathrm{D}_{2} \mathrm{O}$. Nuclear magnetic resonance analysis indicated $95-98 \%$ extent of exchange. Infrared analysis indicated no carboxylic absorption. Fractional distillation under reduced pressure afforded, however, onlý $9 \mathrm{~g}$. of pure, $a, a^{\prime}$-dideuteriophenylacetaldehyde.

Selenium Dioxide Oxidation of 1,3-Diphenylpropene General Procedure. - -A known quantity of selenium dioxide was dissolved in a few drops of water with warming. To this 
solution the indicated amount of 1,3-diphenylpropene was added in $100 \mathrm{ml}$. of pure acetic acid. The reaction mixture was heated for the desired length of time and the precipitated black selenium was removed by gravity filtration. After washing thoroughly with ether the tared filter paper was dried in vacuo for several hours and the weight of the selenium determined. Yields of selenium under favorable reaction conditions corresponded to $70-80 \%$ extent of oxidation.

The clear, golden-yellow reaction mixture was poured into 1 liter of water and was extracted with three 100-ml. portions of ether. The combined extracts were washed with water, and dried over anhydrous magnesium sulfate. All ether was removed in the hood at atmospheric pressure under a heat lamp. (This procedure will be henceforth referred to as the "usual workup.")

The crude oxidate, a thick, dark orange oil was rapidly distilled (less than five minutes) in a small distilling apparatus at 0.05-0.10 mm. pressure while the overhead temperature was not permitted to rise above $180^{\circ}$. This was an essential step for the production of consistent results. The distillate was usually a malodorous, free-flowing liquid of light yellow color. When the crude oxidate was distilled under these carefully controlled conditions practically no residue remained in the pot. Results are summarized in Tables. 
Vapor phase chromatography of the oxidate required about $300^{\circ}$ column temperature (sllicone grease) for good resolution of the components. However at this temperature, fragmentation, rearrangement and elimination reaction of the product occurred and the original composition was obscured. Thin layer chromatography (T. L. C.) plates were prepared by mixing $40 \mathrm{ml}$. of water and $20 \mathrm{~g}$. of silica gel $\mathrm{G}$ made by the Research Specialities Co. The crude, undistilled reaction mixture was separated into distinct spots by a 9:1:1 mixture of Skelly B, ether, and acetic acid solvent system. The plate was first sprayed with a $1 \%$ potassium permanganate solution (to indicate double bonds) and then with a 50\% sulfuric acid solution. After 10 to 15 minutes in an oven at $100^{\circ}$ characteristic colors for the various spots were developed. Continued heating eventually charred all the spots giving diagnostic, easily reproducible retention time values for the separated components. Qualitative comparison with standards indicated 3-acetoxy1,3-diphenylpropene as the major product in the crude oxidate to the extent of about $70-80 \%$. Four other components were also present. The lower spots were organoselenium compounds. No chalcone or 1,3-diphenyl-1-propanone was detectable (except in distilled reaction mixtures).

Infrared spectrum of the crude oxidate further confirmed the T. L. C. results, although small amounts of ketonic products could not be eliminated on the strength of this evidence alone. 
Isolation of the Reaction Products

Elution Chromatography. --On $100 \mathrm{~g}$. of activated neutral

alumina $2.0 \mathrm{~g}$. of crude, undistllled oxidate was absorbed after prior solution in a few milliliters of toluene. After $1750 \mathrm{ml}$. of a continuously varied ratio of methylene chloride and heptane solvent was eluted in 22 fractions it was apparent that no substantial separation of the olefinic components occurred.

In another attempt various solvents of increasing polarity were employed as eluants but no improvement in separation was evident even though the oxidate was distilled.

Fractional Distillation. --When $10.0 \mathrm{~g}$. of crude, undistilled oxidate was carefully fractionated on a Todd column (under reduced pressure) only a fair separation of the components was accomplished. Vapor phase chromatography as well as T.L.C. indicated that the fractions were not pure enough for meaningful physical constant measurements. Furthermore, on extended heating much chalcone and 1,3-diphenyl-1-propanone appeared in increasing amounts. These were not present in the original reaction mixture according to infrared and T.L.C. evidence. There was much undistillable residue left behind. (This same phenomenon was also observed when standard 3-acetoxy-1,3-diphenylpropene was similarly fractionated.) To avoid confusion concerning the origin of the various reaction products this method of product isolation was therefore abandoned. 
Molecular Distillation. - -Two grams of crude oxidate was placed in one end of a $90^{\circ} \mathrm{U}$-tube assembly which was heated at $150^{\circ}$ and then at $170^{\circ}$ in an oil bath at $0.02-0.05 \mathrm{~mm}$. pressure. After several hours (and two distillations) pure 1, 3-diphenylpropene (starting materlal) and pure 3-acetoxy-1,3-diphenylpropene (major product) could be obtained at the other end of the U-tube assembly which was cooled in an acetone-Dry Ice freezing mixture. Some selenium precipitated in this process. No chalcone or 1,3-diphenyl1 -propanone formation was indicated. About $90-95 \%$ of the crude oxidate, could be distilled over in this manner. The 1,3-diphenylpropene and the unsaturated acetate were further confirmed by superimposable infrared spectra with standards.

\section{Fractional Crystallization of Dibromide Derivatives. --When} these derivatives were prepared from a flash distilled oxidate sample. (no pure dibromides could be obtained from undistilled crude oxidate) according to the procedure of Burton and Ingold (1928) careful fractional recrystallization from hot ethanol gave the following pure crystals:

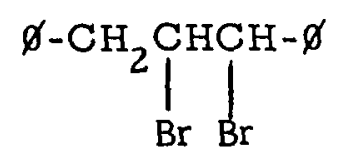

m.p. $109^{\circ}$; lit. $110^{\circ}$ (Burton and Ingold 1928) 
<smiles>O=C1OC(=O)C(Br)C1Br</smiles><smiles>O=C(O)OC(=O)C(Br)C(Br)[14Br]</smiles>

m. p. $157^{\circ}$; lit. $157-8^{\circ}$ (Bülow and von Sicherer 1901)

m.p. $118-20^{\circ} ; 11$ t. $122^{\circ}$ (Burton and Ingold 1928) and b.p. $185-6^{\circ}$; lit. $176-7^{\circ}$ (Burton and Ingold 1928)

Debromination of 1,3-Dipheny1-1,2-propane Dibromide. --

Excess zinc powder in carbon tetrachloride (after 2 hrs. of refluxing and stirring) gave the olefin back. Vapor phase chromatography indicated one major and one adjacent minor peak which were presumbably the cis and trans forms.

Debromination of 3-Acetoxy-1,3-diphenylpropane-1,2dibromide. --Five grams of the title compound was dissolved in 25 ml. of carbon tetrachloride. To this solution, $5 \mathrm{~g}$. of zinc dust was added and the reaction mixture was stirred for 24 hours at room temperature. The inorganic substances were removed by filtration and the solvent was evaporated under reduced pressure. Infrared and T. L. C. analysis however indicated no acetate functional group present in the product. The compound was not further identified. 
Selenium Dioxide Oxidation of Derivatives of 1,3-Diphenylpropene and $\underline{\text { m-Dinitrobenzene }}$

Attempted Oxidation of $\mathrm{m}$-Dinitrobenzene. - - In $50 \mathrm{ml}$. of acetic acid, $1.7 \mathrm{~g}$. of $\mathrm{m}$-dinitrobenzene and $1.1 \mathrm{~g} \cdot(0.010 \mathrm{~mole})$ of selenium dioxide (dissolved in 7 drops of water) were refluxed for 20 minutes. A yellow-colored homogeneous solution resulted, but no trace of selenium precipitated. When the reaction mixture was poured into water all the $\underline{\mathrm{m}}$-dinitrobenzene was recovered, m.p. $88-90^{\circ}$; lit. $89-90^{\circ}$ (Weyler 1932).

Oxidation of 1,3-Diphenylpropene in the Presence of m-Dinitrobenzene. --In seven drops of water, $1.15 \mathrm{~g}$. of selenium dioxide was dissolved with warming and to this solution, $4.0 \mathrm{~g}$. of 1,3-diphenylpropene was added in $100 \mathrm{ml}$. of acetic acid and finally $1.7 \mathrm{~g}$. of $\underline{\mathrm{m}}$-dinitrobenzene was introduced into the reaction mixture and refluxed for 20 minutes. The precipitated selenium (0.594 g.) indicated a $72 \%$ extent of oxidation. No further work was done on this oxidate.

Oxidation of 3-Acetoxy-1,3-diphenylpropene (Standard). --To $2.0 \mathrm{~g} \cdot(0.00795 \mathrm{~mole})$ of the title compound in $100 \mathrm{ml}$. of acetic acid, $0.441 \mathrm{~g} \cdot(0.00366 \mathrm{~mole})$ of selenium dioxide was added in 10 drops of water (dissolved by warming). The solution was refluxed for 20 
minutes. Essentially no selenium precipitated. The reaction mixture was worked up as usual. Thin layer chromatography, however, Indicated considerable chemical activity.

\section{Oxidation of 1,3-Dipheny1-1-propanone. --To $0.441 \mathrm{~g}$.}

(0.00366 mole) of selenium dioxide 10 drops of water was added and solution was effected by warming. This solution was mixed with $2.0 \mathrm{~g}$. of the title compound in $100 \mathrm{ml}$. of acetic acid. After 20 minutes refluxing no selentum precipitated and eventually the saturated ketone was almost all re-isolated indicating no reaction under these conditions.

\section{Catalysis Experiments}

(a) In $0.5 \mathrm{ml}$. of water, $0.573 \mathrm{~g}$. of selenium dioxide was dissolved with warming. To this solution $38 \mathrm{ml}$. methanol and $2 \mathrm{ml}$. of $85 \%$ phosphoric acid was added and the reaction mixture was refluxed for $3 \mathrm{hrs}$. No selenium precipitated under these conditions.

(b) The same experiment was repeated as in a but $1.0 \mathrm{~g}$. of anhydrous sodium acetate was employed as catalyst. Even after 48 hours of refluxing there was still no evidence of selenium precipitation.

Isolation of the Intermediate

General Procedure. --In $1.0 \mathrm{ml}$. of water, $4.29 \mathrm{~g}$. of selenium dioxide was dissolved. To this $15 \mathrm{~g}$. of 1,3-diphenylpropene was added in $250 \mathrm{ml}$. of pure acetic acld. The homogeneous solution was stirred 
at room temperature. In 24 hours a large quantity of white crystals precipitated. The crystals were removed by filtration, and stirring at room temperature was continued for several days until no more crystals precipitated. The mother liquor was further concentrated under reduced pressure (and heat lamp) to about 30-40 $\mathrm{ml}$. The concentrate was mixed with $200 \mathrm{ml}$. of hot, absolute ethanol and set aside to cool. When crystals began to form the solution was placed In a freezer. After several days a copious quantity of white crystals precipitated. Total weight was $6.2 \mathrm{~g} .(30 \%$ yield $)$. The mother liquor was saved for further experimentation.

Purification. --The crude crystalline precipitate was dissolved In a minimum volume of a 1:1 mixture of hot chloroform and absolute ethanol. The volume was then concentrated to one-half of the original and set aside to cool at room temperature. Crystallization was induced by scratching with a glass rod; once crystallization started the sample was placed into a refrigerator where the recrystallization was completed. The product was collected by filtration on sintered disc funnels. After four recrystallizations a melting point of 199-201 was observed.

Anal. C, 68.63; H, 5.91; Se, 10.46 .

A thin layer chromatographic test for organo selenium compounds was developed, patterned after the investigations of 


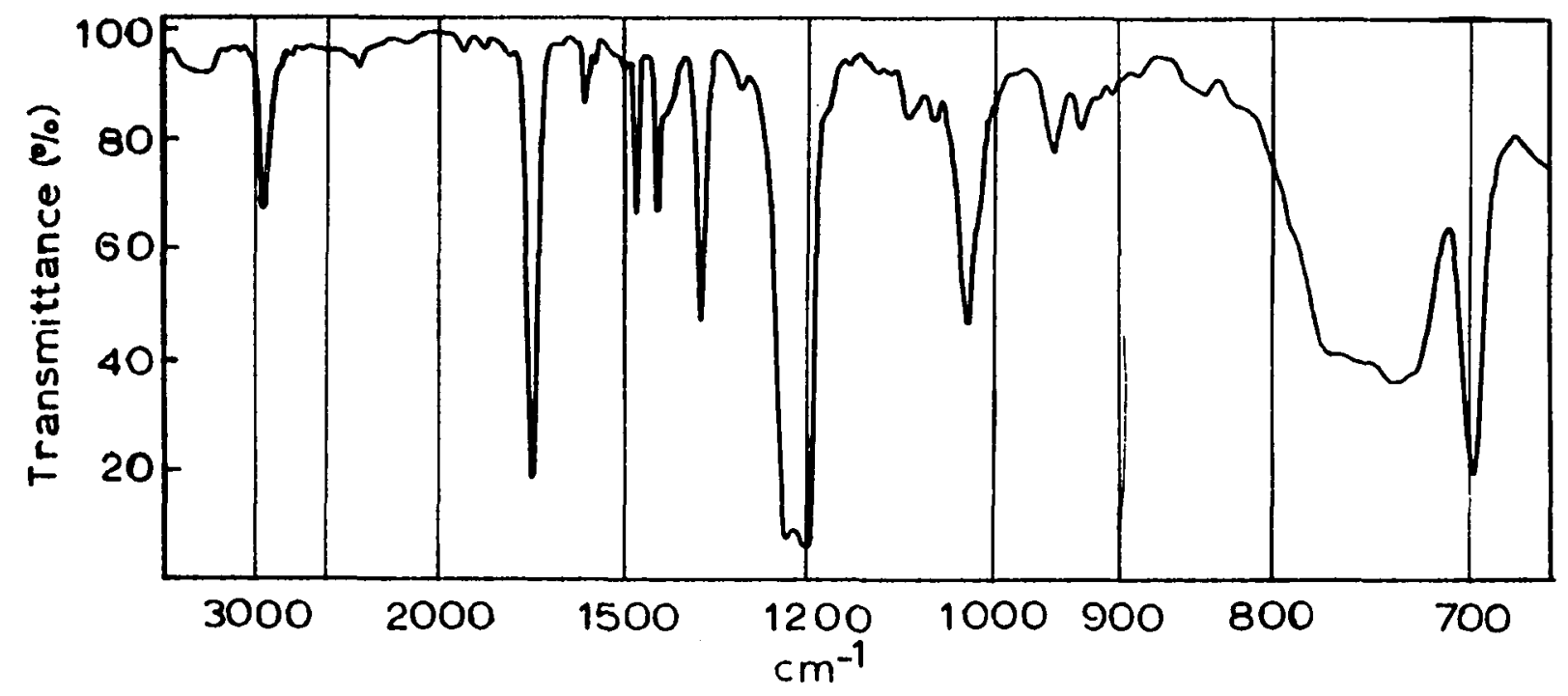

Figure 10. - -Infrared Spectrum of the Crystals.

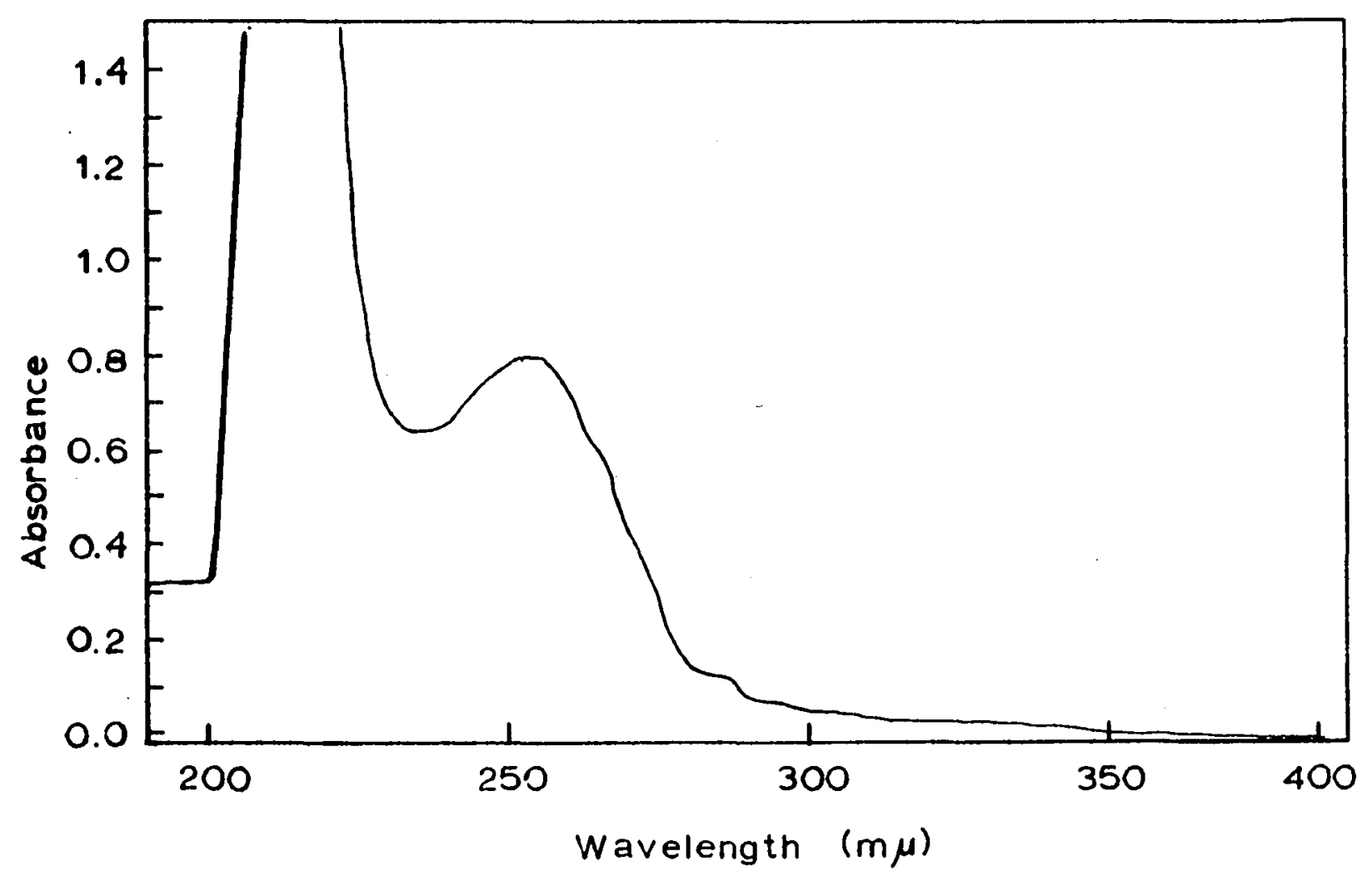

Fiqure 11.--Ultraviolet Spectrum of the Crystals. 
(Bighi 1955), conaerning inorganlc seleniuri species identification' via paper chromatography. Our most effective- developIng spray was a solution of $10 \mathrm{ml}$. concentrated hydrochloric acid + $20 \mathrm{~g}$. of stannous chloride $+70 \mathrm{ml}$. of water.

The sillca gel $G$ plate was well sprayed with an atomizer and it was placed into an oven at $110^{\circ}$ for 5-10 minutes. A characteristic, very sensitive deep-orange or dark red spot (red selenium) appeared for the selenium-containing species. Other compounds either did not show up or were of light gray color.

To separate the spots our regular 9:1:1 of Skelly B, ether and acetic acid solvent system was employed.

Chemistry of the Intermediate

The pure crystals were only sparingly soluble in hot hydrocarbons, absolute alcohols, acetone, DMSO, acetonitrile, chlorinated solvents and acetic acid; soluble in DMF, dioxane.

In 7 drops of water $1.43 \mathrm{~g} .(0.0129 \mathrm{~mole})$ of selenium dioxide was dissolved with warming: To this solution $5 \mathrm{~g} \cdot(0.0258$ mole) of 1,3-diphenylpropene was added in $100 \mathrm{ml}$. of acetic acld and the solution was permitted to stand at room temperature for 4 days. The reaction mixture turned deep yellow, but no selenium (or crystals) precipitated. When this solution was refluxed for 20 mins., $0.518 \mathrm{~g}$. of selenium ( $52 \%$ yield) was removed by filtration. 
After the usual workup, T. L. C. analysis of the crude oxidate indicated normal product distribution.

In $50 \mathrm{ml}$. of acetic acid $1.0 \mathrm{~g}$. of pure crystals (m.p. $198-200^{\circ}$ ) was dissolved with warming and then the solution was refluxed for 20 mins. It gave $0.010 \mathrm{~g} .(3.9 \%$ yield) of selentum, but the rate of oxidation seemed to be slower! After the usual workup, T. L.C. analysis of the crude oxidate indicated the regular product distribution pattern for the oxidation of 1,3-diphenylpropene.

One gram of crystals was heated "neat" in a test tube to $300^{\circ} \mathrm{C}$. in 3-5 minutes. Much selentum precipitated. Thin layer chromatography analysis of the crude reaction mixture indicated the presence of undecomposed crystals, 3-acetoxy-1,3-diphenylpropene. and 1,3-diphenylpropene and nothing else.

Five grams of the "mother liquor" (from which all crystals were precipitated according to T. L. C. analysis) was refluxed for 20 mins. in $100 \mathrm{ml}$. of acetic acid. Considerable amount of selenium precipitated (not welghed though) and T.L.C. revealed the presence of normal oxidation product distribution. Apparently the oxidation product can arise also from as yet unisolated, soluble selenium intermediate(s) present in the mother liquor.

The pure crystals are not affected by (1) cold water, (2) cold dilute hydrochloric acid, and (3) other non-oxidizing acids even on 
extended contact. Concentrated nitric acids and hydrochloric acids however destroyed the compound.

\section{Degradation Experiments}

Selenium Dioxide Oxidation of 3-Deuterio-1,3-diphenyl-

1 -propene. - - To $1.150 \mathrm{~g} .(0.0104$ mole) of purified selenium dioxide was added 7 drops of water and the paste warmed to bring about solution. To this was added $4.0 \mathrm{~g} \cdot(0.0206$ mole) of 3 -deuterio1,3-diphenyl-1-propene and the solution was refluxed for $20 \mathrm{~min}$ utes with an open flame. The solution was cooled rapidly in an ice bath and filtered free of selenium which weighed $0.52 \mathrm{~g} .(63 \%$ yield $)$ The filtrate was poured into $250 \mathrm{ml}$. of water and extracted three times with 100-ml. portions of ether. The combined extracts were washed twice with 100-ml. portions of water and dried with magnesium sulfate.

After removal of the ether a rapid, simple vacuum distillation in a small apparatus was carried out using a free flame so that the distillate temperature remained below $180^{\circ}$ at $0.5 \mathrm{~mm}$; if this step was omitted it was not possible to obtain consistent vapor phase chromatographic analyses or crystalline derivatives.

Reduction of the Crude Oxidate. - - Lithium aluminum hydride (3.0 g.) was dissolved in $100 \mathrm{ml}$. of anhydrous ether and $2.70 \mathrm{~g}$. of 
the crude distillate from the oxidation reaction was added dropwise in $50 \mathrm{ml}$. of anhydrous ether and refluxed for 3 hours. Addition of water followed by acidification, extraction with ether and drying gave $2.5 \mathrm{~g}$. of crude saturated alcohol which was not purified further. The $\mathrm{p}$-nitrobenzoate, m.p. $88.5^{\circ}$; lit. $88-89^{\circ}$ (Kametani and Nomura 1954) contained 0.67 deuterium atoms per mole.

Oxidation of the Saturated Alcohol. --To $2.0 \mathrm{~g}$. of the above alcohol was added $15 \mathrm{ml}$. of $\mathrm{A} . \mathrm{R}$. grade acetone and the solution cooled to $0-5^{\circ}$. To the cold solution was added dropwise, with stirring, over a period of 30 minutes a solution of $1.0 \mathrm{~g}$. of chromic acid, $3.0 \mathrm{ml}$. of water and $1.0 \mathrm{~g}$. of concentrated sulfuric acid. The temperature was permitted to rise to $20-25^{\circ}$, and the solution was stirred for another 2 hours at that temperature; the reaction mixture was then poured into $500 \mathrm{ml}$. of water. The solution, containing some precipitate, was extracted three times with $100 \mathrm{ml}$. of ether, and the ether extracts washed with base, water and dried with magnesium sulfate. The crude ketone was recrystallized from ethanol and $0.91 \mathrm{~g}$. was obtained, m.p. $71-72^{\circ} ; 11$ t. $71-72^{\circ}$ (Adams, Kern and Schreiner 1944) which contained 0.32 deuterium atoms per mole. 
Isomerization Experiments.

Attempted Isomerization of 3-Deuterio-1,3-diphenyl-1-

propene. - - To $50 \mathrm{ml}$. of acetic acid was added $0.60 \mathrm{~g}$. of $85 \%$ phosphoric acid and $2.0 \mathrm{~g}$. of 3-deuterio-1,3-diphenylpropene-1 and the solution was refluxed for 20 minutes. The olefin was recovered and the NMR spectrum was superimposable to that of the starting materlal, indicating the absence of isomerization.

Isomerization of 3-Deuterio-1-acetoxy-1,3-diphenyl-2-

propene. - -To $2.0 \mathrm{~g}$. of the title compound was added $50 \mathrm{ml}$. of acetic acid and $0.60 \mathrm{~g}$. of $85 \%$ phosphoric acid and the reaction mixture was refluxed for twenty minutes. Recovery of the unsaturated acetate was accomplished in the usual manner and an NMR spectrum indicated that extensive scrambling of deuterium occurred. Reduction of the acetate with lithium aluminum hydride and chromic acid oxidzation gave 1, 3diphenylpropan-1-one which contained 0.38 deuterium atoms per mole. Complete equilibration would have led to only 0.29 deuterium atoms per mole in the product ketone.

\section{Competition Experiments}

To 0.0050 mole of selenium dioxide, dissolved in five drops of water, was added a mixture of 0.010 mole of 1,3-diphenylpropene and 0.010 mole of competing olefin dissolved in $50 \mathrm{ml}$. of acetic acid. 
The solution was refluxed for 20 minutes and worked up as described above. The results are summarized in Table 21 .

The analysis for unreacted olefin was done on a two-foot silicone rubber column at $165^{\circ}$ with an .F and M Model 609 Flame Ionization Gas Chromatograph. Peak areas, measured by gravimetric methods, were used to estimate percentage compositions and the values reported in Table 21 are probably good to $\pm 10 \%$. 


\section{RESULTS}

The initial experiments on the mechanism of olefin oxidation were of a non-kinetic nature but designed to extract information related to the rate-determining step, and factors which influence the formation, and ultimate fate of the intermediates involved. These objectives were realized to a significant extent through the extensive use of deuterium labeling techniques.

In wet acetic acid at reflux the only detectable organic oxidation product from 1,3-diphenylpropene was 1,3-diphenyl propen1-ol acetate and high yields of elemental selenium were isolated.

$$
\begin{gathered}
2 \mathrm{C}_{6} \mathrm{H}_{5} \mathrm{CH}_{2} \mathrm{CH}=\mathrm{CHC}_{6} \mathrm{H}_{5}+\mathrm{SeO}_{2} \stackrel{\mathrm{HOAC}}{\longrightarrow} 2 \mathrm{C}_{6} \mathrm{H}_{5} \mathrm{CHCH}=\mathrm{CHC}_{6} \mathrm{H}_{5} \\
70-80 \% \\
+\mathrm{Se}+\mathrm{H}_{2} \mathrm{O}
\end{gathered}
$$

This oxidation proceeded with a hitherto unprecedented rate; it was virtually over in 10-15 minutes (Table 15). The amount of elemental selenium isolated after as much as $24 \mathrm{hrs}$. reaction time was erratic, but on the average it was only $10-15 \%$ more (Table 16). The presence of a significant amount of water markedly 
decreased the rate of oxidation (Table 17) yet no corresponding increase of either chalcone or 1,3-diphenyl-1-propene-3-ol was noticeable by thin layer chromatography and ultraviolet spectrum analysis. Varlations in olefin to selenium dioxide mole ratio (Table 18) indicated nothing instructional. Anhydrous reaction conditions (Table 16) gave comparable ylelds and product distribution to that of wet acetic acid. Solvent effects on the rate of oxidation are profound (Table 13) and generalizations are possible. The rate is by far the most rapid in acidic solvents and slowest in alcohols. Salt effects are anomalous (Table 19).

Deuteriated benzoin was initially prepared by successive exchange reaction with deuterium oxide, but a more efficient method was subsequently developed (Figure 12) which involved formation of the sodium salt of benzoin with sodium hydride, followed by condensation of the deuteriated benzaldehyde with acetophenone, producing benzalacetophenone, which was reduced to the saturated alcohol by lithium aluminum hydride: on dehydration 3-deuterio-1,3-diphenylpropene $(1-D)$ was formed. The validity of this structural assignment was ascertained by NMR spectrum comparison with non-deuteriated 1, 3-diphenylpropene.

Oxidation of $1-\mathrm{D}(0.87 \mathrm{D} /$ mole) with selentum dioxide in wet acetic acid ( $\sim 99 \%$ acetic acid) at reflux gave $2-D$ which 


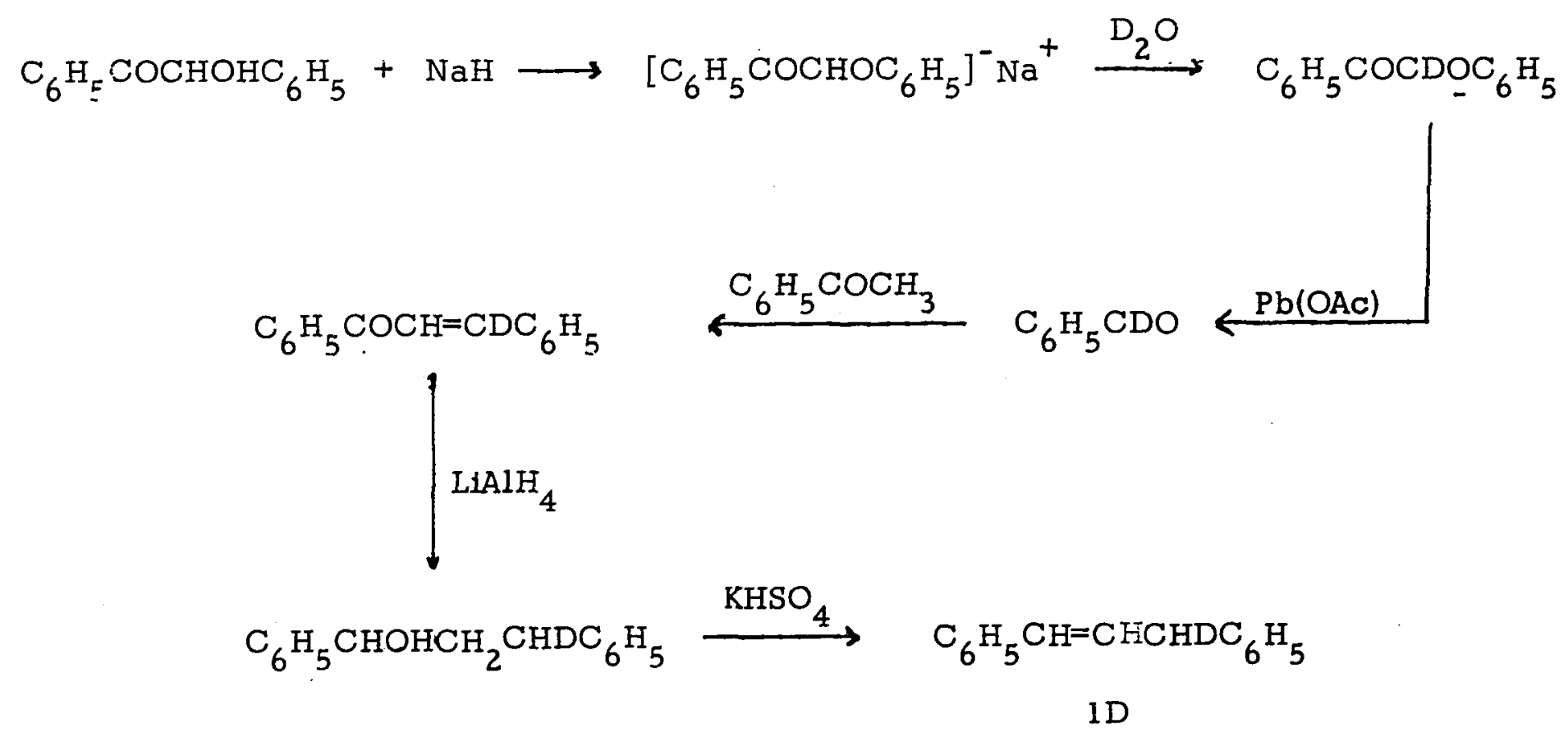

Figure 12. --Preparation of 3-Deuterio-1,3-diphenylpropene. 
contained $0.66 \mathrm{D} / \mathrm{mole}$. Since $13 \%$ of the sample of $1-\mathrm{D}$ was undeuteriated, it follows that 21 atoms of deuterium were lost for every 66 atoms of hydrogen lost. The rate of loss of protium or deuterium can be defined by the rate laws (Wiberg 1955)

$$
\left.\frac{-d H}{d t}=k_{H}\left(\left[\mathrm{SeO}_{2}\right], \text { [olefin }\right]\right)
$$

and

$$
\frac{-d D}{d t}=k_{D}\left(\left[\mathrm{SeO}_{2}\right],[\text { olefin }]\right) .
$$

Dividing a by $b$ results in equation $c$, which can be simplified further to $d$, since an internal competition of the type described will be time independent. Utilizing the above analytical data

$$
\frac{\frac{-d H}{d t}}{\frac{-d D}{d t}}=\frac{k_{H}}{k_{D}}
$$

or

$$
\frac{\Delta \mathrm{H}}{\Delta \mathrm{D}}=\frac{\mathrm{k}_{\mathrm{H}}}{\mathrm{k}_{\mathrm{D}}}
$$

a value of $\mathrm{k}_{\mathrm{H}} / \mathrm{k}_{\mathrm{D}}$ of 3.1 can be caiculated for reaction at $115^{\circ} \mathrm{C}$. the magnitude of this isotope effect suggests that cleavage of a methylenic hydrogen bond occurs during the rate-determining step of the reaction. 
To determine the distribution of deuterium in $2-D$, the unsaturated acetate was reduced with lithium aluminum hydride to 1, 3-diphenylpropan-1 -ol (3-D), which was in turn oxidized with chromic acid to 1,3-diphenylpropan-1-one (4-D). Analysis of 4-D for deuterium indicated that one-half of the deuterium originally present in 3-D was removed during this sequence of reactions. This Indicates that at some stage the two benzylic carbon atoms must become equivalent. These findings are summarized in Figure 13.

To determine if isotopic scrambling occurred before, during, or after oxidation, the following control experiments were done (Figure 14). A solution of 1-D in acetic acid containing a trace of phosphoric acid was heated extenstvely at reflux after which the olefin was reisolated. The NMR spectrum of the olefin was unchanged and showed that no significant isotopic scrambling occurred before oxidation took place.

Partially deuteriated benzalacetophenone was reduced with sodium borohydride under carefully controlled conditions to 3 -deuterio1,3-diphenyl-2-propen-1-ol (5-D) which was acetylated using acetic anhydride in pyridine to give $2-D^{\prime}$. Reduction of $2-D^{\prime}$ with lithium aluminum hydride followed by oxidation of the saturated alcohol $\left(3-D^{\prime}\right)$ to $4-D^{\prime}$ showed that no rearrangement occurred during formation of the acetate and that the reduction of $2-D^{\prime}$ to $3-D^{\prime}$ proceeded 


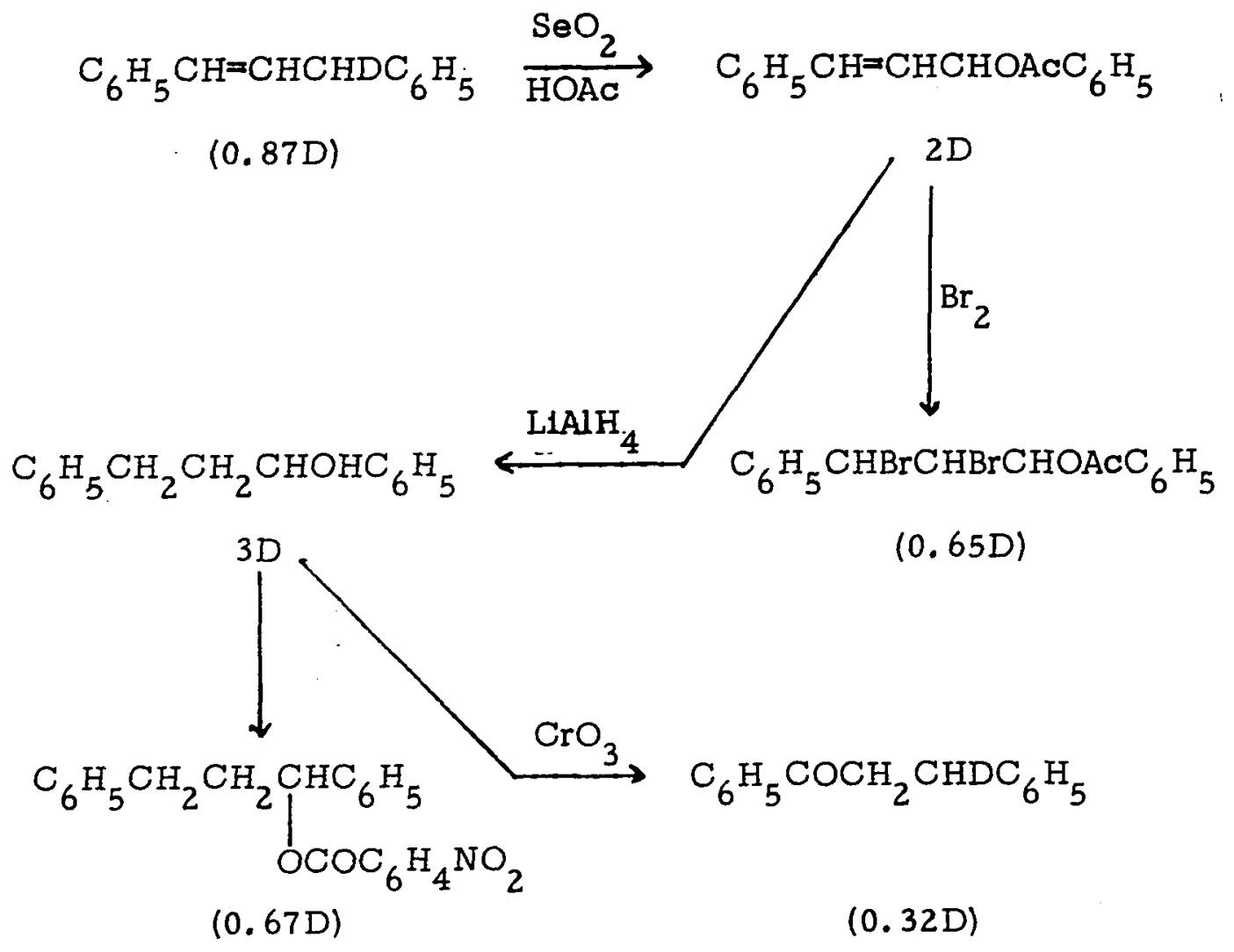

$4 D$

Figure 13.--Oxidation of 3-Deuterio-1,3-diphenylpropene. 


$$
\mathrm{C}_{6} \mathrm{H}_{5} \mathrm{COCH}=\mathrm{CDC}_{6} \mathrm{H}_{5} \stackrel{\mathrm{NaBH}_{4}}{\longrightarrow} \quad \mathrm{C}_{6} \mathrm{H}_{5} \mathrm{CHOHCH}=\mathrm{CDC}_{6} \mathrm{H}_{5}
$$

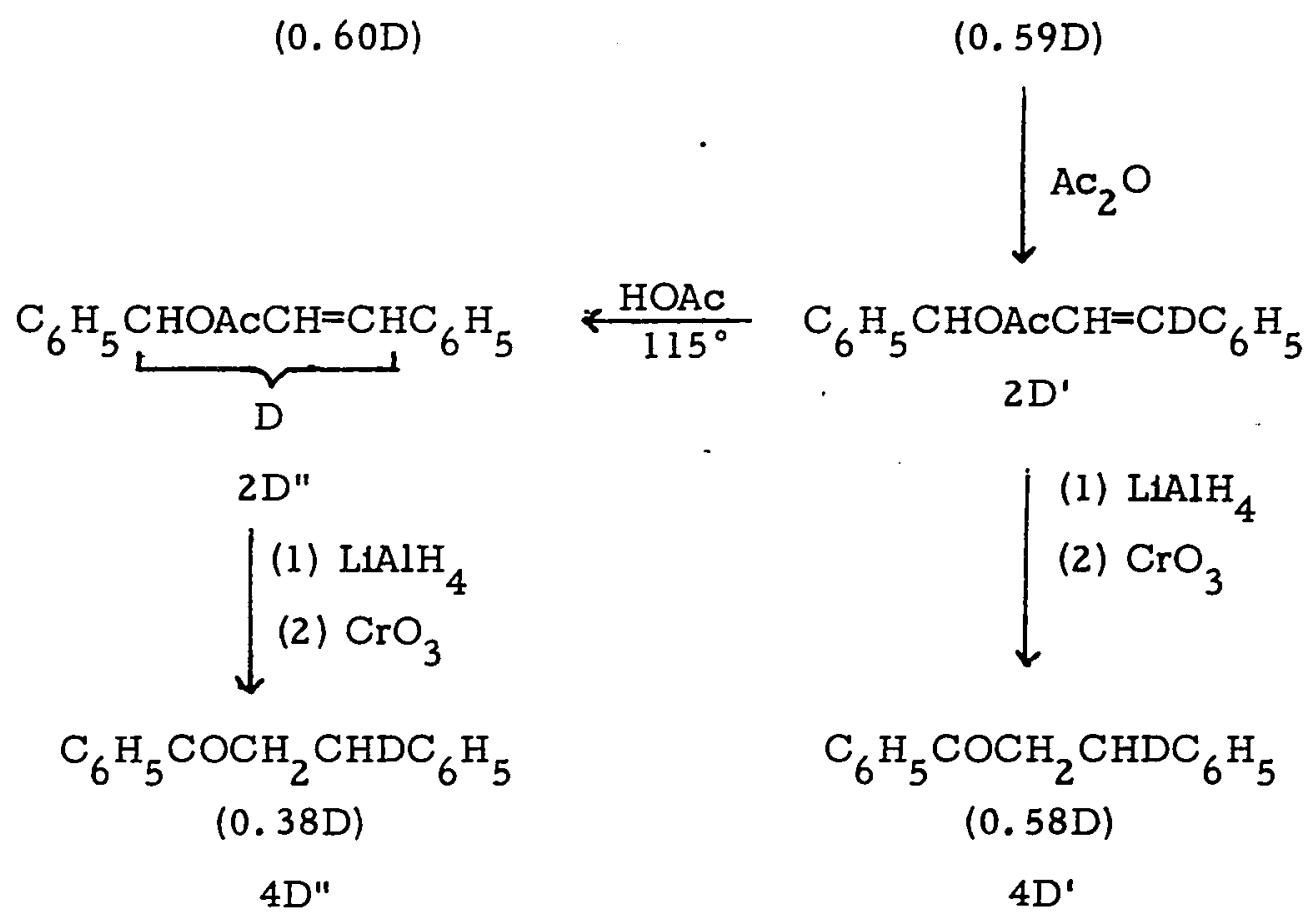

Figure 14. --Isomerization of Dueterlated 1,3-Diphenylpropen-1-ol Acetate. 
without rearrangement. The labeled acetate $\left(2-D^{\prime}\right)$ was refluxed in acetic acid under the same experimental conditions used for the oxidation of $1-D$ with the exception that selentum dioxide was omitted from the solvent. This actually amounted to heating 2-D' for a longer period of time than the oxidation product was subjected to, since a considerable fraction of the reaction time for oxidation of 1-D was required to form the acetate from the olefin.

Deuterium analysis of the ketone $4-\mathrm{D}$ " obtained after reisolation of the isomerized acetate $2-\mathrm{D} "$, : reduction, and oxidation jndicated that scrambling of deuterium, which would occur by solvolysis of $2-D^{\prime}$ followed by internal or external return to one of two equivalent positions, was incomplete. This result requires that a substantial percentage (probably all) of the equilibration of the benzylic positions occurred during oxidation through the formation of a symmetrical intermediate. This intermediate is most likely the allylic carbonium ion (vide infra).

Selenium dioxide oxidation of substituted 1,3-diphenylpropenes (Table 20) indicated about the same rate (visually) and gave yields very similar to that of unsubstituted 1,3-diphenylpropenes.

To assess the influence of electronic and steric factors, a limited series of substituted 1,3-diarylpropenes was competitively 
oxidized (Table 21:). An equimolar mixture of 1,3-diphenylpropene and a 1,3-diarylpropene was reacted with a limited quantity of selenium dioxide and, after reaction, the remaining percentages of olefins were estimated by gas chromatographic analysis. The results of these experiments are tabulated in Table 21.. From an Inspection of these data it is apparent that (1) electron-rich olefins react more rapidly than electron-poor olefins, (2) the electronic environment about the methylene group has little influence on the over-all reaction rate, but the rate is slightly accelerated by electron donors, and (3) steric hindrance of the double bond results in a pronounced retardation of oxidation. 
TABLE 13.--Solvent Medium Experiments.

$\frac{\text { Olefin }}{\mathrm{SeO}_{2}}=2,0.01$ mole olefin

\begin{tabular}{|c|c|c|c|}
\hline $\begin{array}{l}\text { Time } \\
\text { (hrs.) }\end{array}$ & $\begin{array}{l}\text { Temp. } \\
\left({ }^{\circ} \mathrm{C} .\right)\end{array}$ & Reaction Medium & $\begin{array}{l}\text { \% Se ppt. of } \\
\text { theoretical }\end{array}$ \\
\hline 3 & 100 & $40 \mathrm{ml}$. pyridine, $0.5 \mathrm{ml}$. water & 27 \\
\hline 24 & 100 & $100 \mathrm{ml}$. pyridine & 100 \\
\hline 0.33 & 65 & $100 \mathrm{ml}$. methanol & - \\
\hline 48 & 78 & $100 \mathrm{ml}$. ethanol & 16 \\
\hline 48 & 118 & $100 \mathrm{ml} . \underline{\text { n-butanol }}$ & 61.3 \\
\hline 0.33 & $128-32$ & $100 \mathrm{ml}$. 1 -amyl alcohol & - \\
\hline 48 & 101 & $100 \mathrm{ml}$. dioxane & 99 \\
\hline 0.50 & 153 & $50 \mathrm{ml}$. dimethylformamide & 97.5 \\
\hline 16 & 129 & $50 \mathrm{ml}$. morpholine & 100 \\
\hline 36 & 82 & $50 \mathrm{ml}$. acetonitrile & 57 \\
\hline 10 & 65 & $50 \mathrm{ml}$. tetrahydrofuran & 50 \\
\hline 1 & $160-63$ & $100 \mathrm{ml}$. diglyme & 100 \\
\hline 0.16 & 101 & $150 \mathrm{ml}$. formic acid, $98 \%$ & 100 \\
\hline 0.08 & 194 & $40 \mathrm{ml}$. dichloroacetic acid & 100 \\
\hline 0.33 & 141 & $50 \mathrm{ml}$. propionic acid & 100 \\
\hline 0.33 & 164 & $50 \mathrm{ml}$. butanoic acid & 92 \\
\hline
\end{tabular}


TABLE 14. --Optimum Reaction Time Experiments.

$$
\frac{\text { Olefin }}{\mathrm{SeO}_{2}}=2,0.01 \text { mole olefin }
$$

\begin{tabular}{|c|c|c|c|}
\hline $\begin{array}{c}\text { Time } \\
\text { (mins.) }\end{array}$ & $\begin{array}{l}\text { Temp. } \\
\left({ }^{\circ} \mathrm{C} .\right)\end{array}$ & Reaction Medium & $\begin{array}{l}\% \text { Se ppt. of } \\
\text { theoretical }\end{array}$ \\
\hline 15 & 114 & $100 \mathrm{ml} . \mathrm{HOAC}$ & 85 \\
\hline 20 & 114 & $100 \mathrm{ml} . \mathrm{HOAC}$ & 74 \\
\hline 20 & 114 & $\begin{array}{l}100 \mathrm{ml} . \text { HOAc }+1.7 \mathrm{~g} . \\
\text { dinitrobenzene }\end{array}$ & 72 \\
\hline 20 & 114 & $100 \mathrm{ml} . \mathrm{HOAC}$ & 77 \\
\hline 20 & 114 & $100 \mathrm{ml} . \mathrm{HOAC}^{\mathrm{a}}$ & 58 \\
\hline 30 & 114 & $100 \mathrm{ml} \cdot \mathrm{HOAc}^{\mathrm{b}}$ & 59 \\
\hline
\end{tabular}

axidant was added to hot solvent and olefin.

bolefin was added to hot solvent and oxidant. 
TABLE 15. --Optimum Reaction Time Experiments.

\begin{tabular}{|c|c|c|c|}
\hline $\begin{array}{l}\text { Time } \\
\text { (hrs.) }\end{array}$ & $\begin{array}{l}\text { Temp: } \\
\left({ }^{\circ} \mathrm{C} .\right)\end{array}$ & Reaction Medium & $\begin{array}{l}\% \text { Se ppt. of } \\
\text { theoretical }\end{array}$ \\
\hline $3 / 4$ & $95-8$ & $\begin{array}{l}40 \mathrm{ml} . \mathrm{HOAc} \\
0.5 \mathrm{ml}: \mathrm{H}_{2} \mathrm{O}\end{array}$ & 39 \\
\hline $3 / 4$ & $95-8$ & $\begin{array}{l}40 \mathrm{ml} . \mathrm{HOAc} \\
0.5 \mathrm{ml} \cdot \mathrm{H}_{2} \mathrm{O}\end{array}$ & 40 \\
\hline $1-1 / 2$ & $95-8$ & $\begin{array}{l}40 \mathrm{ml} . \mathrm{HOAC} \\
0.5 \mathrm{ml} \cdot \mathrm{H}_{2} \mathrm{O}\end{array}$ & 47 \\
\hline $1-1 / 2$ & $95-8$ & $\begin{array}{l}40 \mathrm{ml} . \mathrm{HOAC} \\
0.5 \mathrm{ml} \cdot \mathrm{H}_{2} \mathrm{O}\end{array}$ & 55 \\
\hline 3 & 90 & $\begin{array}{l}50 \mathrm{~m}_{\mathrm{l}} \text {. HOAc } \\
3 \text { drops } \mathrm{H}_{2} \mathrm{O}\end{array}$ & 50 \\
\hline 3 & $95-8$ & $\begin{array}{l}40 \mathrm{ml} . \mathrm{HOAC} \\
0.5 \mathrm{ml} \cdot \mathrm{H}_{2} \mathrm{O}\end{array}$ & 55 \\
\hline 3 & $95-8$ & $\begin{array}{l}40 \mathrm{ml} . \mathrm{HOAC} \\
0.5 \mathrm{ml} \cdot \mathrm{H}_{2} \mathrm{O}\end{array}$ & 55 \\
\hline 3 & 90 & $\begin{array}{l}20 \mathrm{ml} \text {. HOAc } \\
3 \text { drops } \mathrm{H}_{2} \mathrm{O}\end{array}$ & 52 \\
\hline 4 & $92-3$ & $\begin{array}{l}120 \mathrm{ml} . \mathrm{HOAC} \\
2.5 \mathrm{ml} \cdot \mathrm{H}_{2} \mathrm{O}\end{array}$ & 59 \\
\hline 5 & $95-8$ & $\begin{array}{l}40 \mathrm{ml} . \mathrm{HOAC} \\
0.5 \mathrm{ml} \cdot \mathrm{H}_{2} \mathrm{O}\end{array}$ & 85 \\
\hline 5 & $95-8$ & $\begin{array}{l}40 \mathrm{ml} . \mathrm{HOAC} \\
0.5 \mathrm{ml} \cdot \mathrm{H}_{2} \mathrm{O}\end{array}$ & 79 \\
\hline 12 & 100 & $60 \mathrm{ml} . \mathrm{HOAC}$ & 80 \\
\hline
\end{tabular}


TABLE 15--Continued

\begin{tabular}{|c|c|c|c|}
\hline $\begin{array}{c}\text { Time } \\
\text { (hrs.) }\end{array}$ & $\begin{array}{l}\text { Temp. } \\
\left({ }^{\circ} \mathrm{C} .\right)\end{array}$ & Reaction Medium & $\begin{array}{l}\% \text { Se ppt. of } \\
\text { theoretical }\end{array}$ \\
\hline 12 & 90 & $\begin{array}{l}50 \mathrm{ml} \text {. HOAC } \\
6 \text { drops } \mathrm{H}_{2} \mathrm{O}\end{array}$ & 76 \\
\hline 18 & 90 & $80 \mathrm{ml} . \mathrm{HOAC}$ & 72 \\
\hline 24 & 90 & $\begin{array}{l}50 \mathrm{ml} . \mathrm{HOAc} \\
3 \text { drops } \mathrm{H}_{2} \mathrm{O}\end{array}$ & 70.5 \\
\hline 24 & $95-8$ & $\begin{aligned} 198 \mathrm{ml} . & \text { HOAc } \\
2 \mathrm{ml} . & \mathrm{H}_{2} \mathrm{O}\end{aligned}$ & 86 \\
\hline 24 & $95-8$ & $\begin{array}{c}49.5 \mathrm{ml} . \mathrm{HOAC} \\
0.5 \mathrm{ml} . \mathrm{H}_{2} \mathrm{O}\end{array}$ & 100 \\
\hline 24 & $85-8$ & $\begin{array}{c}49.5 \mathrm{ml} . \mathrm{HOAc} \\
0.5 \mathrm{ml} . \mathrm{H}_{2} \mathrm{O}\end{array}$ & 94 \\
\hline 24 & $95-8$ & $\begin{array}{c}49.5 \mathrm{ml} . \mathrm{HOAC} \\
0.5 \mathrm{ml} . \mathrm{H}_{2} \mathrm{O}\end{array}$ & 100 \\
\hline 24 & $95-8$ & $\begin{array}{r}200 \mathrm{ml} . \mathrm{HOAC} \\
1 \mathrm{ml} \cdot \mathrm{H}_{2} \mathrm{O}\end{array}$ & 64 \\
\hline
\end{tabular}


TABLE 16. --Effect of Anhydrous Conditions.

$$
\frac{\text { Olefin }}{\mathrm{SeO}_{2}}=2,0.01 \text { mole olefin }
$$

\begin{tabular}{|c|c|c|c|}
\hline $\begin{array}{l}\text { Time } \\
\text { (hrs.) }\end{array}$ & $\begin{array}{l}\text { Temp. } \\
\left({ }^{\circ} \mathrm{C} .\right)\end{array}$ & Reaction Medium & $\begin{array}{l}\% \text { Se ppt. of } \\
\text { theoretical }\end{array}$ \\
\hline 24 & $95-8$ & $\begin{array}{l}90 \mathrm{ml} \cdot \mathrm{HOAC} \\
90 \mathrm{ml} \cdot \mathrm{Ac}_{2} \mathrm{O} \\
2 \mathrm{ml} \cdot \mathrm{H}_{2} \mathrm{O}\end{array}$ & 77 \\
\hline 24 & $95-8$ & $\begin{array}{l}4.50 \mathrm{ml} . \mathrm{HOAC} \\
50 \mathrm{ml} \cdot \mathrm{Ac}_{2} \mathrm{O} \\
3 \mathrm{ml} \cdot \mathrm{H}_{2} \mathrm{O}\end{array}$ & 87 \\
\hline 3 & $95-8$ & $\begin{array}{l}40 \mathrm{ml} \cdot \mathrm{Ac}_{2} \mathrm{O} \\
0.5 \mathrm{ml} \cdot \mathrm{H}_{2} \mathrm{O}\end{array}$ & 67 \\
\hline 20 mins. & 140 & $100 \mathrm{ml} \cdot \mathrm{Ac}_{2} \mathrm{O}$ & 60 \\
\hline
\end{tabular}

TABLE 17. --The Effect of Water on Reaction Rate. 0.01 mole olefin

\begin{tabular}{ccccc}
\hline$\frac{\text { Olefin }}{\mathrm{SeO}_{2}}$ & $\begin{array}{c}\text { Time } \\
\text { (mins.) }\end{array}$ & $\begin{array}{c}\text { Temp. } \\
\left({ }^{\circ} \mathrm{C} .\right)\end{array}$ & Reaction Medium & $\begin{array}{c}\text { \% Se ppt. of } \\
\text { theoretical }\end{array}$ \\
\hline 1 & 20 & 114 & $100 \mathrm{ml}$. HOAC & 80 \\
1 & 20 & 114 & $100 \mathrm{ml}$. of $95 \%$ HOAC & 68 \\
1 & 20 & 114 & $100 \mathrm{ml}$. of $80 \%$ HOAC & 35 \\
\hline
\end{tabular}


TABLE 18. --The Effect of Olefin Concentration.

\begin{tabular}{ccccc}
\hline$\frac{\text { Olefin }^{\mathrm{a}}}{\mathrm{SeO}_{2}}$ & $\begin{array}{c}\text { Time } \\
(\mathrm{hrs} .)\end{array}$ & $\begin{array}{c}\text { Temp. } \\
\left({ }^{\circ} \mathrm{C} .\right)\end{array}$ & Reaction Medium & $\begin{array}{c}\text { \% Se ppt. of } \\
\text { theoretical }\end{array}$ \\
\hline 1 & 86 & 90 & $40 \mathrm{ml}$. HOAc & 30 \\
2 & 86 & 90 & $40 \mathrm{ml}$. HOAc & 29 \\
4 & 86 & 90 & $40 \mathrm{ml}$. HOAC & 34 \\
8 & 86 & 90 & $40 \mathrm{ml}$. HOAC & 48 \\
16 & 86 & 90 & $40 \mathrm{ml}$. HOAc & 41 \\
\hline
\end{tabular}

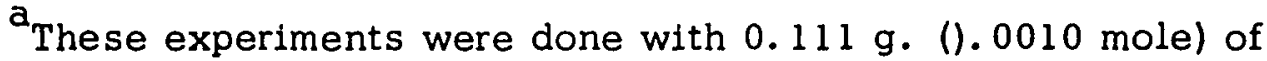
selenium dioxide.

TABLE 19. --Salt Effects

$$
\frac{\text { Olefin }}{\mathrm{SeO}_{2}}=2,0.01 \text { mole olefin }
$$

\begin{tabular}{|c|c|c|c|}
\hline $\begin{array}{l}\text { Time } \\
\text { (hrs.) }\end{array}$ & $\begin{array}{l}\text { Temp. } \\
\left.\text { ( }{ }^{\circ} \mathrm{C} .\right)\end{array}$ & Reaction Medium & $\begin{array}{l}\text { \% Se ppt. of } \\
\text { theoretical }\end{array}$ \\
\hline 1 & $160-63$ & $100 \mathrm{ml}$. diglyme & quantitative \\
\hline 2 & $160-63$ & $\begin{array}{l}50 \mathrm{ml} . \text { diglyme } \\
5 \mathrm{ml} \text {. NaOAc, anhyd. }\end{array}$ & 16.5 \\
\hline 2 & $160-63$ & $\begin{array}{l}50 \mathrm{ml} . \text { diglyme } \\
5 \mathrm{~g} . \mathrm{NaCl}\end{array}$ & quantitative \\
\hline 2 & $160-63$ & $\begin{array}{l}50 \mathrm{ml} . \text { diglyme } \\
5 \mathrm{~g} . \mathrm{NaN}_{3}\end{array}$ & 3 \\
\hline
\end{tabular}


TABLE 20. - -Selenium Dioxide Oxidation of Substituted 1,3-Diphenylpropenes.

$$
\frac{\text { Olefin }}{\mathrm{SeO}_{2}}=2,0.01 \text { mole olefin }
$$

\begin{tabular}{lllll}
\hline Substrate & $\begin{array}{c}\text { Time } \\
\text { (mins.) }\end{array}$ & $\begin{array}{c}\text { Temp. } \\
\left({ }^{\circ} \mathrm{C} .\right)\end{array}$ & $\begin{array}{c}\text { Reaction } \\
\text { Medium }\end{array}$ & $\begin{array}{l}\% \text { Se ppt. } \\
\text { of theor: }\end{array}$ \\
\hline
\end{tabular}

(O) $-\mathrm{CH}_{2} \mathrm{CH}=\mathrm{CH} \bigcirc \mathrm{OMe} \quad 20 \quad 114 \quad 100 \mathrm{ml} . \mathrm{HOAC} \quad 66$<smiles>COc1ccc(CC=Cc2ccccc2)cc1</smiles><smiles>CC(C)(O)O[14C](=O)O</smiles>
○. $\mathrm{CH}_{2} \mathrm{CH}=\mathrm{CH} \bigcirc \mathrm{Cl} \quad 20 \quad 114 \quad 100 \mathrm{ml} . \mathrm{HOAc} \quad 76$ 
TABLE 21. --Competition of 1,3-Diarylpropenes and 1,3-Diphenylpropene for Selentum Dioxide.

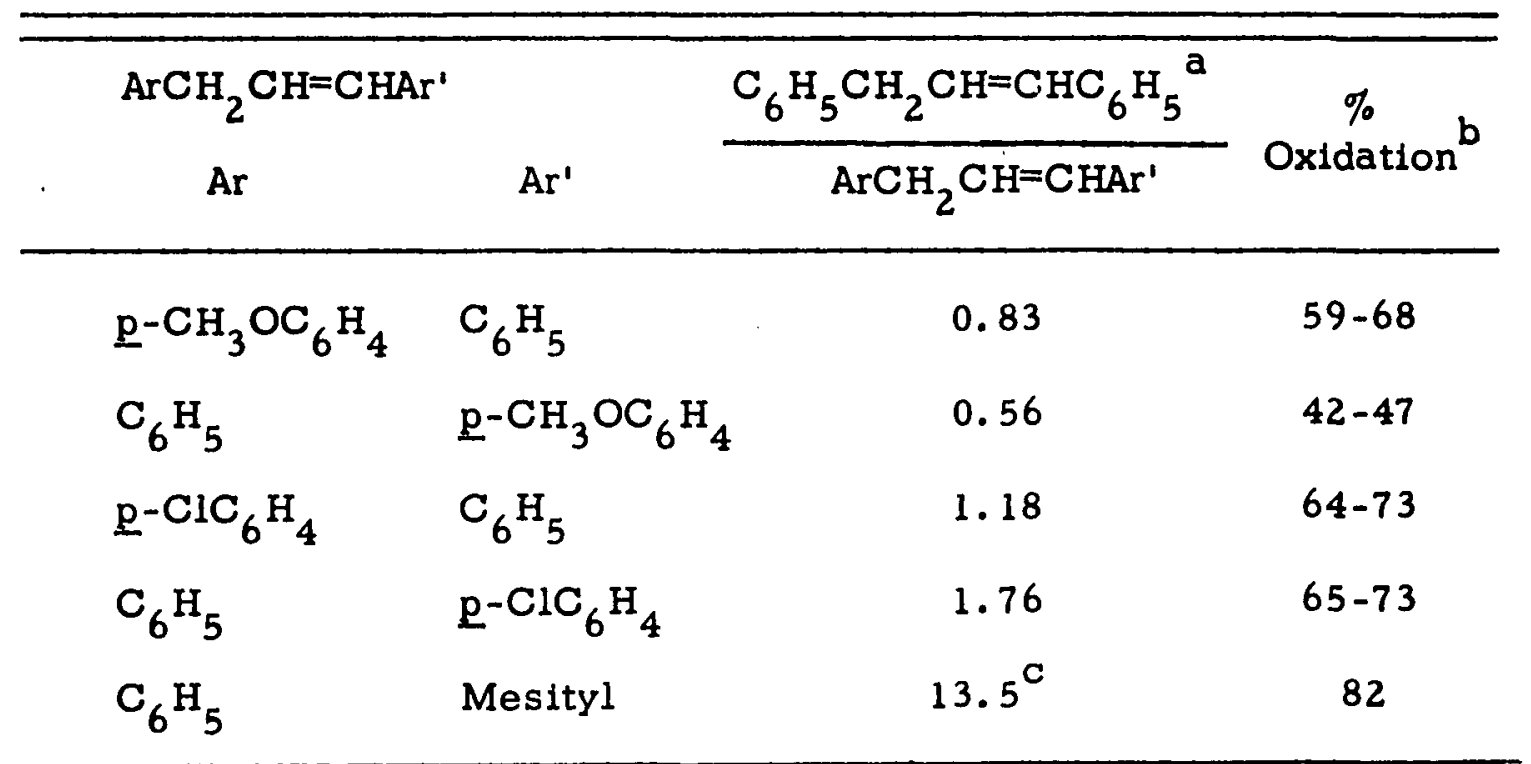

${ }^{a}$ Experiments utilized one molar equivalent of each olefin and one-half of a molar equivalent of selenium dioxide. The ratios reported are the ratios of olefins consumed during oxidation.

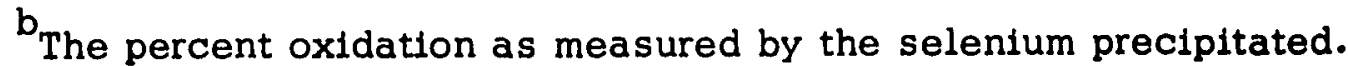
Reactions were all run in duplicate.

$\mathrm{C}_{\text {This }}$ is a minimum value. 


\section{DISCUSSION}

The reactions cited in the historical section illustrate some of the difficulties involved in finding a suitable system for theoretical studies. In fact, no system is known to date (to this author) that would satisfy all of the idealized requirements:

(1) A good yield of a single major product.

(2) A rapid reaction under moderate experimental conditions (suitable for isotope work).

(3) No double bond migration in the reactants before or after the reaction.

(4) Easily isolable products.

(5) A substrate in which the influence of electronic effects can be evaluated.

After considerable experimentation, 1, 3-diphenylpropene was accepted as the compromise substrate since it met most of the requirements. Isolation of the pure reaction product (e.g., the unsaturated allylic acetate) posed the greatest difficulty.

A complicating feature was that cis and trans isomers of the olefin are possible and they may show different reactivity. However, in the current work identical methods of preparing the various olefins 
was employed, and a constant composition of cis-trans isomers is probably present in all studies.

Qualitative observations indicated that the reaction was not inhibited by free-radical inhibitors; in the presence of $1.5 \%$ by weight of $\underline{m}$-dinitrobenzene a $72 \%$ extent of oxidation was observed in 20 minutes reaction time. This is an average value for the oxidation.

The reaction appears to be acid catalyzed. Qualitative observations indicate that oxidation occurs more rapidly in formic and dichloroacetic acid than in acetic acid, which is, in turn, a more effective medium for oxidation than an alcohol.

Nevertheless, no noticeable increase in the rate of oxidation was apparent when $\mathrm{H}_{3} \mathrm{O}^{+}$was introduced into an otherwise poor reaction medium such as methanol or ethanol. Apparently the reaction medium (and temperature) are of much greater importance.

The relative order of reactivity found for 1-aryl-3-phenylpropenes (Table 21.$)$ in which the activating order of substituents was $\underline{p}$-methoxyphenyl $>$ phenyl $>\underline{p}$-chlorophenyl is in accord with electrophilic attack on the double bond by selenium dioxide, or more likely by its conjugate acid, $\mathrm{SeO}_{2} \mathrm{H}^{+}$.

A remarkable deactivating influence is exerted by o-methyl substituents (Table 21, Entry 5) which is in the opposite direction from that expected on the basis of their normal electronic effects; this 
suggests that an Interaction (complex formation?) between selenium dioxide and the double bond is occurring at some stage.

A mechanism to accommodate most of the observations and other facts in the literature is the following:

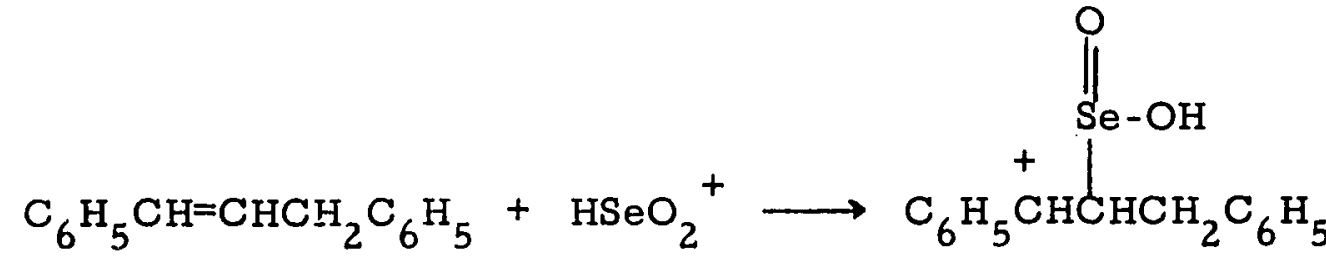<smiles>C=CC</smiles>

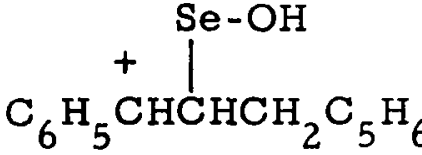

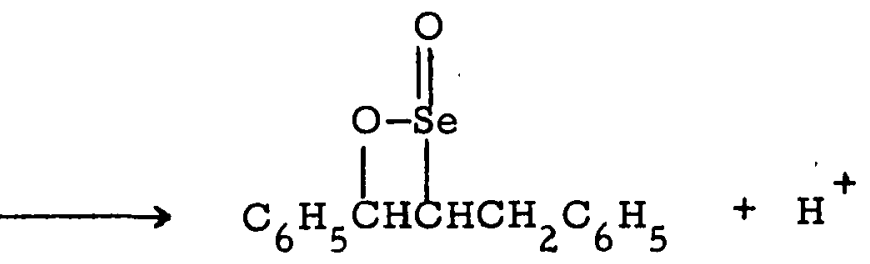
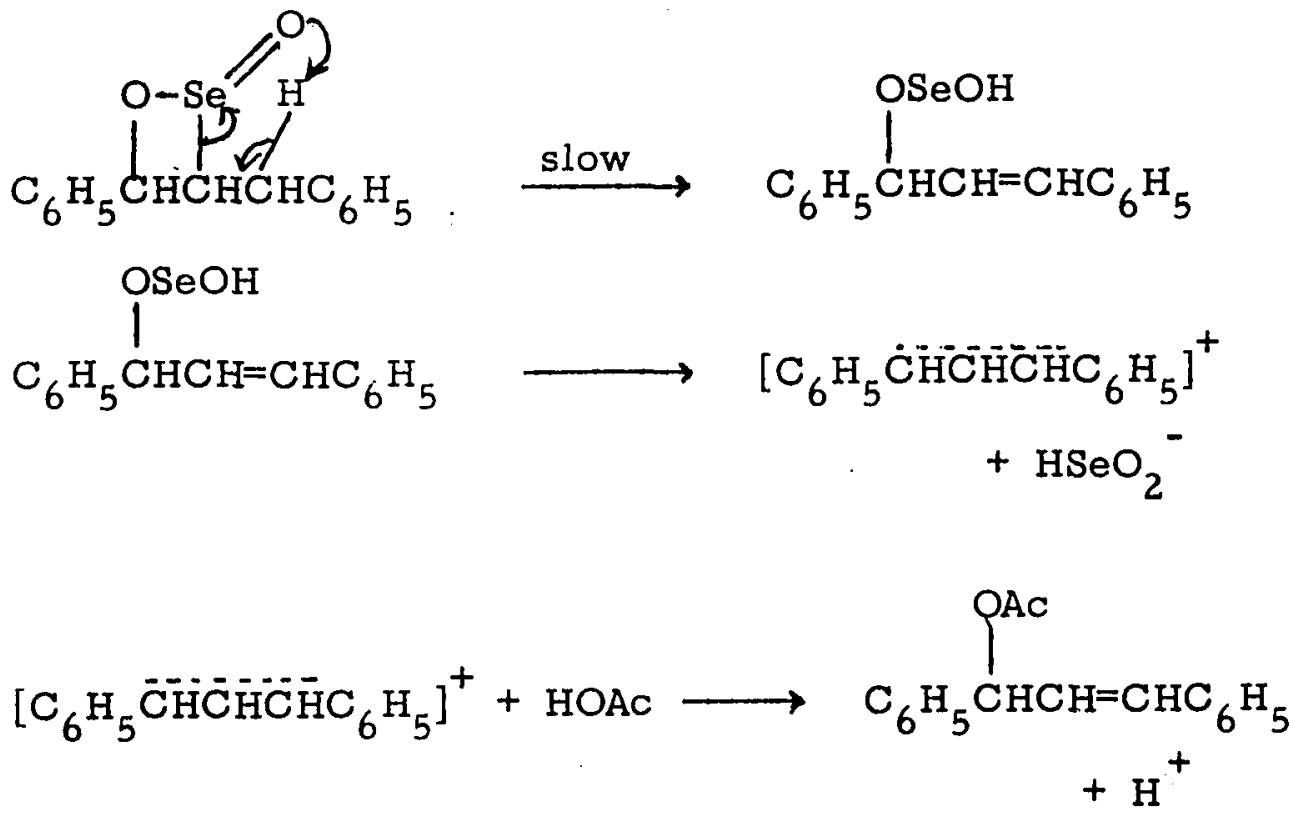
Reaction 1 is similar to the initial reaction which is thought to occur on ozonolysis of an olefin; in view of the periodic relationship and structural similarity between ozone and selenium dioxide this reaction is not unreasonable, even though selenium dioxide is a linear polymer in the solid state. Substituent effects lend further support to this postulate of electrophilic attack.

In reaction 2 proton elimination with subsequent ring closure is postulated since this intermediate may account most conveniently for the formation of other, more complex, products by the addition of another mole of olefin (vide ante, vide infra).

Since the four-membered ring complex is quite strained, molecular reorgantzation occurs (3) in which a new double bond is formed as a selenium (II) ester is generated. The large isotope effect, 3.1 at $115^{\circ} \mathrm{C}$. , suggests that this is the slow step in the reaction. Some precedence for writing a selenium (II) ester intermediate can be found in previous mechanistic studies on the oxidation of ketones, and 1,4-diketones (Schaefer and Corey 1960; Schaefer 1962). Solvolysis of this ester $(4,5)$ would produce the product observed and result in equilibration of the benzylic positions.

The postulate of a selenium (II) ester of the type indicated is attractive since a spectrum of decomposition paths is available to it which can account for many observations in the literature. 
In solvents of low nucleophilicity and high ionizing power, as well as with olefins where a highly stabilized symmetrical allylic carbonium ion can be formed, this $\mathrm{S}_{\mathrm{N}}{ }^{1}$ type dissociation process is favored to occur.

The 1,3-diphenylpropene gives a particularly stable allylic cation (perhaps to the point of being an atypical system) and therefore decomposes by this pathway. This route of decomposition also explains the formation of racemic products from optically active olefins.

In solvents of high nucleophilicity (low lonizing power) reactions 3 and 4 probably merge and may approach an $S_{N}{ }^{2}$ or $S_{N}{ }^{\prime}$ extreme under favorable circumstances. For optically active olefins such a pathway for decomposition would accommodate the formation of optically active products which are occasionally reported.

The stereochemical consequences of an $\mathrm{S}_{\mathrm{N}}{ }^{2}$ decomposition with solvent as the nucleophile would involve an over-all migration of the double bond to an adjacent position. A selenium-oxygen fission (in 4), which may be readily detectable by $\mathrm{O}^{18}$ studies, would result in the same stereochemistry.

The formation of ketones which is frequently observed on oxidation of olefins is conveniently accounted for by decomposition of the selenium (II) ester in a manner analogous to that previously 
outlined for the oxidation of ketones to diketones. The ketone could

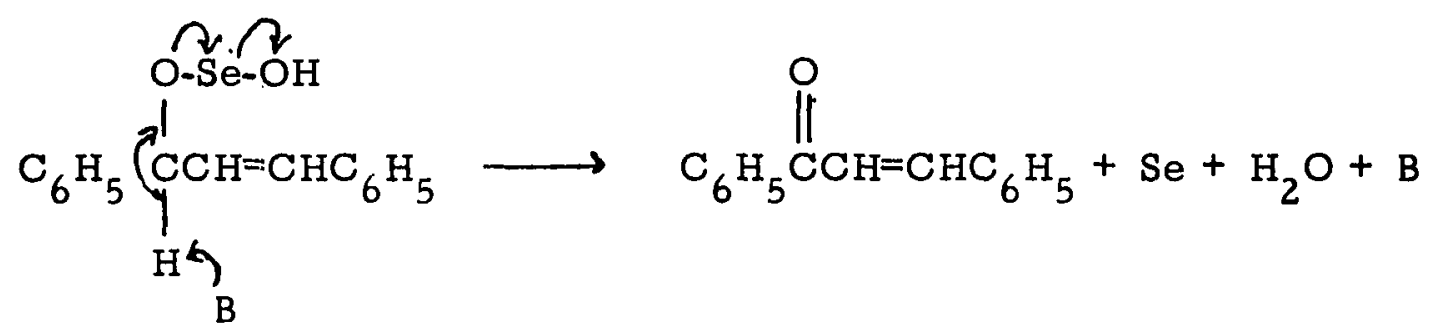

also arise by a secondary oxidation of the alcohol.

Although the mechanistic pathway outlined above seems adequate for the olefin in question, a survey of the literature indicates that the process cannot be completely general, since in many cases it will lead to the prediction of the incorrect product, for example:
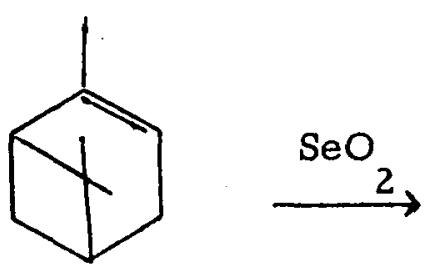<smiles>CC1(C)C2CC=C(CO)C1C2</smiles><smiles>CC1(C)C2=CCC1CC2</smiles>

a-pinene<smiles>CC1CC=C(C(C)C)CC1</smiles>

optically active<smiles>CCCOC1CC(C)CC=C1C(C)C</smiles>

racemic 
A number of investigators (Zacharewicz 1948, 1949; Sakuda 1961) isolated selenium-containing intermediates from olefins in the course of the oxidation reaction. They were identified "as selenides, diselenides and R-selenious acid"; they all gave normal oxidation products on pyrolysis or in solvolysis reaction.

Wiberg and Nielsen (1964) examined the nature of the selenium-containing intermediate using $\mathrm{C}^{13}$ at the double bond in cyclohexene. They state that "the carbon holding the acetoxy group was found to have $1.405 \% \mathrm{C}^{13}$ as compared with $1.442 \%$ at each end of the double bond in the cyclohexene molecule, indicating that the acetoxy group was introduced at one of the two originial olefinic carbons $90 \%$ of the time." They did not have a pure compound (no m. p. or analysis is given) but by physical methods of investigation (infrared and NMR) they assigned the following structure to it:

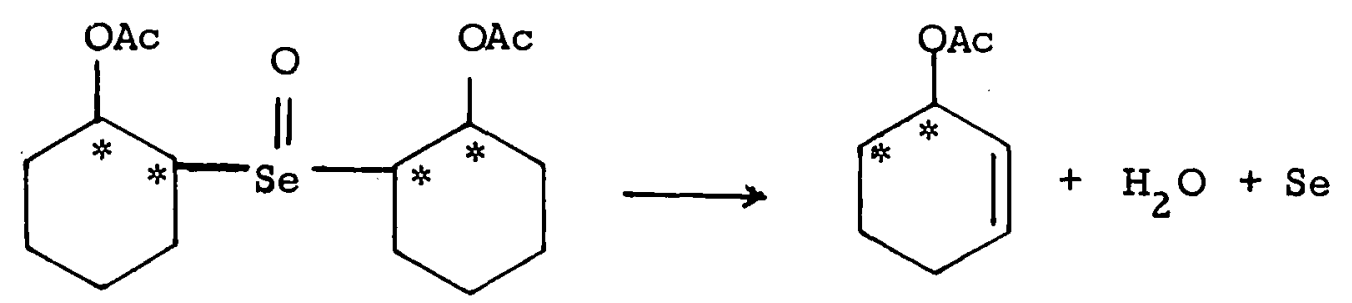
a selenoxide

or 


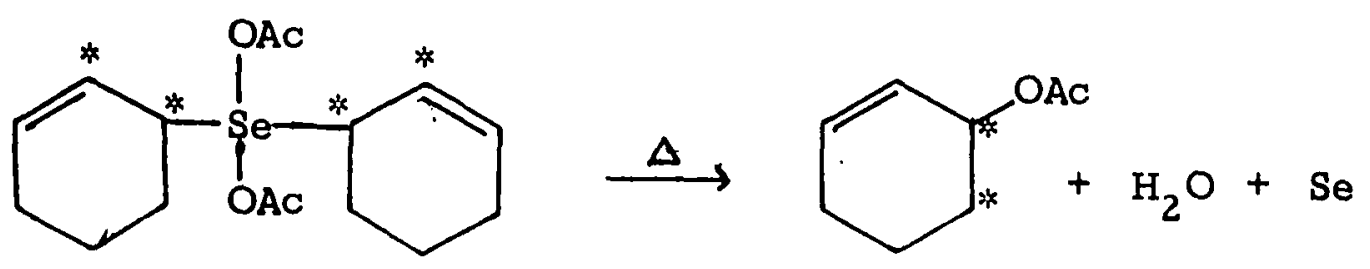

\section{a hydrated selenoxide derivative}

An intermedlate was isolated from 1,3-diphenylpropene, but an unambiguous structure could not be assigned to it. That it was a true intermediate was shown by subsequent solvolysis and pyrolysis to normal oxidation products as well as olefinic starting material. Since the literature gives no definite clue to the exact nature of these intermediates, and because our product needs further identification, we can only speculate about its chemical structure. The sum total of the chemical and physical evidence points toward some selenoxide derivative, with at least two moles of olefin per mole of selenium dioxide being in the complex. Although selenious acid (and presumably its derivatives) reputedly do not add to double bonds (Gilman and Cason $1951)$ the formation of a selenoxide (or its derivative) may be convenlently postulated as arising from the following process: 

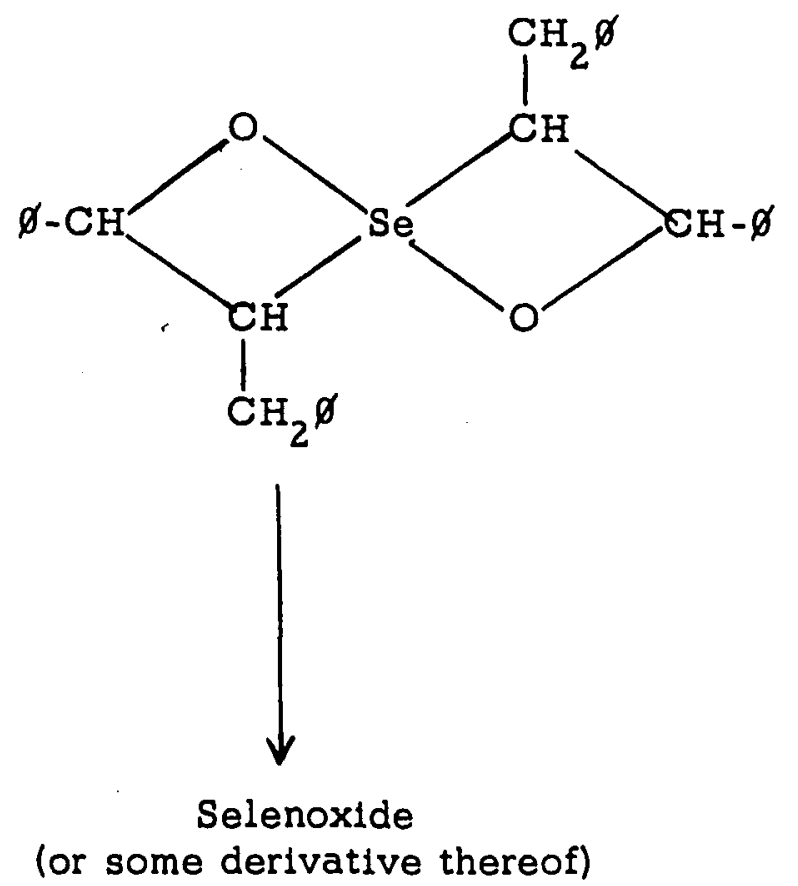

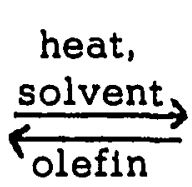

$+\varnothing-\mathrm{CH}_{2} \mathrm{CH}=\mathrm{CH}-\varnothing$

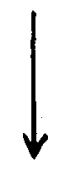

normal oxidation product

If these postulates are proved correct, it may be the first

general method of introducing the selenoxide (, $\mathrm{Se}=0)$ functional group directly into a molecule. 
BIBLIOGRAPHY OF OLEFIN OXIDATIONS BY $\mathrm{SeO}_{2}$ (1948 TO. MARCH.1964)

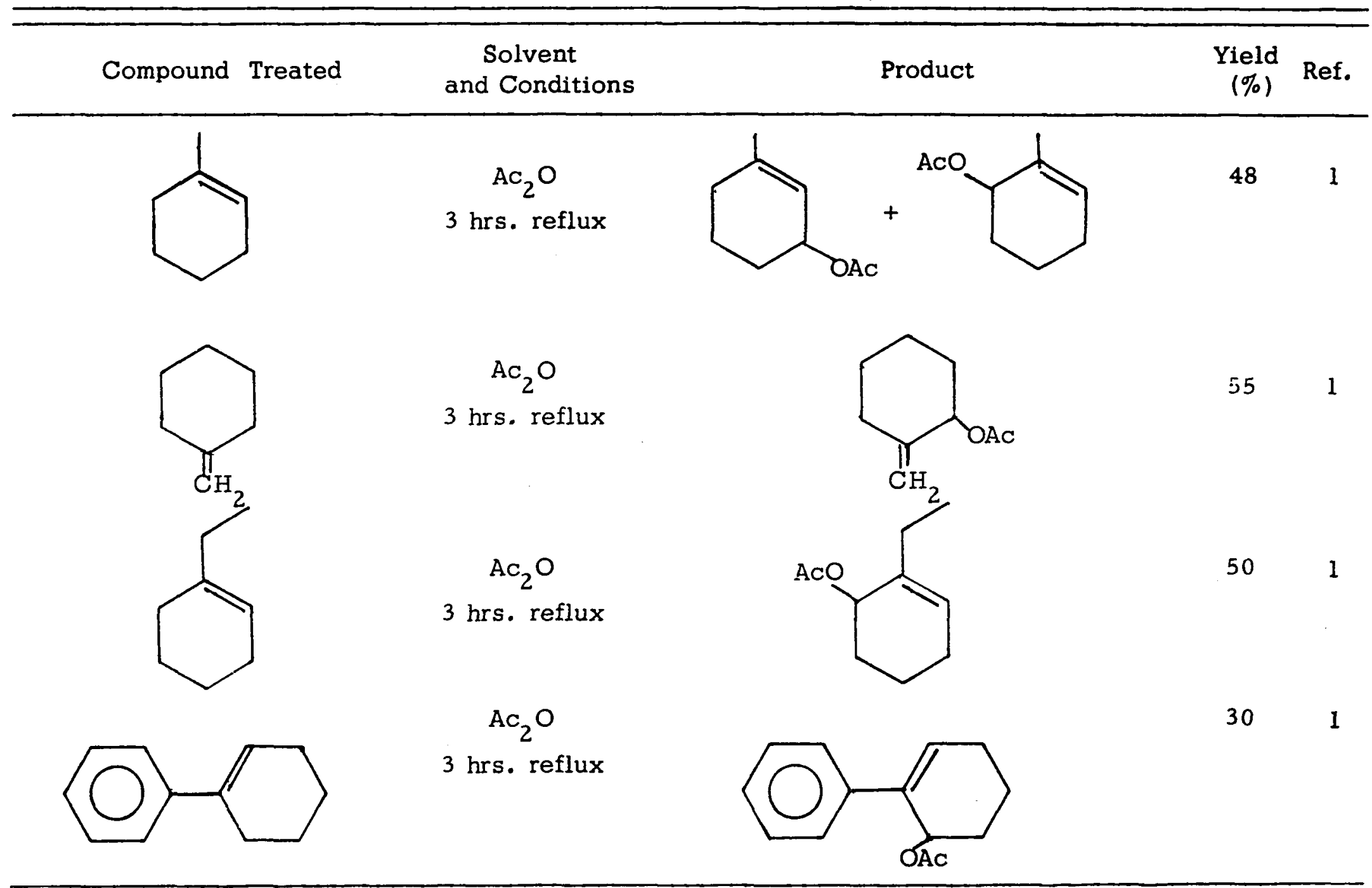




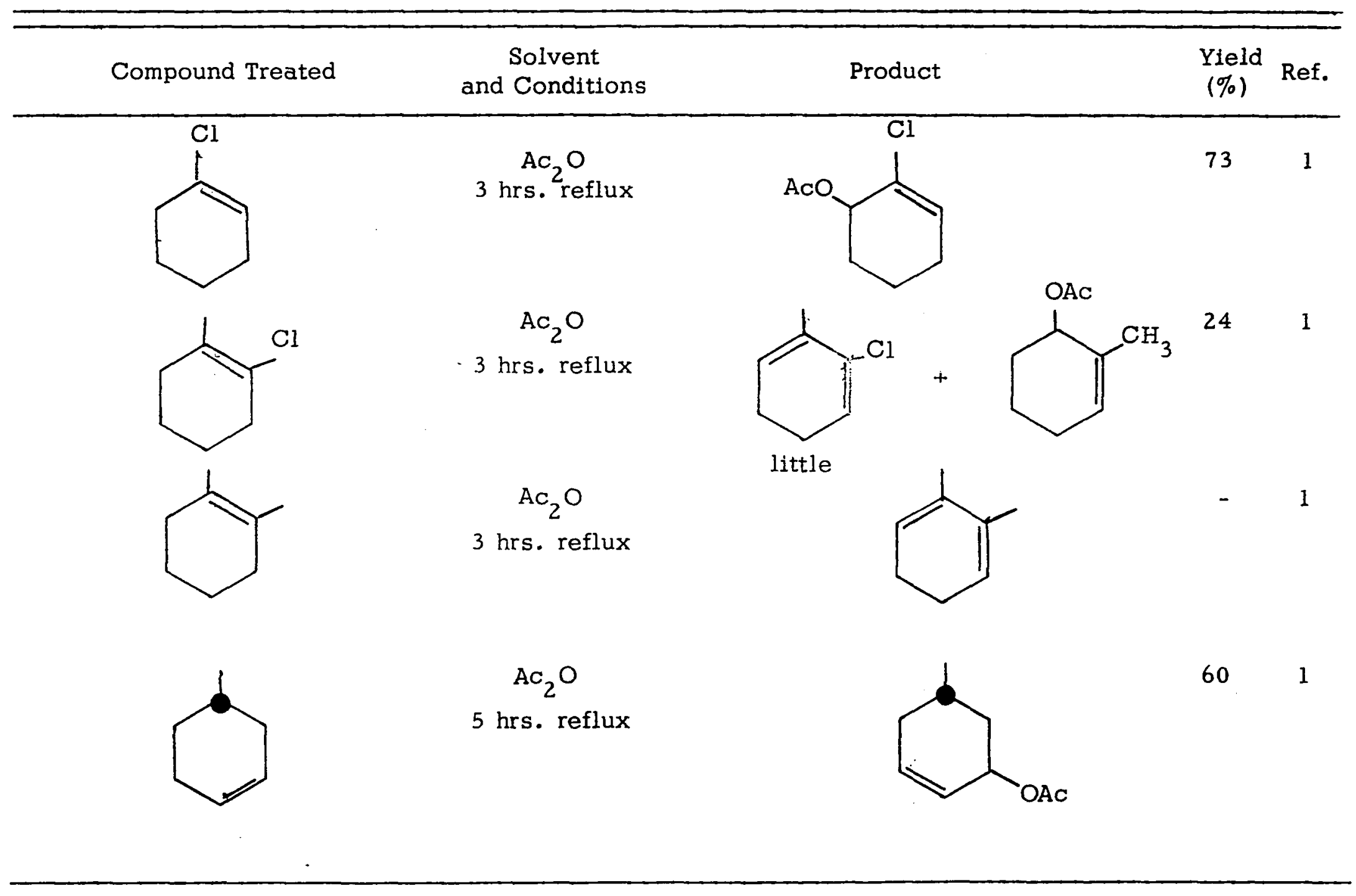




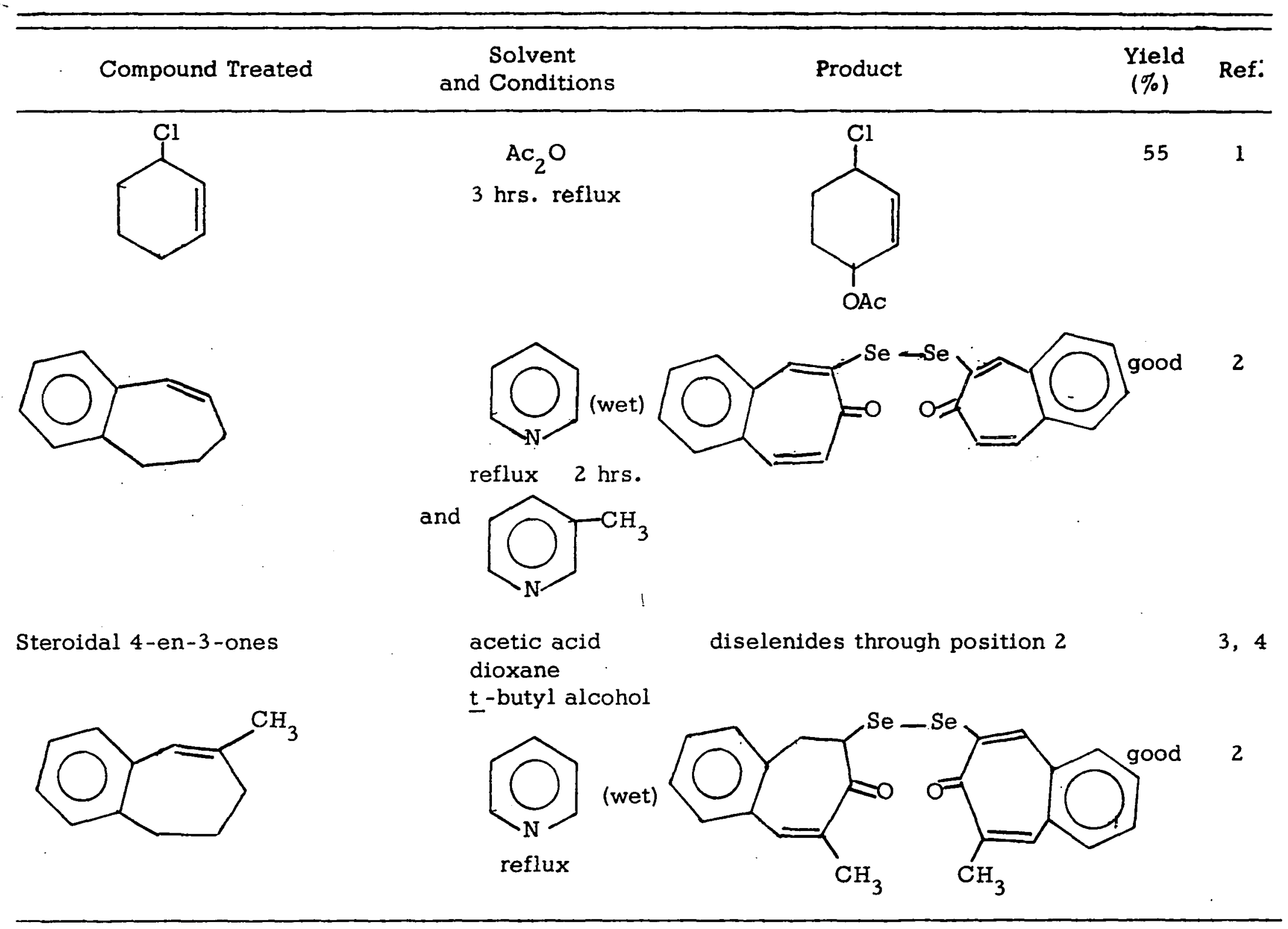




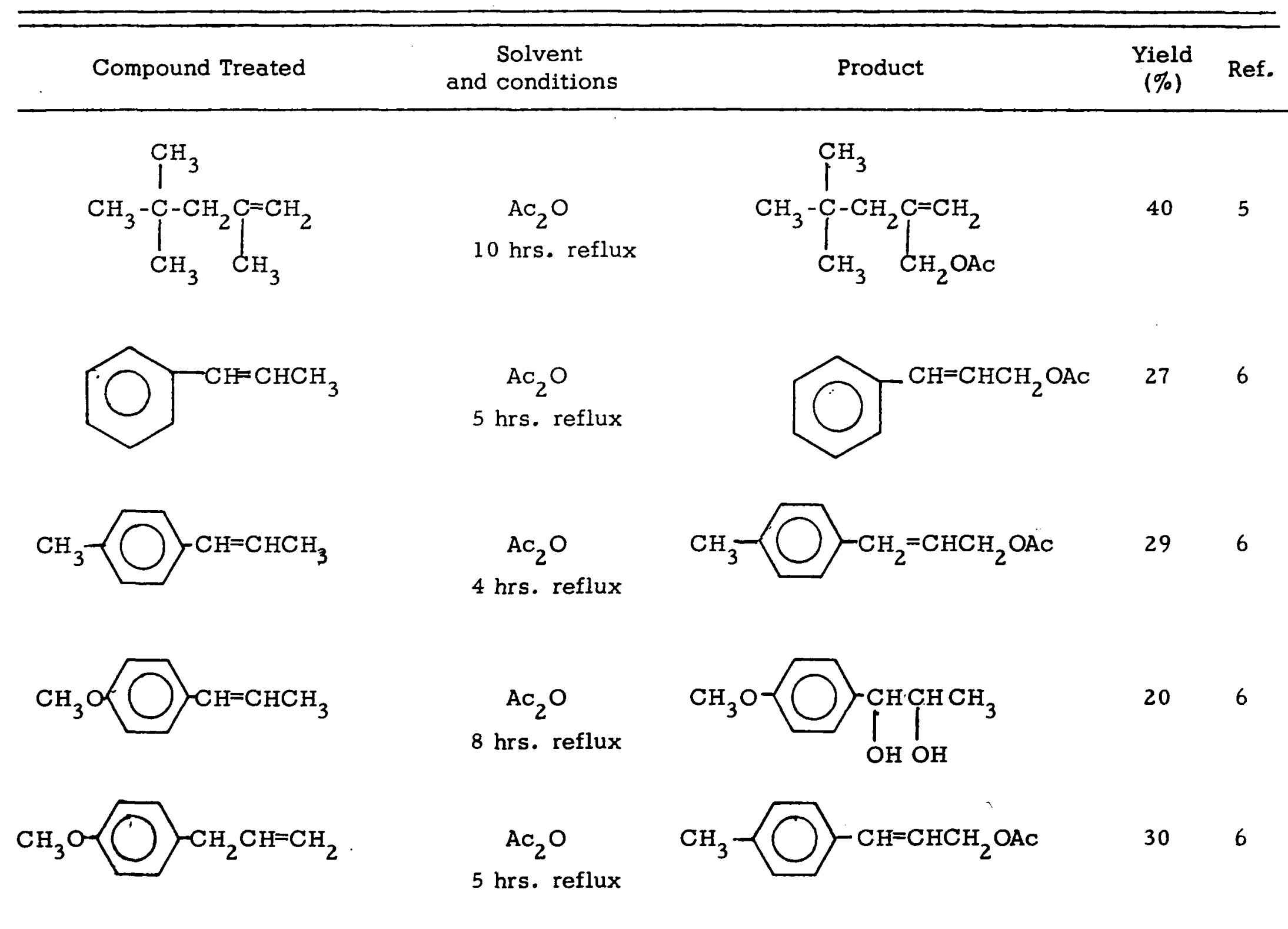




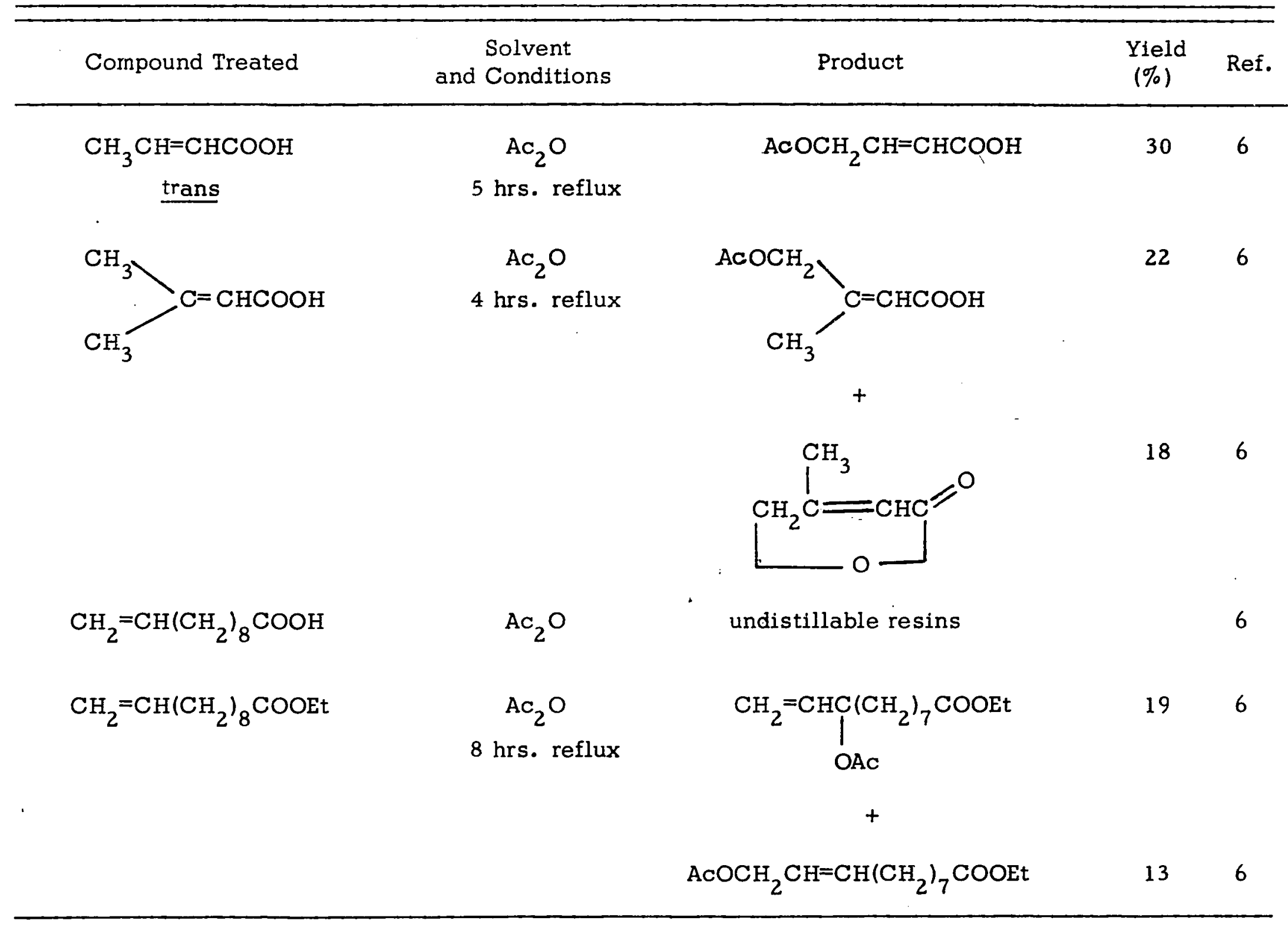




\begin{tabular}{|c|c|c|c|c|}
\hline Compound Treated & $\begin{array}{l}\text { Solvent } \\
\text { and Conditions }\end{array}$ & Product & $\begin{array}{l}\text { Yield } \\
(\%)\end{array}$ & Ref. \\
\hline Terpinolene & $\begin{array}{c}\mathrm{EtOH} \\
60^{\circ}\end{array}$ & $\begin{array}{l}\frac{\mathrm{p} \text {-cymene }}{1 \text {-methyl-4-isopropenylbenzene }} \\
+ \\
\text { 4-isopropenylbenzyl alcohol }\end{array}$ & 52 & 7 \\
\hline Camphene & $\begin{array}{l}\mathrm{Ac}_{2} \mathrm{O} \\
\text { reflux }\end{array}$ & $\begin{array}{l}\text { camphene glycol carbonate } \\
\qquad+ \\
2,2 \text {-dimethylbicyclo-[3.2.1]- } \\
\text { octane-3,4-dione and other } \\
\text { products }\end{array}$ & - & 8 \\
\hline Camphene & neat & Camphene selenide & good & 9 \\
\hline$(-)-\beta$-cedrene & & $(+)$-trans- $\beta$-cedrenol acetate & - & 10 \\
\hline
\end{tabular}




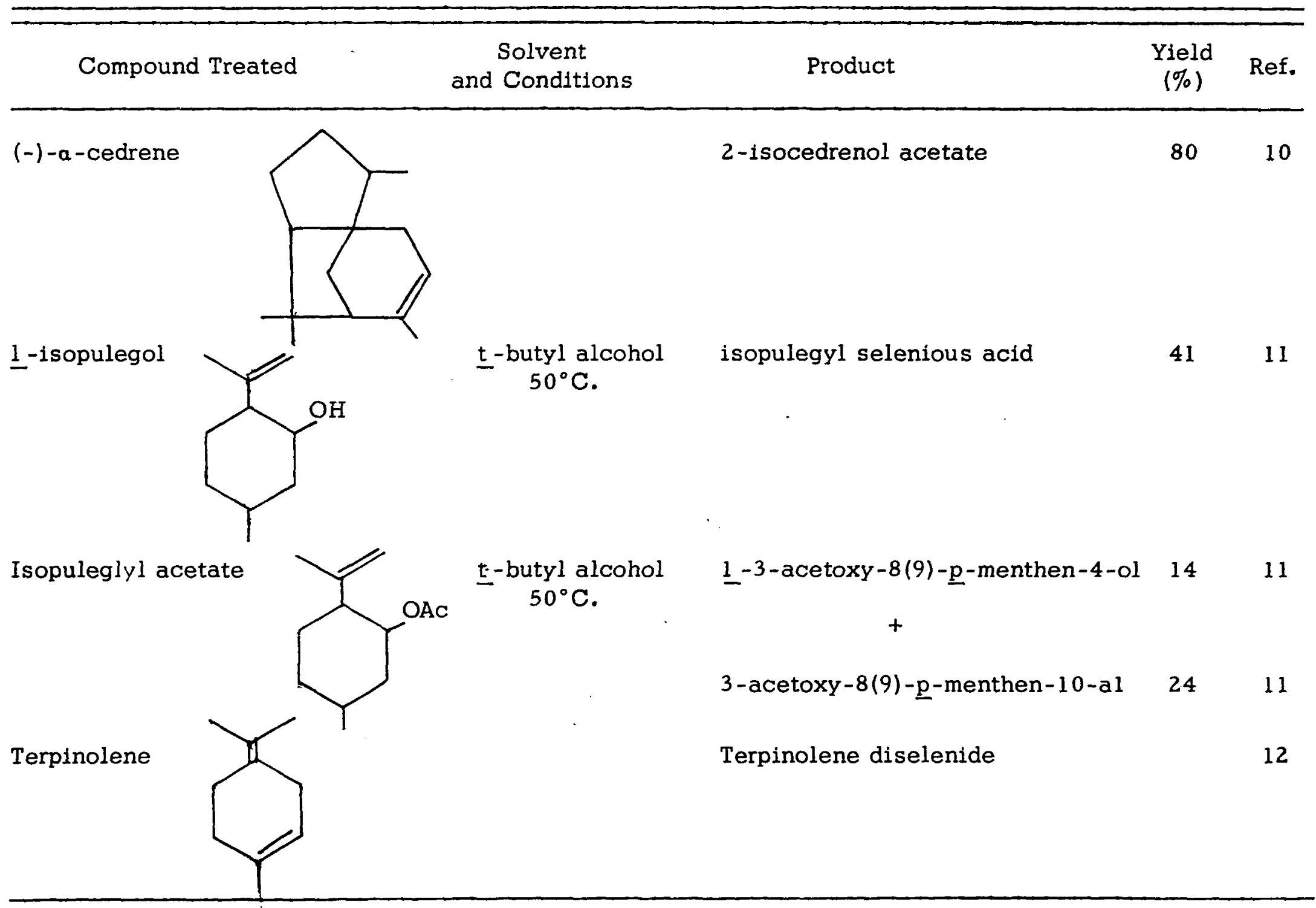




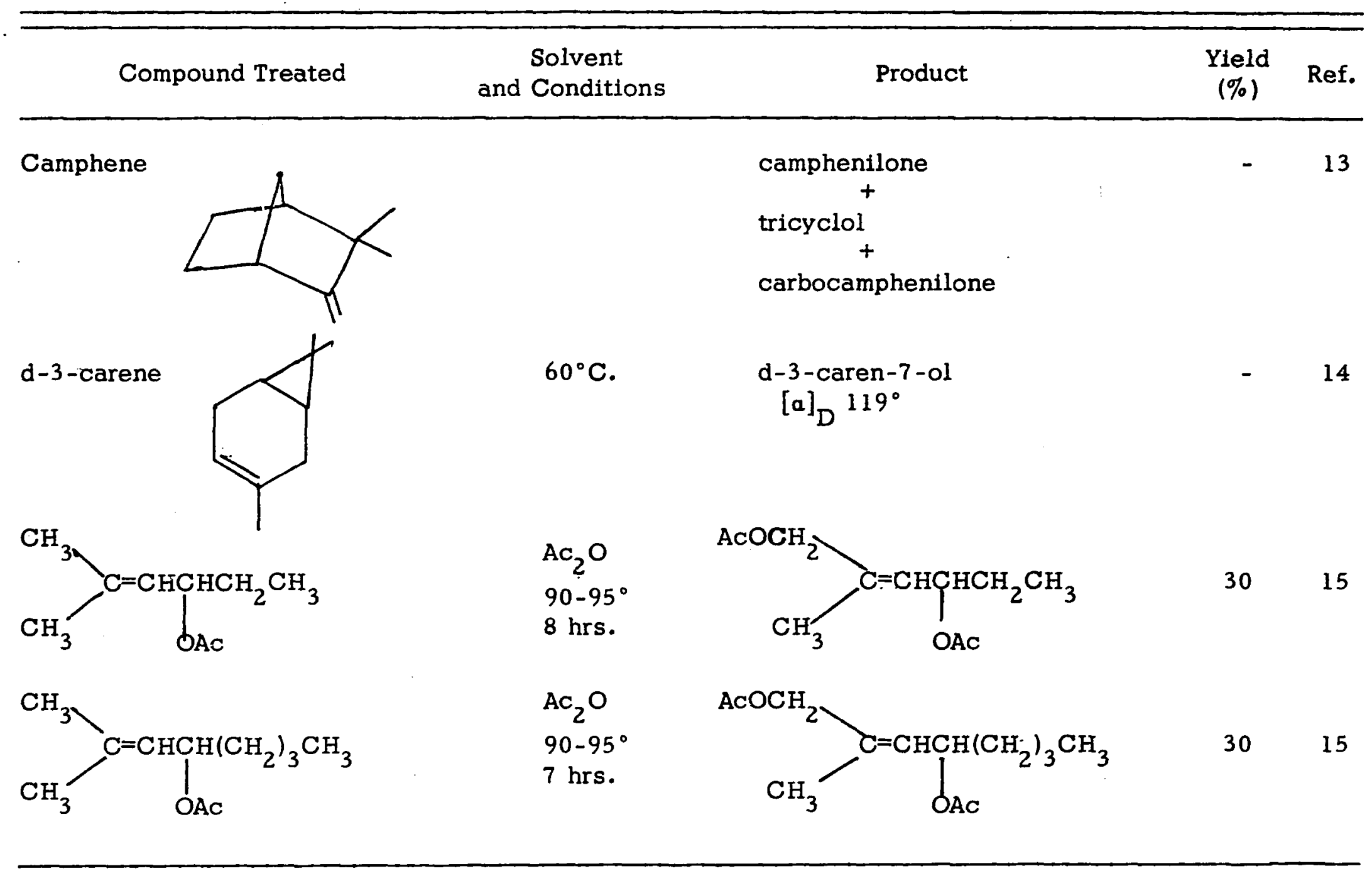




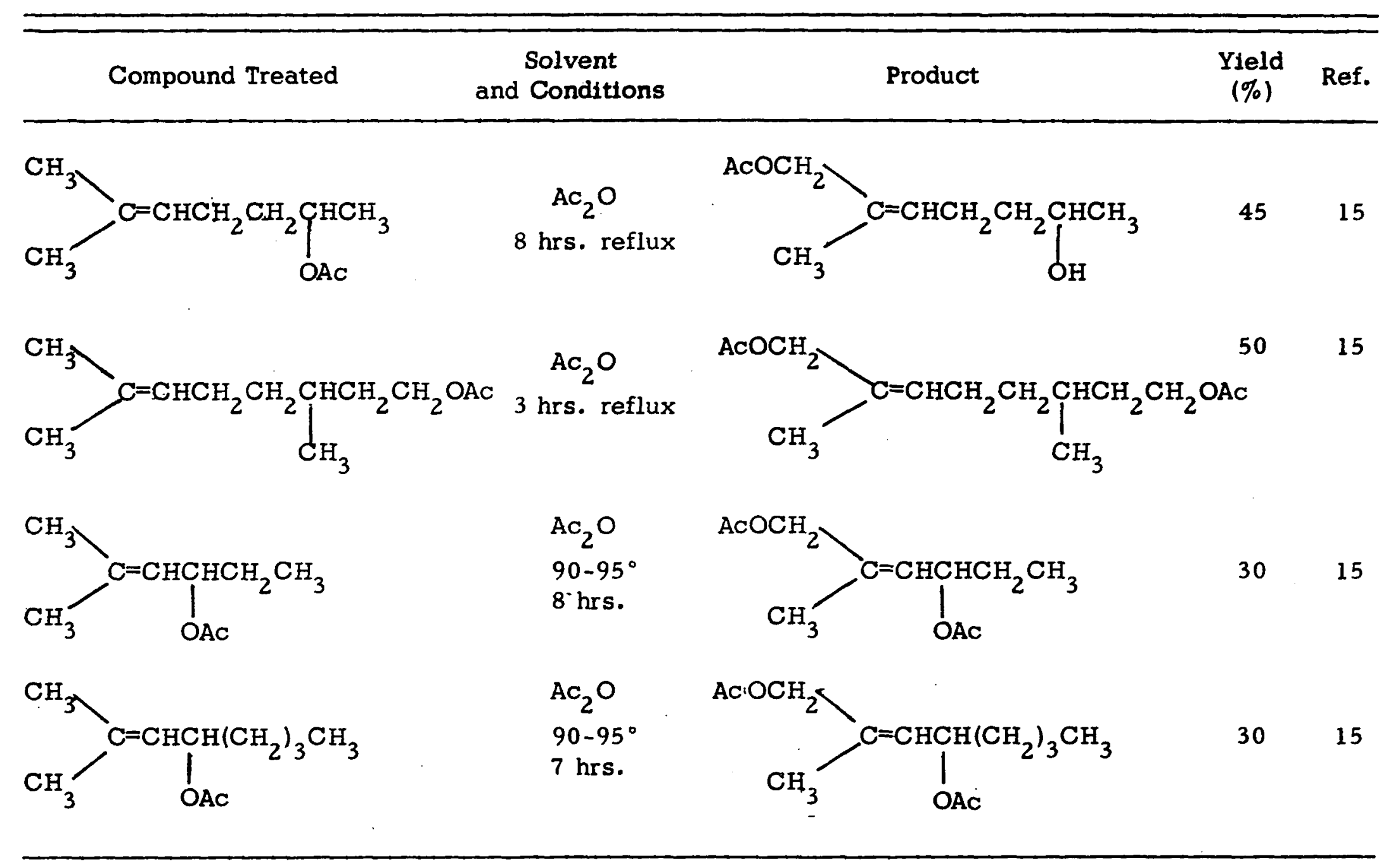




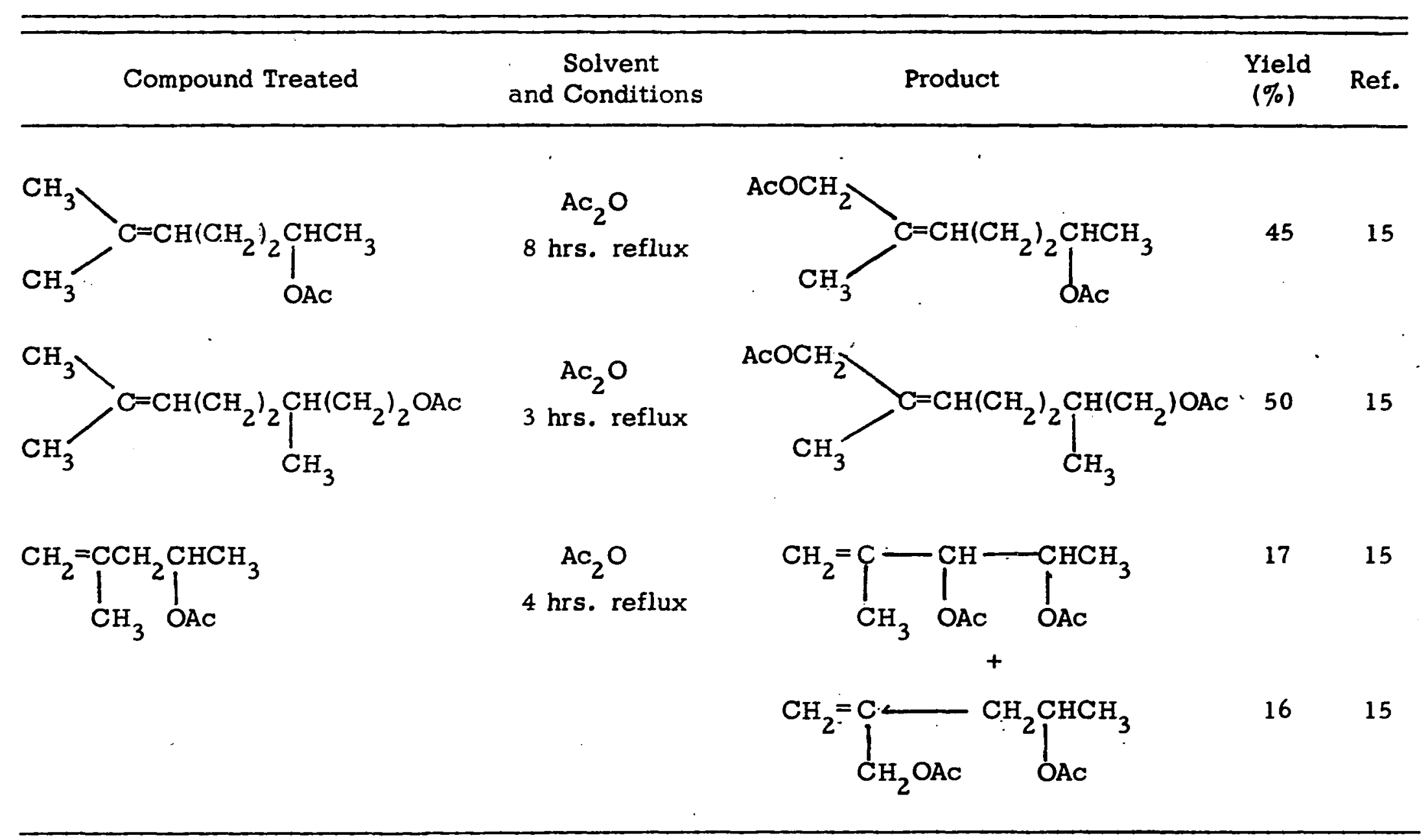




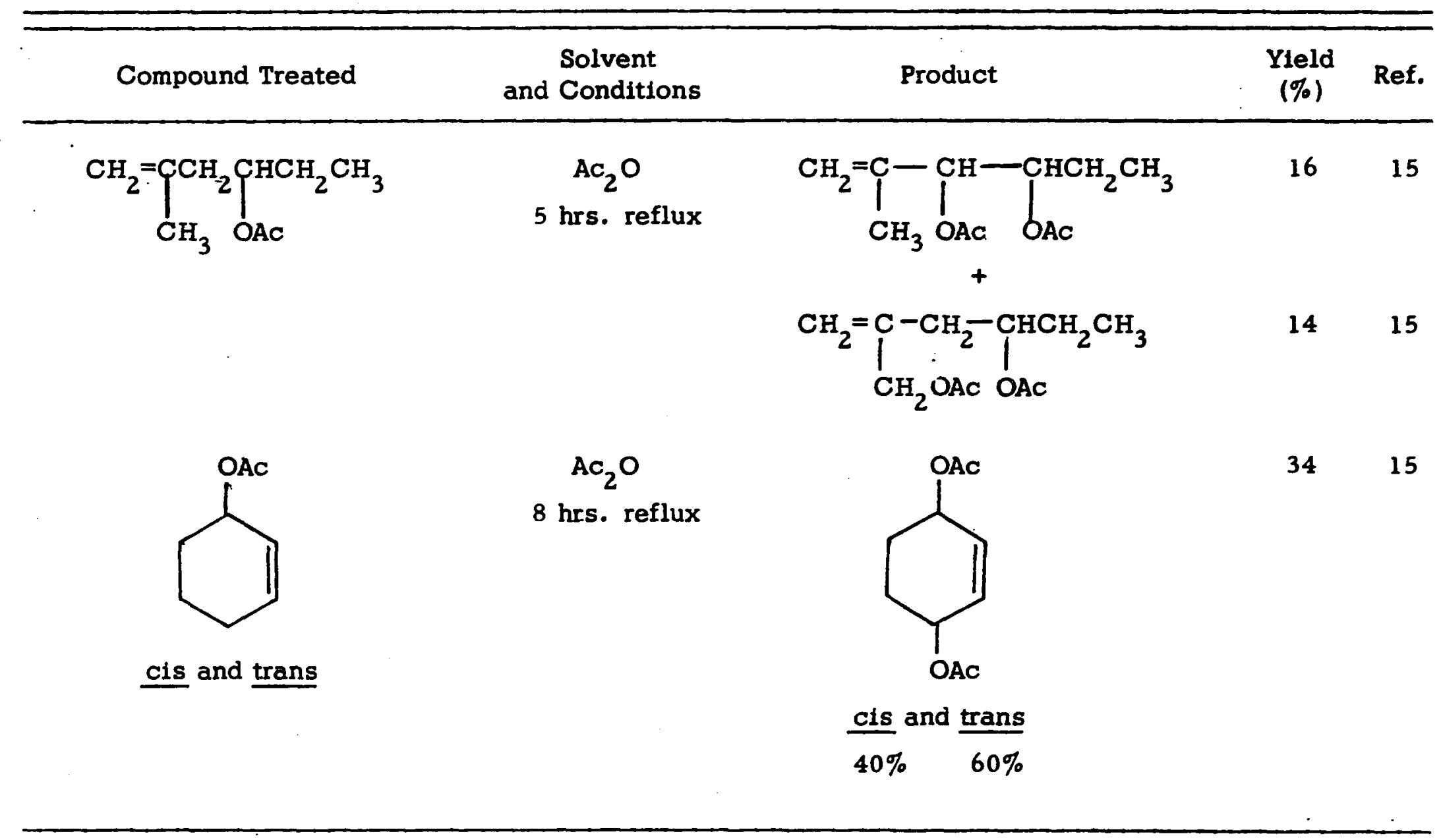




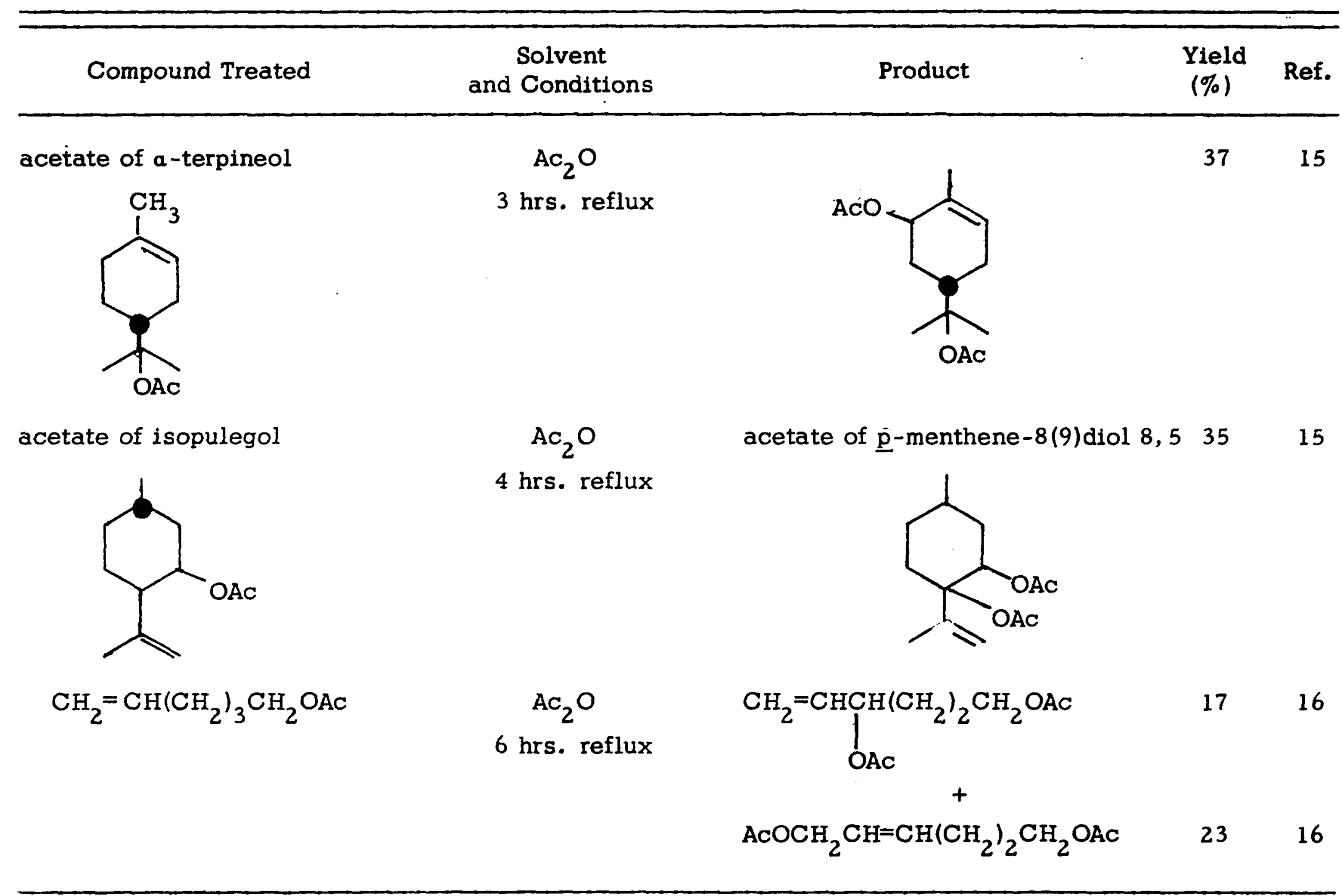




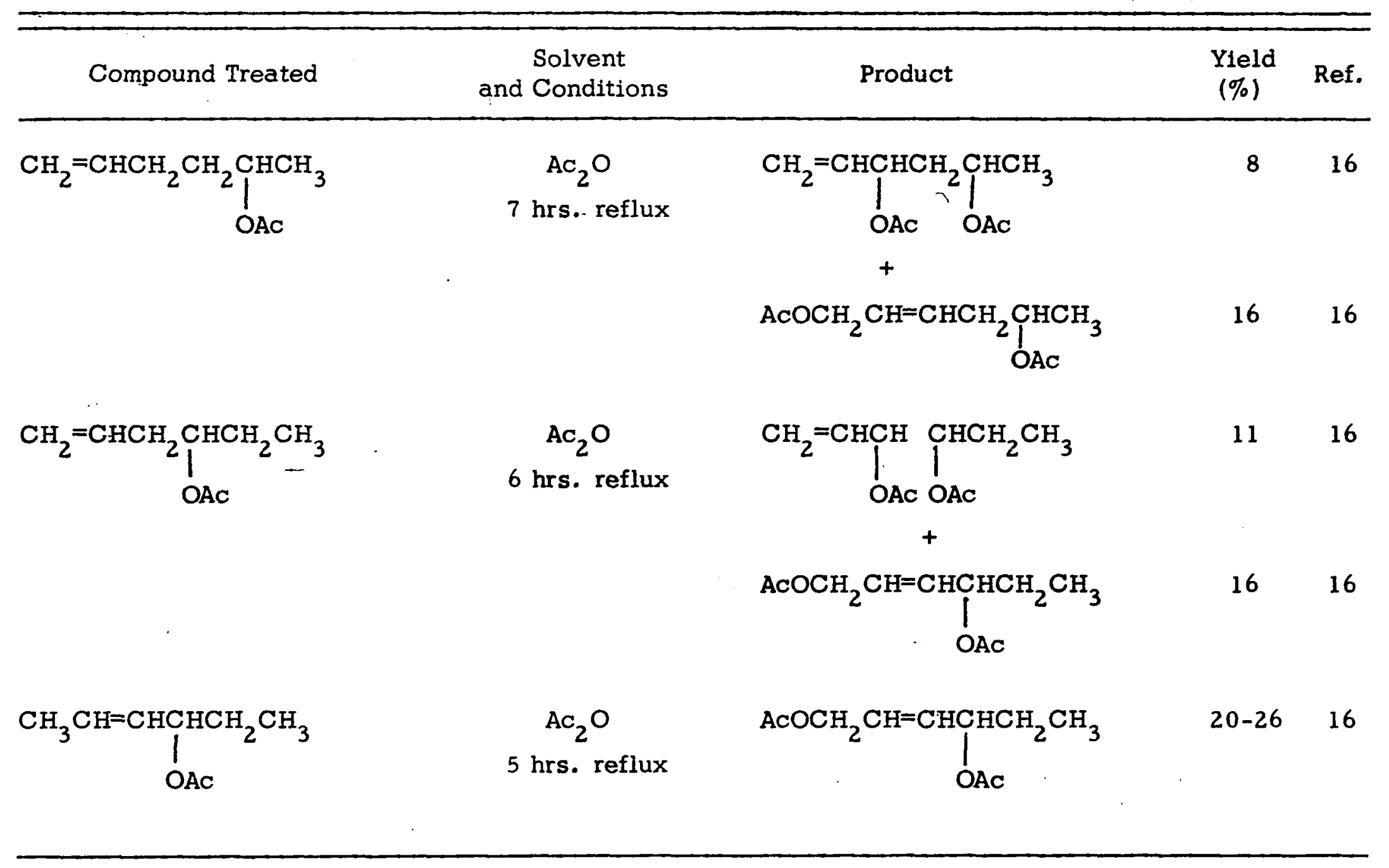




\begin{tabular}{|c|c|c|c|c|}
\hline Compound Treated & $\begin{array}{c}\text { Solvent } \\
\text { and Conditions }\end{array}$ & Product & $\begin{array}{c}\text { Yield } \\
\langle \%\rangle\end{array}$ & Ref. \\
\hline \multirow[t]{3}{*}{$\mathrm{CH}_{2}=\mathrm{CH}\left(\mathrm{CH}_{2}\right)_{8} \mathrm{CH}_{2} \mathrm{OAC}$} & & $\mathrm{CH}_{2}=\left.\right|_{\mathrm{OAC}} ^{\mathrm{CHCH}\left(\mathrm{CH}_{2}\right)_{7} \mathrm{CH}_{2} \mathrm{OAC}}$ & 22 & 16 \\
\hline & & + & & \\
\hline & & $\mathrm{AcOCH}_{2} \mathrm{CH}=\mathrm{CH}\left(\mathrm{CH}_{2}\right)_{7} \mathrm{CH}_{2} \mathrm{OAC}$ & 12 & 16 \\
\hline \multirow[t]{3}{*}{ 10-undecen-1-ol acetate } & $\mathrm{Ac}_{2} \mathrm{O}$ & 10-undecene-1,9-diacetate & 19 & 17 \\
\hline & & + & & \\
\hline & & 2-undecene-1, 11 -diacetate & 8 & 17 \\
\hline \multirow[t]{3}{*}{ 1-hexen-5-ol acetate } & $\mathrm{Ac}_{2} \mathrm{O}$ & 2-hexene-1,5-diacetate & 10 & 17 \\
\hline & & + & & \\
\hline & & 1 -hexene-3,5-diacetate & 10 & 17 \\
\hline \multirow[t]{3}{*}{ 1-hexen-4-ol acetate } & $\mathrm{Ac}_{2} \mathrm{O}$ & 1-hexene-3,4-diacetate. & 11 & 17 \\
\hline & & + & & \\
\hline & & 2-hexene-1,4-diacetate & 16 & 17 \\
\hline 2-hexen-4-ol acetate & $\mathrm{Ac}_{2} \mathrm{O}$ & 2-hexene-1,4-diacetate & 19 & 17 \\
\hline
\end{tabular}




\begin{tabular}{|c|c|c|c|c|}
\hline Compound Treated & $\begin{array}{c}\text { Solvent } \\
\text { and Conditions }\end{array}$ & Product & $\begin{array}{l}\text { Yield } \\
(\%)\end{array}$ & Ref. \\
\hline$d, 1-\beta$-terpineol & $\begin{array}{l}\text { HOAC } \\
+ \\
\mathrm{AC}_{2} \mathrm{O} \\
95-115^{\circ} \\
2 \mathrm{hrs} .\end{array}$ & 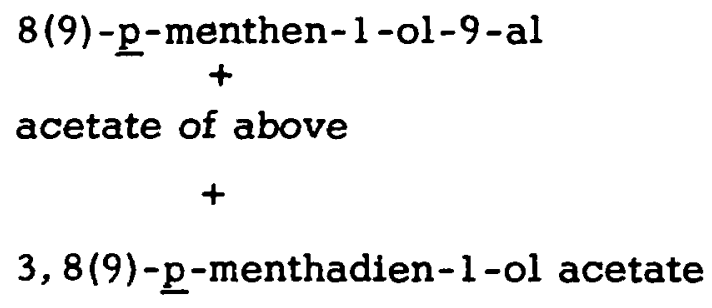 & - & 18 \\
\hline$d, 1-\beta$-terpineol & room temp. & 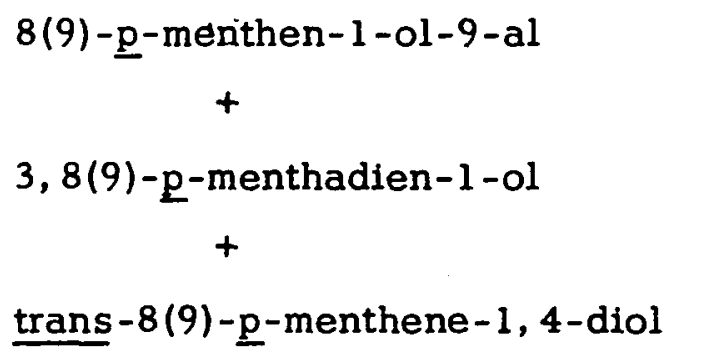 & - & 18 \\
\hline 1-dihydrocarveol & $\begin{array}{l}+-\mathrm{BuOH} \\
15-50^{\circ} \mathrm{C} .\end{array}$ & oxidize at C9 & $6-9$ & 19 \\
\hline
\end{tabular}




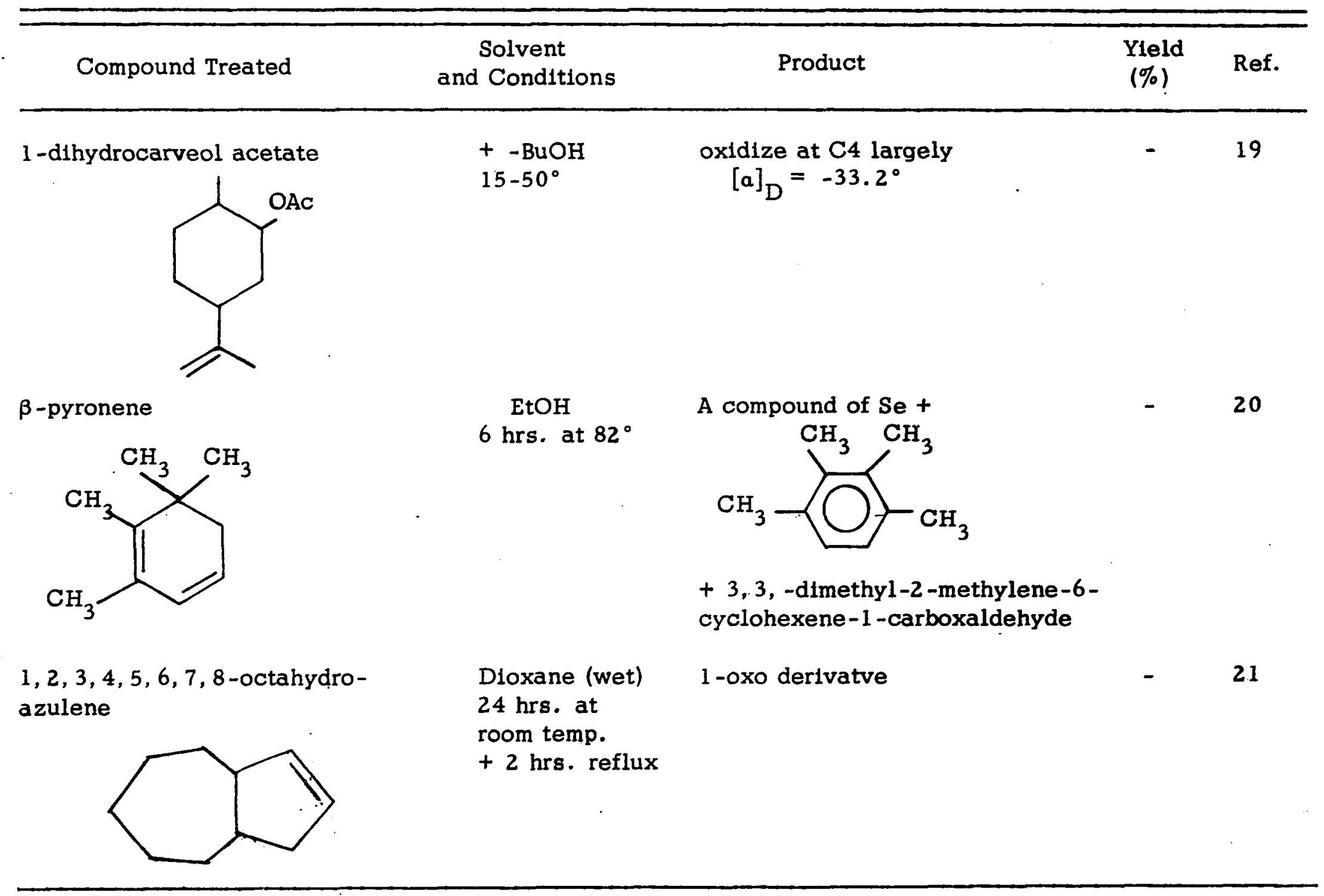




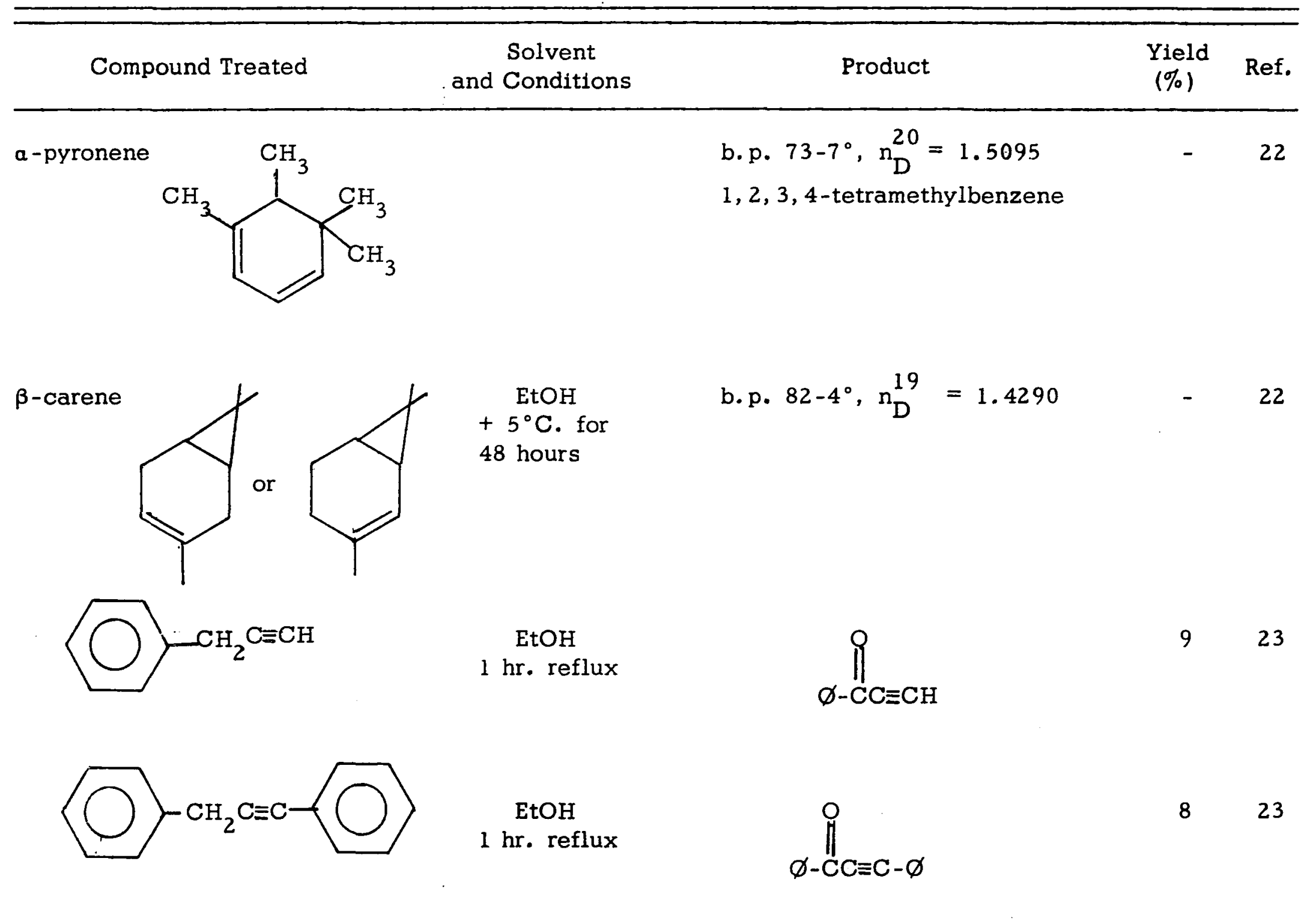




\begin{tabular}{|c|c|c|c|c|}
\hline Compound Treated & $\begin{array}{l}\text { Solvent } \\
\text { and Conditions }\end{array}$ & Product & $\begin{array}{r}\text { Yield } \\
(\%)\end{array}$ & Ref. \\
\hline menthene & $\begin{array}{c}\text { EtOH } \\
4 \text { hrs. reflux }\end{array}$ & $\begin{array}{c}\text { 3-menthen-5-one } \\
+ \\
\text { 3-menthen-5-ol } \\
+ \\
\text { menthene selenide }\end{array}$ & mostly & 24 \\
\hline indole & $\begin{array}{l}\text { benzene } \\
1 / 4 \mathrm{hr} \text {. reflux }\end{array}$ & $\mathrm{C}_{16} \mathrm{H}_{8} \mathrm{~N}_{2} \mathrm{Se}$ m.p. 195 & - & 25 \\
\hline skatole & $\begin{array}{l}\text { benzene } \\
120^{\circ} \mathrm{C} .\end{array}$ & some reaction & - & 25 \\
\hline limonene & & 2 isomeric alcohols & - & 26 \\
\hline
\end{tabular}




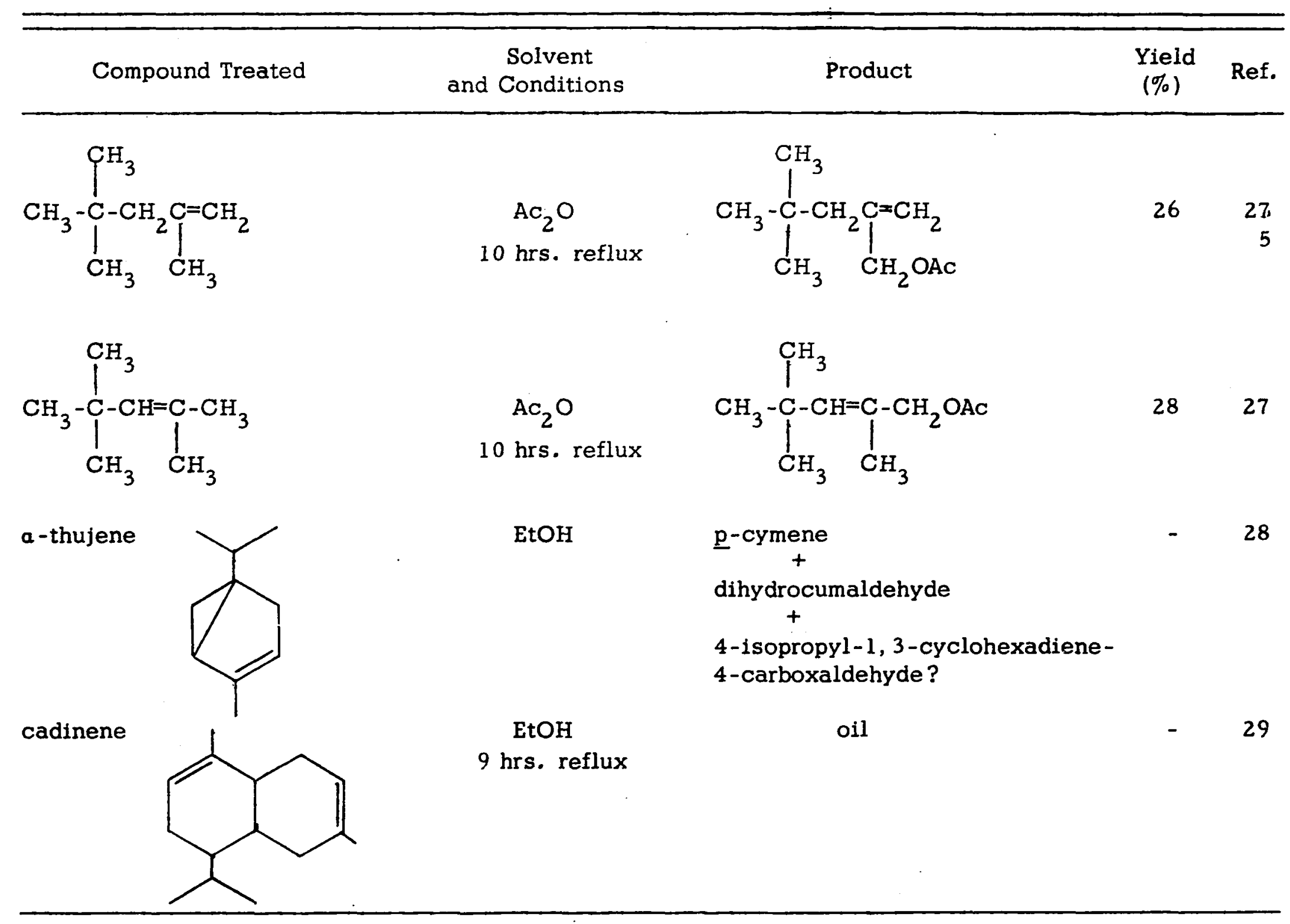


$+$

Compound Treated

Solvent

and Conditions

Product

Yield

(\%)

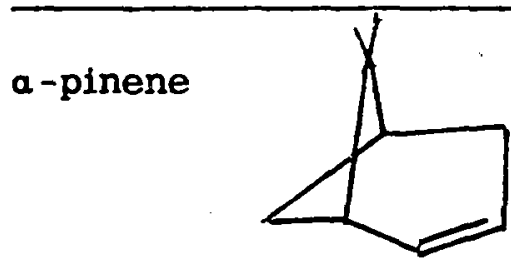

$$
\mathrm{Ac}_{2} \mathrm{O}
$$

myrtenol.

$+$

pinol

$23 \quad 30$

4.430

dihydronaphthalene

naphthalene

30
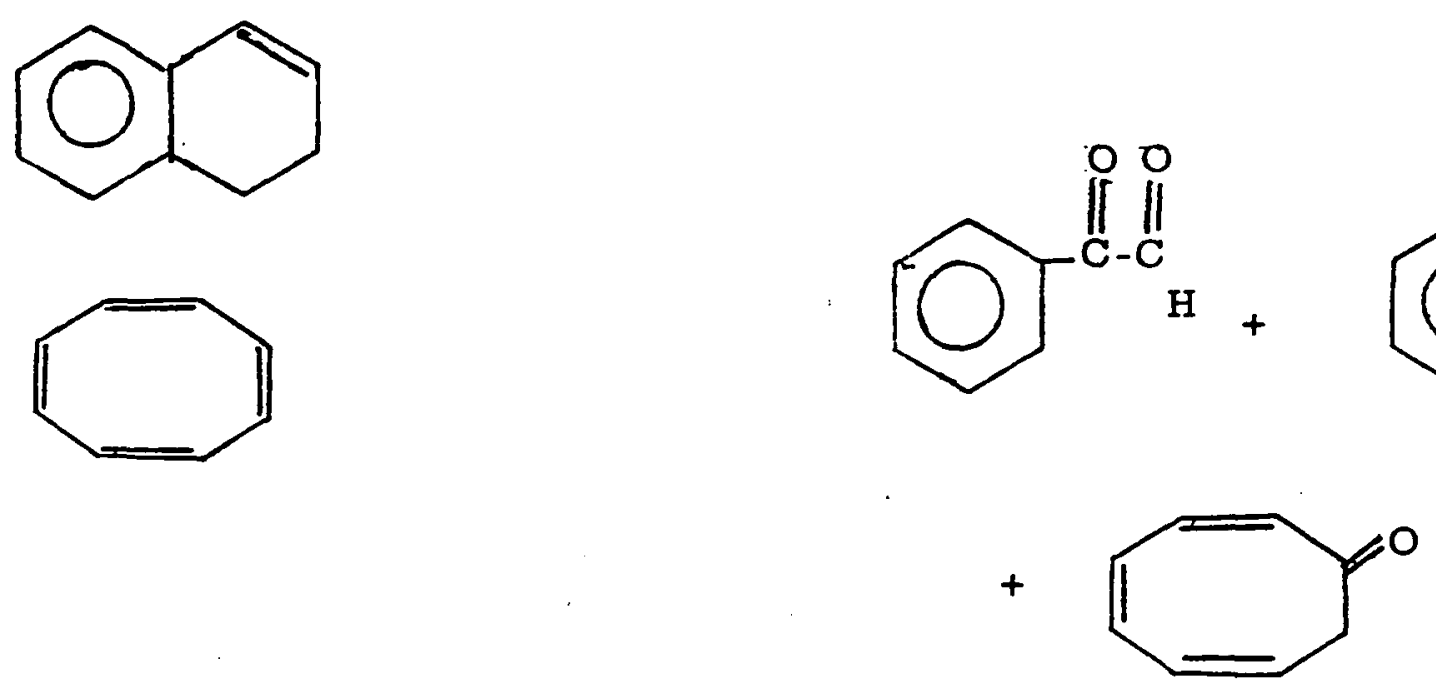


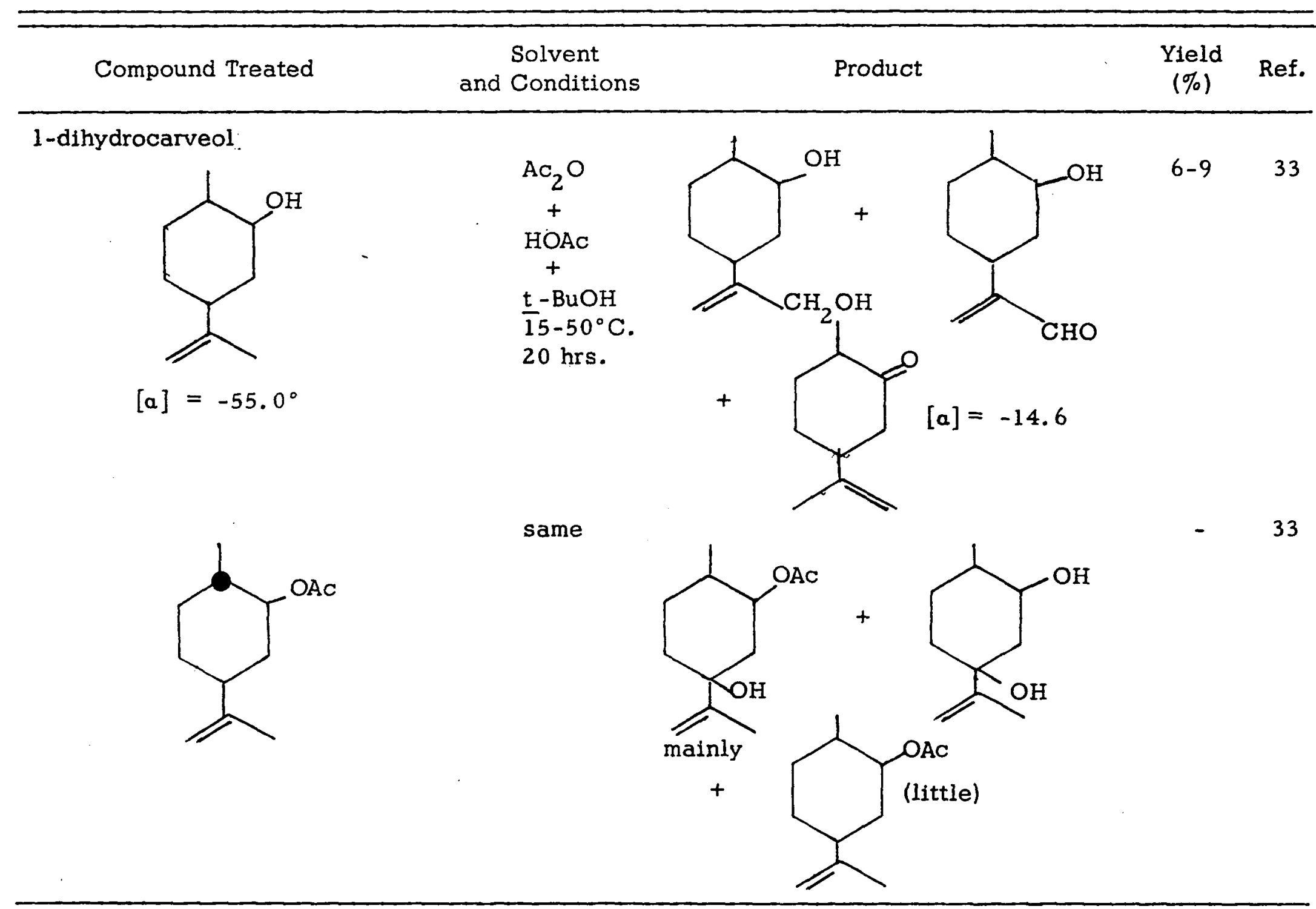




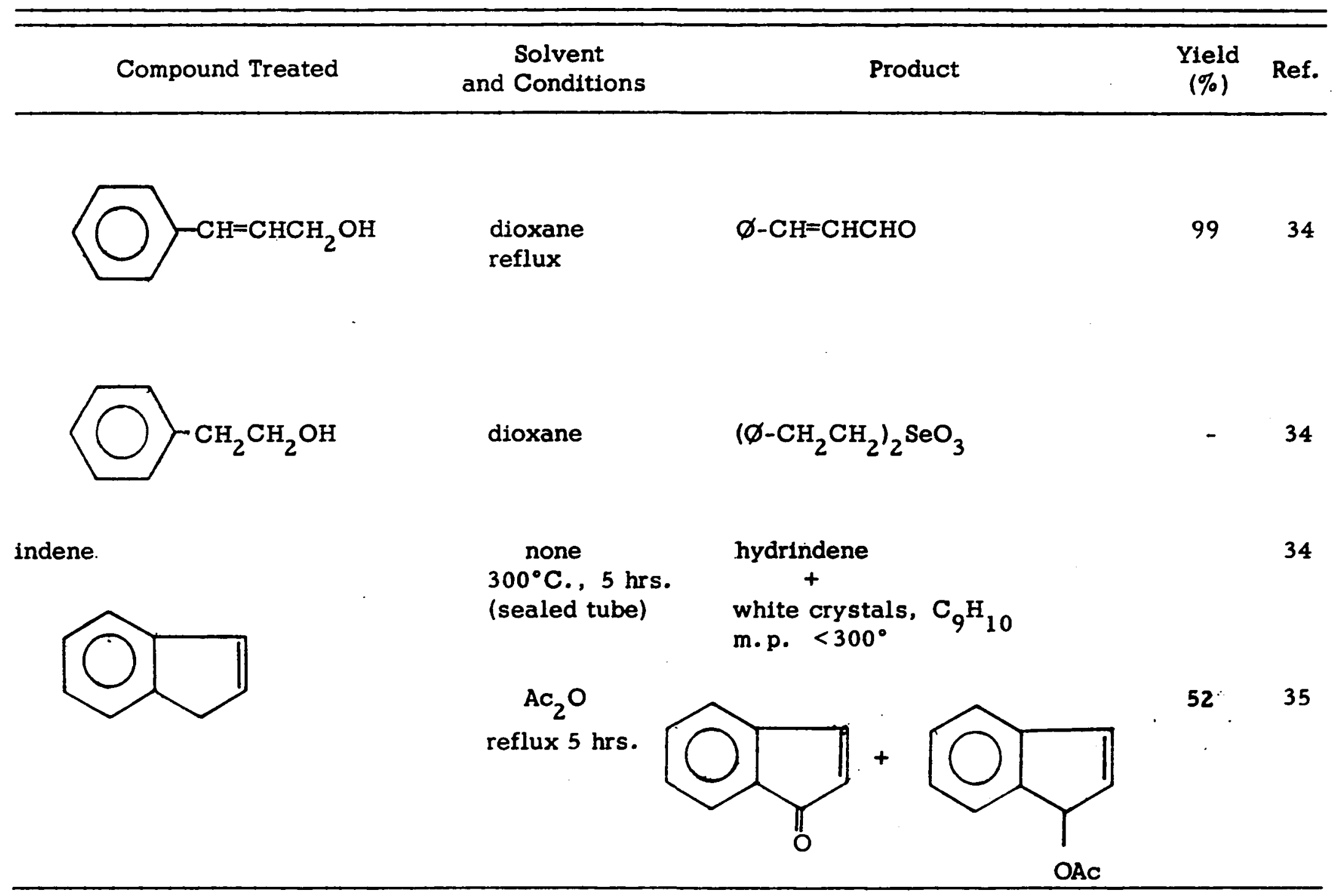




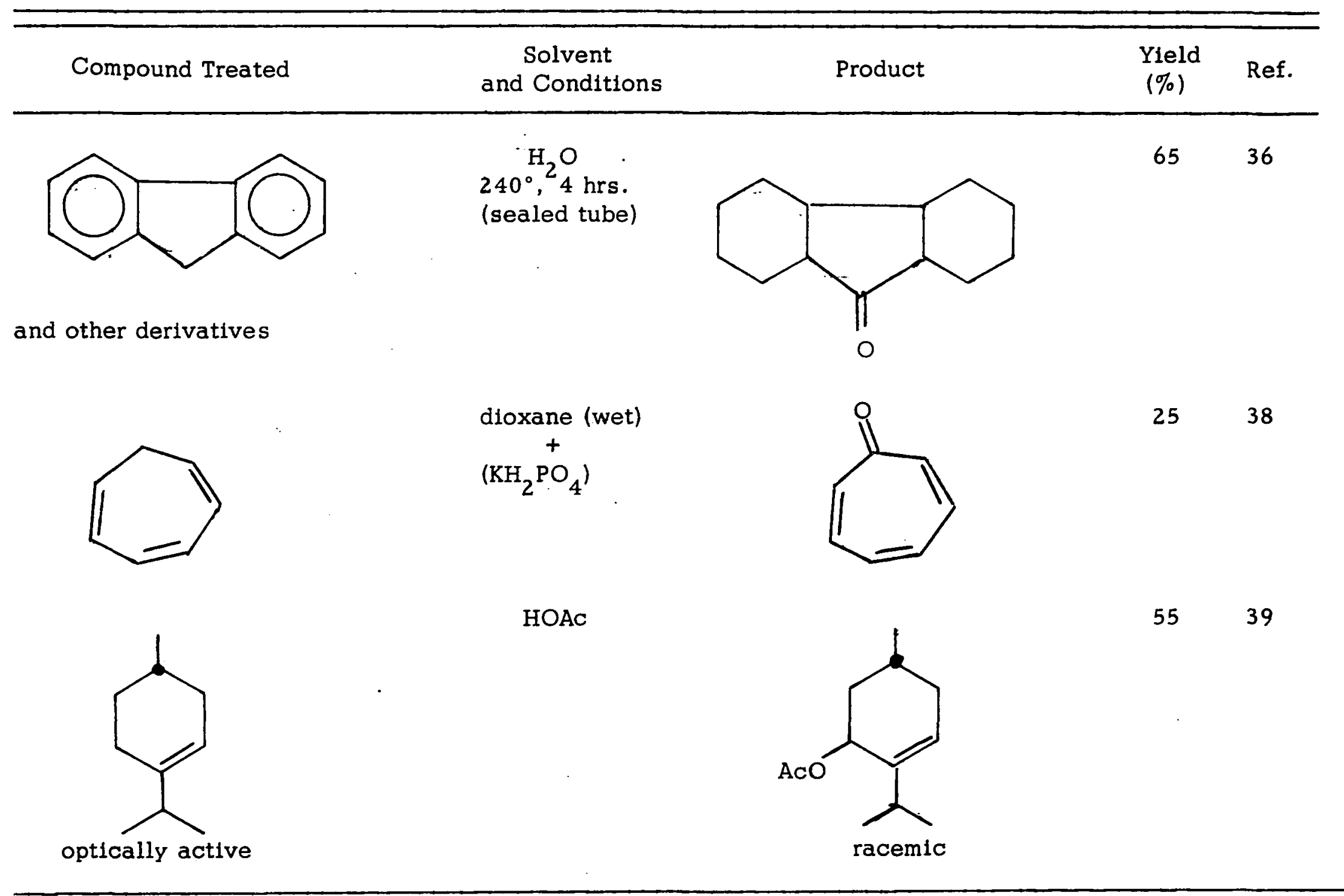




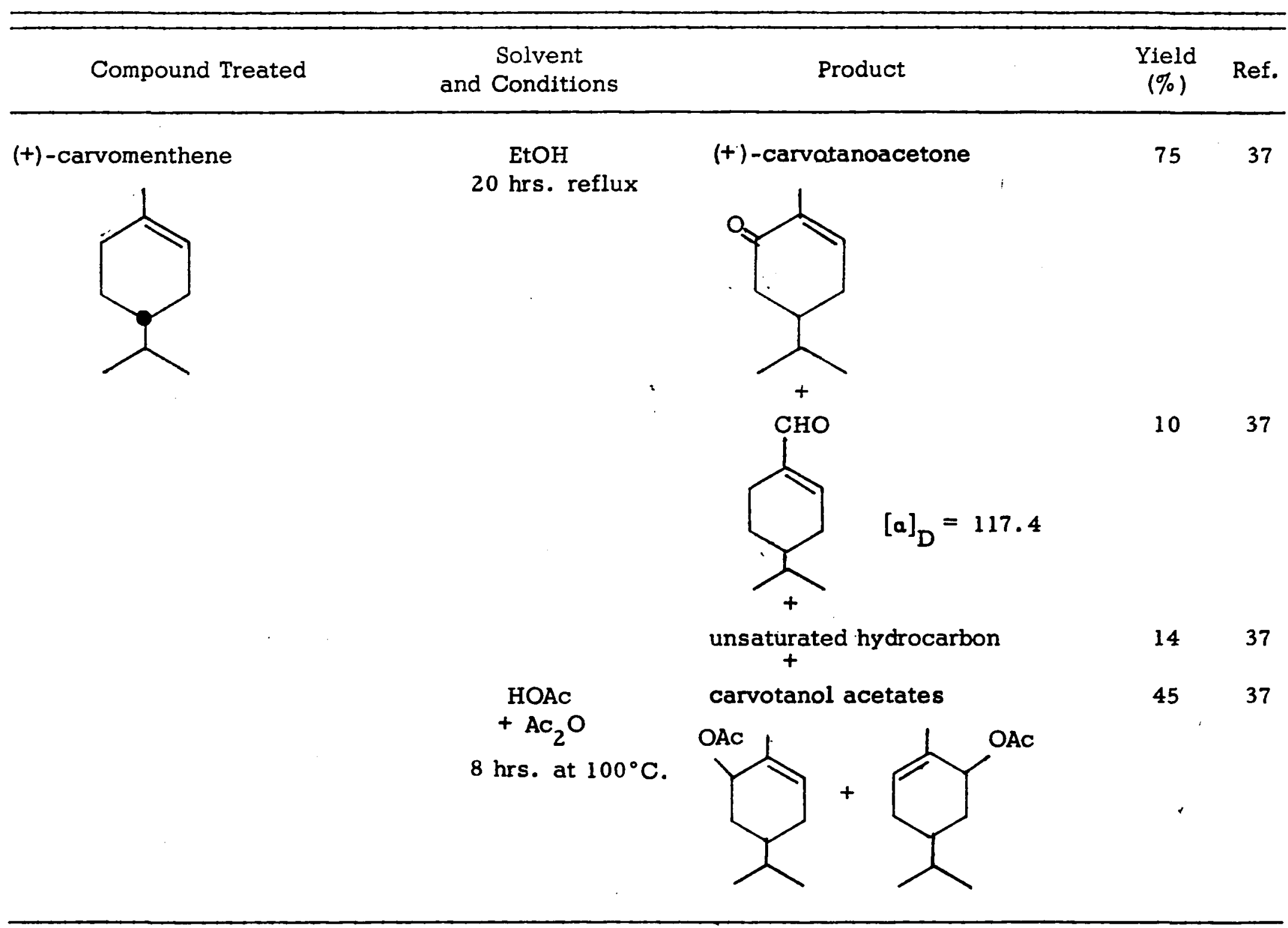




\begin{tabular}{|c|c|c|c|c|}
\hline Compound Treated & $\begin{array}{c}\text { Solvent } \\
\text { and Conditions }\end{array}$ & Product & $\begin{array}{c}\text { Yield } \\
(\%)\end{array}$ & Ref. \\
\hline & $\begin{array}{c}\mathrm{HOAC} \\
+ \\
\mathrm{Ac}_{2} \mathrm{O} \\
100^{\circ} \mathrm{C} \text {. for } \\
12 \mathrm{hrs} .\end{array}$ & selenium complex & 50 & 37 \\
\hline
\end{tabular}


1. Mousseron and Jacquier, Bull. Soc. Chim. France, 467 (1952).

2. Pete, Rona, J. Chem. Soc., 3629 (1962).

3. Florey and Restivo, J. Org. Chem., 22, 406 (1957).

4. J. Pàran, J. Am. Chem. Soc., 80, 1687 (1958).

5. A. Byers and W. J. Hickinbottom, J. Chem. Soc., 1328 (1948).

6. Jean Colonge and Maurice Reymermier, Bull. Soc. Chim. France, 195 (1956).

7. Lucina Tomaszewska and Witold Zacharewicz, Roczinki Chem., 39; 1597 (1961); C. A., 57, 9884 (1962).

8. Pekka Hirsjärvi, et al., Suomen Kemistilehti, 34B, 152 (1961); C. A., $57,16,6 \overline{62 f}(1962) ;$ ibld., 29B, $145(1 \overline{956}) ;$ C. A., 51 , 8042 f (1957).

9. Zacharewicz, Roczniki Chem., 16, 290 (1936); C. A., 30, 819 (1936).

10. G. Lucius and Chr. Schaefer, Z. Chem., 2, No. 1, 29 (1962).

11. Yoshitugu Sakuda, J. Sc1. Hiroshima Univ. [Ser. A-II], 25, 207 (1961).

12. Lucijna Tomaszewska and Witold Zacharewicz, Roczniki Chem., 35, 1511 (1961); C. A., 57, 7314e (1962).

13. Pekka Hirsjärvi, Marjatta Hirsjärvi and Juhani O. W. Kalla, Suomen Kemistileht1, 30B, 72 (1957); C. A. , 53, 16, 194g (195.9).

14. Witold Zacharewicz, Jan Krupowicz and Lucjan Borowiecki, Roczniki Chem., 33, 87 (1959).

15. Jean Colonge and Maurice Reymermier, Bull. Soc. Chim. France, 153 (1955).

16. J. Colonge and M. Reymermier, Bull. Chim. Soc., 188 (1956).

17. Jean Colonge and Maurice Reymermier, Compt. Rend., 237, 266 (1953); C. A., 47, 12, 236b (1953). 
18. Yoshitsugu Sakuda, Nippon Kagaku Zasshi, 82, 117 (1961); C. A. 56, 98, 752c (1962).

19. Yoshitsugu Sakuda, Bull. Chem. Soc. Japan, 34, 514 (1961).

20. Arkadiusz Uzarewicz and Witold Zacharewicz, Roczniki Chem., 35, 541 (1961); C. A., 55, 3, 378d (1962).

21. Hiroshi Watanabe, Pharm. Bull. Japan, 5, 426 (1957); C. A., 52, 9, 059d, 1 (1958).

22. Arkadi.sz Uzarewicz and Witold Zacharsewicz, Roczniki Chem., 31, 729, 739 (1957); C. A., 52, 5312b, c, d (1958); 1bid., 34, 413 (1960); C. A., 55, 42 of $(1961)$.

23. Issel Iwai and Yakutaro Okajima, C. A., 55, 11,367b (1961).

24. Witold Zacharewicz, Roczniki Chem., 22, 68 (1948); C. A., 43, 2976a (1949).

25. B. Witkop and H. Fiedler, Ann., 558, 91 (1947).

26. Witold Zacharewicz, Roczniki Chem., 23, 301 (1949).

27. W. J. Hickinbottom, J. Chem. Soc., 1328 (1948).

28. F. Petri and J. Kovar, Coll. Chech Chem. Comm., 15, 478 (1950).

29. Jun-Cheih Wang, Formosan Sci., 2, 62 (1948); C. A., 48a, 7853 b (1954).

30. Famou Matsuura and Koze Fufita, : J. Sci. Hiroshima Univ. Ser. A., 15,277 (1951).

31. Lidia Prajer, Roczniki Chem., 28, 55 (1954); C. A., 49, 9581 a (1955).

32. Takashi Keobayashi, et al., Yuki Gosei Kagaku Kyoskai Shi, 20, 551 (1962); C. A., 58, 4436d (1963).

33. Yoshitsugu Sakuda, Bull. Chem. Soc. Japan, 34, 514 (1961).

34. Yokoyama,J. Chem. Soc. Japan, 59, 262, 271 (1938); C. A., 32, 9062 (1938). 
35. Horvath and Schaefer, unpublished results.

36. Badger;, J. Chem. Soc., 535 (1941).

37. K. B. Wiberg and S. D. Nielsen, private communication; unpublished results.

38. P. Radlick, J. Org. Chem., 29, 960 (1964).

39. T. Suga, M. Sugimote, and T. Matsuura, Bull. Chem. Soc. Japan, 36, 1363 (1963). 


\section{REFERENCES}

R. Adams and I. Levine, J. Am. Chem. Soc., 45, 2375 (1923).

R. Adams, J. W. Kern and R. L. Schreiner, Organic Syntheses, Coll. Vol. I, John Wiley and Sons, Inc., New York, N. Y., p. 101.

R. Adams and C. S. Marvel, Organic Syntheses, Coll. Vol. I, p. 88.

R. Adams, C. M. Smith, and S. Loewe, J. Am. Chem. Soc., 64, 2087 (1942).

Kurt Alder and Gerhard Stern, Ann., 504, 205 (1933).

S. Astin, L. De V. Moulds and H. L. Riley, J. Chem. Soc., 901 (1935).

M. G. J. Beets, W. Meerburg, and H. Van Essen, Rec. Trav. Chim. Pays-Bas, 78, 584 (1959).

C. Bight and I. Montovani, Boll. sci. fae. chim. ind. Bologna, 13, 102 (1955); C. A., 50, 8388b (1956).

Erich Borgwardt and Erwin Schwenk, J. Am. Chem. Soc., 56, 1185 (1934).

H. Burton and C. K. Ingold, J. Chem. Soc., 905 (1928).

C. Bülow and W. von Sicherer, Res., 34, 2372 (1901).

W. P. Campbell and G. C. Harris, J. Am. Chem. Soc., 63, 2721 (1941).

E. J. Corey and J. P. Schaefer, J. Am. Chem. Soc., 82, 818 (1960).

Elizabeth Dane, Joseph Schmitt, Curt Rautenstrauch, Ann., 532, 29 (1937).

Elizabeth Dane, Joseph Schmitt, and Curt Rautenstrauch, Ann., 536, 196 (1938). 
W. Dleckman and H. Kämmerer, Ber., 39, 3049 (1906).

R. Erlenmeyer and H. Lipp, Ann., 219, 182 (1883).

L. F. Fleser, "Experiments in Organic Chemistry, "3rd ed., D. C. Heath and Co., Boston, Mass. (1957), p. 281.

R. C. Fuson and H. L. Jackson, J. Am. Chem. Soc., 72, 1637 (1950).

R. C. Fuson and A. I. Rachlin, J. Am. Chem. Soc., 67, 2055 (1945).

R. C. Fuson, W. R. Hatchard, R. H. Kottke and J. L. Fedrick, J. Am. Chem. Soc., 82, 4330 (1960).

H. Gilman and L. F. Cason, J. Am. Chem. Soc., 73, 1074 (1951).

Gmelin's Handbuch der Anorganischen Chemie, Verlag Chemie, Berlin 1907, pp. 756 and 764 .

A. Guillemonat, Compt. rend., 200, 1416 (1935); 1bid., 201, 904 (1936); ibid., 205, 67 (19537); 1bid., 206, $1 \overline{126}$ (1938).

A. Guillemonat, Ann. Chim., 11, 143 (1939).

L. F. Hatch and T. L. Patton, J. Am. Chem. Soc., 76, 2705 (1954).

Ian Hellbron and H. M. Bunbury, "Dictionary of Organic Compounds," Oxford University Press, New York, N. Y., 1953.

D. Heyl, J. Am. Chem. Soc., 70, 3434 (1948).

Pekka Hirsjärv1, et al., Suomen Kemistlleth1, 29B, 145 (1956); C. A., 51,8042 e (1957); ibld., 30B, $72-3$ (1957); C. A., 16, 144g (1958); 1bid., 34B, $152(\overline{1961}) ;$ C. A., 57, 16, 662f (1962).

Houben-Weyl, "Methoden Der Organtschen Chemle, "Vierte Auflage, Georg Thleme Verlag, Stuttgart, Germany, 1955, pp. 917-1209

R. W. Hufferd and N. A. Noyes, J. Am. Chem. Soc., 43, 928 (1921).

C. K. Ingold and C. W. Shoppe, J. Chem. Soc., 447 (1929). 
T. Kametani and Nomura, J. Pharm. Soc. Japan, 74, 1037 (1954);

C. A., $49,11,593$ (1955).

E. P. Kohler and H. M. Chadwell, in "Organic Syntheses," Coll. Vol. I (A. H. Blatt, ed.), 2nd ed., John Wiley and Sons, Inc., New York, N. Y., 1944, p. 78.

E. P. Kohler and J. B. Conant, J. Am. Chem. Soc., 39, 1702 (1917).

I. M. Kolthoff and E. B. Sandell, "Textbook of Analytical Chemistry," 1946, pp. 486, 493, and 594 .

Lange's "Handbook of Chemistry, " Handbook Publishers, Inc., 9th ed., Sandusky, Ohio (1956).

R. E. Lyle and L. P. Paradis, J. Am. Chem. Soc., 77, 6667 (1955).

A. K. Macbeth and J. A. Mills, J. Chem. Soc., 205 (1947).

D. A. McCaulay, A. P. Lien and P. J. Launer, J. Am. Chem. Soc., 76, 2354 (1954).

M. Mousseron and R. Jacquier, 1bid., 74, 467 (1952).

M. Mousseron, R. Richaud, and R. Granger, Bull. Soc. Chim. France, 13,222 (1946).

C. H. Nelson and E. T. Trachtenberg, Abstracts, 142 nd Meeting of the American Chemical Society, September 1962, p. $78 \mathrm{Q}$.

A. N. Nesmeyanov and V. A. Sazanova, Izvest. Akad. Nauk. SSSR, Otdel Kh1m. Nauk.., 422 (1949); C. A., 44, 1403 (1950).

H. Normart, Compt. Rend., 240, 1111, 1435 (1955).

R. F. Nystrom and W. G. Brown, I. Am. Chem. Soc., 69, 1197 (1947).

Y. Okamoto and H. C. Brown, J. Am. Chem. Soc., 79, 1909 (1957).

N. Rabjohn, "Organic Reactions, " Vol. V, John Wiley and Sons, Inc., New York, 1949, Ch. 8. 
H. L. Riley, J. F. Morley and N. A. C. Friend, J. Chem. Soc., 2342 (1932).

H. L. Riley, J. F. Morley and N. A. C. Friend, J. Chem. Soc., 1875 (1932).

C. S. Rondestvedt, Jr., J. Am. Chem. Soc., 73, 4509 (1951).

J. Sabatier and F. Murat, Ann. Chim., 4, 286 (1915).

Yoshitsugu Sakuda, J. Sci. Hiroshima Univ. [Ser. A-II], 25, 207 (1961); C. A., 57, 7313g (1962).

J. P. Schaefer, J. Am. Chem. Soc., 84, 713, 717 (1962).

A. Skita and H. Ritter, Ber., 43, 3398 (1911).

R. Staudinger and A. Kon, Ann., 384, 123 (1907).

E. C. Sterling and M. T. Bogert, J. Org. Chem., 4, 25 (1939).

H. H. Szmant and A. J. Basso, J. Am. Chem. Soc., 74, 4397 (1952).

L. Tomaszewska and W. Zacharewicz, Roczniki Chem., 35, 1511 (1961); C. A., 57, 7314 (1962).

W. Treibs, Ber., 70, 2060 (1937).

E. Urion, Compt. rend., 199, 363 (1934).

G. P. Waitkins and G. W. Clark, Chem. Revs., 36, 235 (1945).

H. H. Wasserman and N. E. Aubrey, J. Am. Chem. Soc., 77, 590 (1955).

O. Weyler, Helv. Chim. Acta, 15, 23 (1932).

G. K. Wiberg, Chem. Revs., 55, 713 (1955).

K. B. Wiberg and S. D. Nielsen, private communication of unpublished results, March 1964.

A. N. Wilson and S. A. Harris, J. Am. Chem. Soc., 73, 4693 (1951). 
W. Zacharewicz, Roczniki Chem., 22, 68 (1948); C. A., 43, 2976 (1947).

W. Zacharewicz, ibid., 23, 301 (1949); C. A., 45, 5661f (1950). 